This PDF is a selection from a published volume from the National Bureau of Economic Research

Volume Title: Law and Employment: Lessons from Latin American and the Caribbean

Volume Author/Editor: James J. Heckman and Carmen Pagés, editors

Volume Publisher: University of Chicago Press

Volume ISBN: 0-226-32282-3

Volume URL: http://www.nber.org/books/heck04-1

Conference Date: November 16-17, 2000

Publication Date: August 2004

Title: The Impact of Regulations on Brazilian Labor Market Performance

Author: Ricardo Paes de Barros, Carlos Henrique Corseuil

URL: http://www.nber.org/chapters/c10072 


\title{
The Impact of Regulations \\ on Brazilian Labor Market Performance
}

\author{
Ricardo Paes de Barros and Carlos Henrique Corseuil
}

\subsection{Introduction}

Labor market regulations are invariably introduced with two objectives. The first one is to improve the welfare of the labor force, even at the cost of introducing some degree of economic inefficiency. The second consists of improving efficiency, when external factors and/or other labor market imperfections are present.

These regulations may eventually become inadequate due to an unsuitable original design or unexpected changes in the economic environment. This inadequacy may lead to results contrary to the original goals of labor market regulations. Consequently, as a general rule, labor market regulations (as any other market regulation) need to be constantly evaluated and updated if their original goals are to be preserved.

However, any empirical study of the impact of labor market regulations on labor market performance faces three main difficulties. First, it is necessary to face the facts that labor market regulations do not change very often and tend to apply universally to all sectors in the economy. Hence, variations in labor market regulations, which are necessary to identify their

Ricardo Paes de Barros is a researcher at the Institute for Applied Economic Research (IPEA), Brazil. Carlos Henrique Corseuil is a researcher at the Institute for Applied Economic Research (IPEA), Brazil.

This chapter is a compiled version of Barros, Corseuil and Gonzaga (1999) and Barros, Corseuil, and Bahia (1999). The authors would like to thank Wasmália Bivar for valuable information about the PIM database. We also would like to thank Carmen Pagés, James Heckman, Rosane Mendonça, Gustavo Gonzaga, Ricardo Henriques, and Miguel Foguel for comments on previous versions of this chapter. Finally, we cannot forget to mention the extreme dedication of our team in IPEA involved in this project, especially Mônica Bahia, Phillippe Leite, Danielle Milton, Eduardo Lopes, Gabriela Garcia, Viviane Cirillo, and Luis Eduardo Guedes. 
impact on labor market performance, are hard to find, both in time series and cross-sections.

Second, even when legislation varies over time, it is difficult to isolate its impact on labor market performance from the impact of other macroeconomic factors. This is particularly important in Brazil, because over the past two decades macroeconomic instability has reached unprecedented levels. Inflation, economic growth, internal and external imbalances, and the degree of openness of the economy have changed considerably. If one opts for using cross-section variations, the drawbacks are not less. In this case, it is necessary to isolate the impact of differences in regulations from all other sector-specific factors that could make performance measures different across sectors.

Finally, measures of labor market performance are needed. The problem here is that performance is a multidimensional aspect of the labor market with no consensus about its precise definition. Hence, there is not a single unidimensional measure for this aspect. The use of the measure for the (supposed) main dimension is usually implemented as a measure of labor market performance.

In respect to the Brazilian labor market, many analysts have been very critical about the benefits of the prevailing labor market regulations. ${ }^{1}$ On the whole, these regulations were designed to improve welfare, giving the workers more protection. The analysts claim these regulations have not been wisely designed and, consequently, are failing to reach their objective. Actually their arguments go further, claiming that the regulation worsened not only the welfare of the labor force, but also the efficiency, based on the observation of increasingly poor working conditions and lower wages and a drop in the degree of employability of the Brazilian labor force. They argue that this occurs in a new economic environment that increasingly requires greater labor flexibility. As a consequence, labor market regulation reform has become a central item on the current Congress agenda, particularly after the recent leap in unemployment. ${ }^{2}$

Despite the importance of evaluations of the impact of these regulations on labor market performance, the number of such studies focusing on Brazilian labor markets has been very limited. ${ }^{3}$ The three difficulties pointed out are not sufficient to justify the relatively few studies on the subject. First, labor market regulations underwent considerable changes in 1988, when

1. See Jatobá (1994) for a survey of those analyses that consider that a higher nonwage labor cost reduces the job creation. This survey includes the arguments of Bacha, Mata, and Modenesi (1972), Camargo and Amadeo (1990), Almeida (1992), Chahad (1993), Macedo (1993), Pastore (1993), and World Bank (1991).

2. Deseasonalized unemployment in the six main Brazilian metropolitan regions increased from around 5.7 percent in October 1997 to 7.4 percent in June 1998.

3. Some examples are Amadeo et al. (1995), Amadeo and Camargo (1993), Amadeo and Camargo (1996), and Málaga (1992). 
a new constitution was enacted, containing most of the prevailing labor market regulations. Moreover, the wealth of information available allows the implementation of promising methodological possibilities for identifying the impact of labor market regulations, based on alternative proxies of labor market performance that can be obtained using the information available.

Hence, the objective of this chapter is to identify whether the prevailing Brazilian labor market regulations, in large extension originated by the 1988 constitutional change, have any impact on labor market performance. To reach this objective we will explore alternative methodologies, sources of information, and measures of labor market performance. The diversification is an attempt on accessing the robustness of our result.

We have two alternatives to measure labor market performance. The first is based on parameters estimated from a labor demand model, and the second is based on turnover rates. Some alternative methodologies for estimation of the effect of the constitutional change are associated to each of these two measures. Regression analysis is the only alternative developed for labor demand parameters estimation. The turnover rates are mainly analyzed through the difference-in-differences methodology, but regressions are also developed as a complement of the difference-in-differences method.

The chapter is organized in five sections, including this introduction. In the next section we briefly describe the 1988 constitutional change, with special emphasis on the topics related to labor costs, which, basically, will be used as the main sources of variation on labor market regulations. The two sections that follow the institutional analysis will focus on the two alternative measures of labor market performance. Section 5.3 is dedicated to the description and implementation of the regression analysis through which we estimate the parameters of labor demand. Section 5.4 contains the description and results achieved when we use turnover rates to measure labor market performance according to difference-in-differences methodology complemented by regression analysis. Finally, section 5.5 summarizes our main findings.

\subsection{The Institutional Analysis}

\subsubsection{The 1988 Constitutional Change}

A new Brazilian Constitution was enacted in 1988 as part of the process of redemocratization in Brazil during the second half of the 1980s. Traditionally, Brazilian constitutions are very detailed, stipulating not only general rules, but also many specific legal provisions. Most labor regulations, for instance, are written in the constitution and are, consequently, very difficult to amend. The new constitution of 1988, in particular, consider- 
ably affected labor regulations, causing changes in many labor codes that had remained intact since the 1940s. ${ }^{4}$ Most of these changes, in tune with the redemocratization environment, increased the degree of the workers' protection.

These changes, shown in table 5.1, affected both individual rights and workers' organizations. The new constitution gave more freedom and autonomy to unions. The possibilities for government intervention in unions were drastically reduced. In fact, many mechanisms of official interference were eliminated (e.g., the right of intervention by the Ministry of Labor and the need to be registered and approved at the same Ministry) as well as many restrictions of an institutional nature used to limit workers' organizations (such as representation scales and diversity of occupational categories). Many regulations on union management were also weakened, ensuring more autonomy to unions during elections of their representatives and in their decisions.

From the point of view of individual rights, we can perceive important changes that increase variable labor costs and the level of dismissal penalties. The increase in protection ensured by the new constitution considerably increased a firm's costs of employment. The maximum number of working hours per week dropped from forty-eight to forty-four hours; the maximum number of hours for a continuous work shift dropped from eight to six hours; the minimum overtime premium increased from 20 percent to 50 percent; maternity leave increased from three to four months; and the value of paid vacations increased from 1 to, at least, $4 / 3$ of the normal monthly wage.

The new constitution also considerably increased the level of dismissal penalties. This change in legislation will be one of the fundamental sources of variation used throughout this study to estimate the impact of regulations on labor market performance.

It is worth mentioning that the changes altered the level of the penalties but not their nature. Traditionally, Brazilian legislation affects the cost of dismissal through two channels. First, employers must give notice to their employees in the case of dismissal. Moreover, between the notice and actual dismissal, workers are granted two hours per day to look for a new job, with no cut in wages. Second, the law states that all workers dismissed for no just cause must receive monetary compensation paid by the employer.

Prior to the 1988 constitution, notice had to be given at least one month in advance. The 1988 constitution states that the period of notice should be given in proportion to the worker's tenure. However, because no specific law has ever regulated this constitutional device, notice continues to be given, as before 1988, one month prior to dismissal for all workers, independent

4. One major exception was the rule regulating dismissals, which suffered major changes in 1966 when the FGTS was created. 


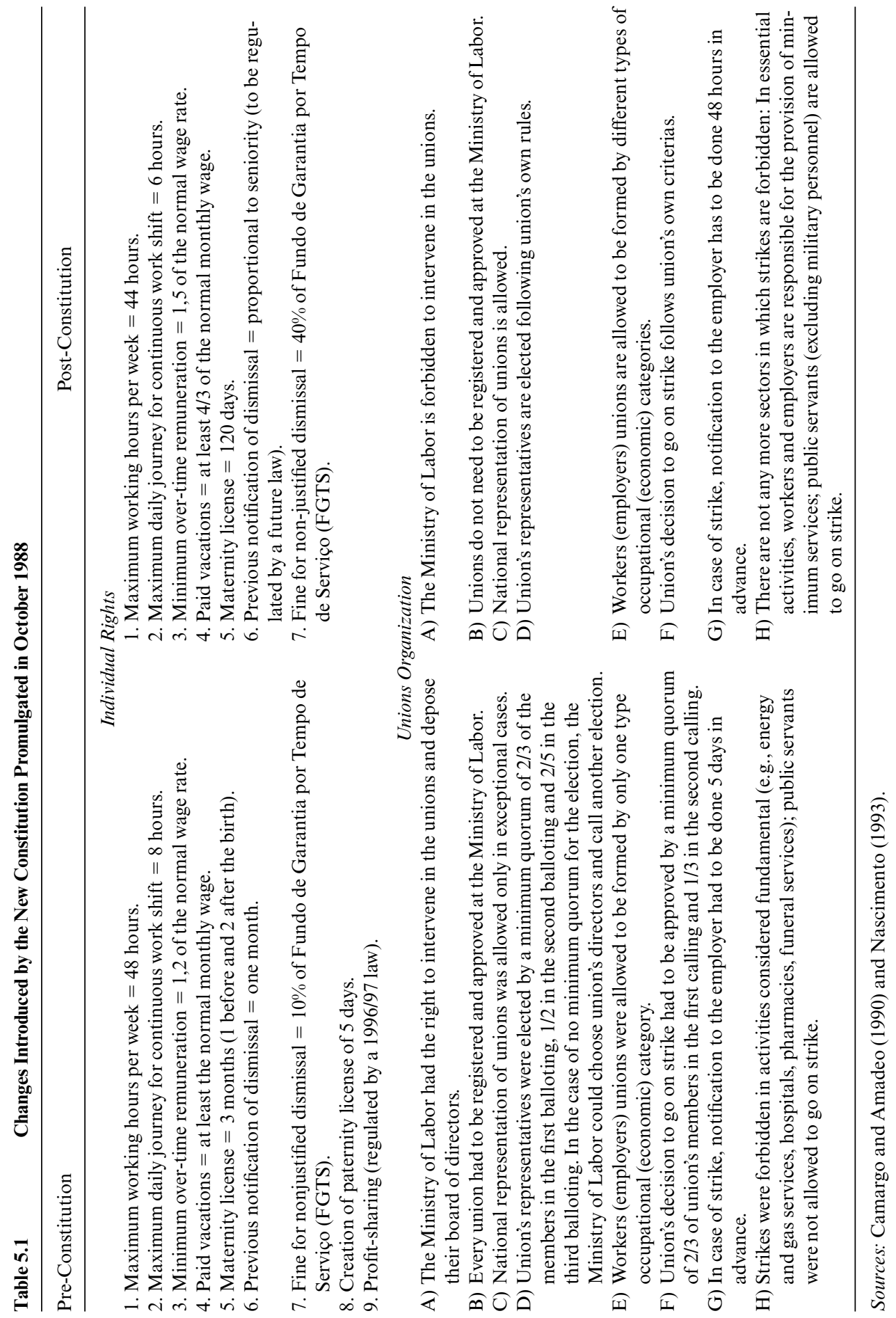


of their tenure. Hence, it cannot be used as our source of variation in labor regulations.

Concerning the monetary compensation for dismissed workers, the law states that a fixed percentage of the Fundo de Garantia por Tempo de Serviço (FGTS), a sort of job security fund accumulated while the worker was employed by the firm, is to be paid to every worker dismissed for no just cause. There was a fourfold increase in the value of this penalty as a result of the 1988 constitutional change.

The basic characteristics of the FGTS are the following. First, each worker in the formal sector has his own fund; in other words, it is a private fund instead of a single fund for the workers as a group. Second, to build the fund of each individual worker, the employer must contribute, every month, the equivalent of 8 percent of his employee's current monthly wage; consequently, the accumulated FGTS of a worker in any given firm is proportional to the worker's tenure and his or her average wage over his or her stay in the firm. Third, the fund is administrated by the government. Fourth, workers have access to their own fund only if dismissed without just cause or upon retirement. ${ }^{5}$ Fifth, if they resign they are not granted access to this fund. Sixth, on dismissal, workers have access to their entire fund, including all funds accumulated in previous jobs, plus a penalty in proportion to their accumulated fund in the job from which they are being dismissed. ${ }^{6}$

Before 1988, this compensation was equal to 10 percent of the cumulative contribution of the current employer to the worker's FGTS. After 1988 , this penalty was increased to 40 percent of the employer's cumulative contribution to the worker's FGTS. As the monthly rate is 8 percent of the monthly wage, the FGTS accumulates at a rate of approximately one full monthly salary per year in the job. So, quantitatively, the penalty accumulates in a rate equivalent to 40 percent (10 percent prior to 1988) of the worker's current monthly wage per year in the firm. This compensation was certainly very small prior to 1988 . In fact, under the former constitution, the worker had to be employed in the firm for at least ten years in order for the compensation to reach the magnitude of one monthly salary. Now it takes 2.5 years in the job for the compensation to reach this value.

Finally, it is worth mentioning that despite the 1988 fourfold increase in the FGTS penalty it is not clear that, even now, this penalty constitutes a major constraint to dismissals or even a major fraction of overall dismissal costs. For instance, the cost of advance notice may be larger than the penalty. In principle, the need for notice would increase the cost of dismissal only to the extent that, for a period of one month, 25 percent of the

5. There are a few exceptions. Workers can use their FGTS as a part of the payment for acquiring their home. They also can use it to pay for large health expenses.

6. The FGTS is a fund created by the military regime in 1966 to serve as an alternative to the job security law prevailing at that time. In practice, all new contracts after 1966 adopted the new system because it was preferred by both employees and employers. 
hours of the dismissed worker would be paid but not worked. In practice, the productivity of a dismissed worker will drop once he or she has been given notice, implying an overall decline of well over 25 percent in his or her contribution to production. As a result, it is not uncommon for firms to pay a full salary to dismissed workers, without their being required to work a single hour. In other words, the cost of notice is actually between 25 percent and 100 percent of one month's salary, being in practice closer to 100 percent than to 25 percent.

Consequently, the costs of advance notice tend to be higher than the dismissal compensation paid to all workers with tenure of less than 2.5 years. Because most employment relationships in Brazil are short, employers may be more sensitive to the cost of advance notice than to the value of the dismissal compensation.

\subsubsection{Dismissal Penalties, Incentives, and Possible Labor Market Outcomes}

As far as incentives are concerned, it is worth emphasizing that being fired is the chief mechanism to achieve access and control over their overall FGTS. Furthermore, there are strong incentives for workers to seek access to their FGTS. First, the FGTS has been poorly managed by the government, typically generating negative real returns or returns well below market rates. ${ }^{7}$ Second, due to shortsightedness or credit constraints, workers may be heavily discounting the future. The facts that (1) all dismissal penalties are immediately received individually by the dismissed worker, and (2) being dismissed is the chief mechanism for workers to acquire control over their own fund that is poorly managed by the government give them considerable incentives to induce their own dismissal after a certain time in any job. However, those incentives are related to the existence of the FGTS and the amount accumulated in this fund. As we saw in the last section, the constitution did not change those aspects of regulation.

There are other incentives associated with the dismissal penalty that may indeed drive the results estimated on this paper. On one hand this penalty is paid by the employer to the employee, as opposed to the employer's paying into a social fund held for all workers as a group. In other words, the dismissed worker (only him) receives the penalty on an individual basis. This characteristic of the law has well-established and major negative effects on the workers' behavior, giving them significant incentives to induce their own dismissal. ${ }^{8}$

On the other hand, firm behavior tends, however, to reduce dismissals when there is an increase on the dismissal's penalties value. Additionally,

7. See Almeida and Chautard (1976) for a broad analysis of the FGTS, including topics such as management of the fund and workers' welfare. Carvalho and Pinheiro (1999) provide a more updated analysis, focusing on the role of FGTS on fomenting investments.

8. See Macedo (1985) and Amadeo and Camargo (1996). 
as a result of the increase in dismissal penalties, firms become more selective in their hiring procedures, leading to an overall decline even greater in dismissal rates. Hence, the net effect on turnover will depend on the respective responses' intensities of each part (firms and workers) to the magnitude of the penalties. It is worth mentioning that these incentives are associated with employment spells longer than three months because before that employers can fire workers free of any penalty.

Hence, the aggregate effect on turnover will depend also on the firm reaction during the first months of the relation, namely the training period. The firm may become more selective in the first three months because the firing process becomes more expensive later. It means that the turnover may increase during this period as a consequence of an increase on dismissal penalties. So we have to contrast the results related to both periods in order to access the aggregate result on turnover.

According to the incentives described previously, it is not clear that legislation would achieve the original goal of a lower firing level. We can either have an opposite or null result. Additionally, a null net result can also arise from the absence of any reaction. This would be the case if the penalty is not a bidding constraint. In fact, we have some evidence that workers and firms collude to turn voluntary quits into dismissals. Under this circumstance workers can have access to their fund, but firms do not pay any penalty. Barros, Corseuil, and Foguel (2001) show that approximately $2 / 3$ of the workers that voluntarily quit from jobs in the formal sector access their FGTS, which means that these quits were officially registered as dismissals. ${ }^{9}$

\subsection{Demand for Labor Estimation}

This part of the chapter describes an attempt to estimate the impact of regulations on labor market performance based on the first of the two measures mentioned in the introduction - the labor demand parameters. These parameters constitute our proxy for labor market performance. As we estimate the parameters monthly, we can try to identify whether the evolution of these parameters is associated to the constitutional change or to the evolution of macroeconomic indicators. This exercise constitutes our second step, where we run regressions of the labor demand parameters on an indicator of the constitutional change and on macroeconomic indicators.

This part is organized in five sections. Section 5.3.1 describes a structural model for labor demand on which we base our first step. The estimation procedure of the relation suggested by the theoretical model is described in section 5.3.2. The second step and a data base description are the focus of sections 5.3.3 and 5.3.4, while the results of both steps are commented on in section 5.3.5.

9. There are questions about access to the fund in some Brazilian household surveys. 


\subsubsection{A Structural Model for Labor Demand}

In this section we estimate a structural dynamic labor demand model using longitudinal data on establishments. The model, one of the most simple in the literature, assumes labor as a homogeneous input and that labor is the only input undergoing adjustment costs. ${ }^{10}$ Moreover, this basic theoretical model assumes that each firm $i$, at each point in time $t$, chooses the level of employment, $n_{i}(t)$, in order to maximize the expected present value of profits; that is, each firm chooses $n_{i}(t)$ in order to maximize

$$
\begin{aligned}
E_{t}\left(\sum _ { r = 0 } ^ { \infty } \rho ^ { r } \left\{R\left[n_{i}(t+r), \mathbf{p}_{i}(t+r), \boldsymbol{\theta}(t+r), \mu_{i}(t+r)\right]\right.\right. \\
\left.\left.-\delta(t+r) w_{i}(t+r) n_{i}(t+r)-C\left[\Delta n_{i}(t+r), \eta(t+r)\right]\right\}\right),
\end{aligned}
$$

where $R$ is the revenue function and $C$ is the employment adjustment cost function.

Hence, at each point in time the revenue function, $R$, can be obtained by choosing the level of production and of all nonlabor variable inputs that maximize a current profits condition on a given choice for employment and the state of the technology. ${ }^{11}$ As a consequence, the arguments of the revenue function can be divided into three groups: (1) level of employment, $n_{i}(t) ;(2)$ price of all other variable inputs relating to the product price, $p_{i}(t)$; and (3) all factors determining the state of technology. We divide the factors determining the state of technology into two groups: (1) a vector of parameters defining the overall form of technology at each point in time, $\boldsymbol{\theta}(t)$, that is common to all firms; and (2) a certain firm and time-specific technological innovation, $\mu_{i}(t)$.

The second term in equation (1) is the direct cost of labor. In this equation, $w_{i}(t)$ is the real wage rate ${ }^{12}$ paid by firm $i$ at time $t$, and $\delta(t)$ is the ratio between the overall variable cost of labor and the wage rate. We are implicitly assuming that all nonwage variable costs are proportional to wages with the proportionality constant and common to all firms but possibly time varying due to changes in the legislation.

Finally, the cost of adjustment $(C)$ is assumed to be a function of the net change in employment, $\Delta n_{i}(t)=n_{i}(t)-n_{i}(t-1)$, and a parameter, $\eta(t)$. This parameter may vary over time to capture changes in the economic environment and in the labor legislation, but it is common to all firms, indicating that all firms face the same adjustment cost.

According to this model, the form of technology and labor costs may vary freely over time. However, idiosyncratic shocks of a firm can only

10. See Nickell (1986), Hamermesh (1993), and Hamermesh and Pfann (1996) for surveys of dynamic labor demand models.

11. In the state of the technology, we include the impact of the level of all fixed or exogenously determined inputs.

12. The real wage rate is obtained by dividing the nominal wage rate by the product price. 
affect technology. Labor costs are determined by firm-specific wages and a legislation that is common to all firms.

In order to obtain an explicit solution to this problem of maximization, we introduce a series of simplifying assumptions that allow us to write the solution of equation (1) as the following expression defined for the employment level: ${ }^{13}$

$$
n_{i}(t)=\lambda n_{i}(t-1)+\frac{(1-\lambda)}{\theta^{12}}\left[\theta^{11}(t)+\mu_{i}(t)+\sum_{s=1}^{m} \varphi_{s}(t) I_{i s}-\delta(t) w_{i}(t)\right],
$$

where $\lambda$ is implicitly defined by

$$
\theta^{12} \lambda=(1-\lambda)(1-\rho \lambda) \eta,
$$

and $I_{i s}$ indicates whether firm $i$ belongs to sector $s$, that is, $I_{i s}=1$ if firm $i$ belongs to sector $s$ and $I_{i s}=0$ otherwise. Finally, $\theta^{11}(t), \theta^{12}(t)$ are originated from $\boldsymbol{\theta}(t)$ and correspond to parameters of a quadratic revenue function, the same assumption made for the adjustment cost function.

\subsubsection{Econometric Specification}

To obtain an empirically feasible econometric specification for the demand for labor, we must be more specific about the firm- and time-specific technological innovation, $\mu_{i}(t)$. We assume that this innovation consists of three underlying components; that is, we assume that

$$
\mu_{i}(t)=\beta_{i}+\gamma(t)+U_{i}(t),
$$

where $\beta_{i}$ captures a firm-specific, time-invariant technological component, $\gamma(t)$ an aggregated time-specific technological shock, and $U_{i}(t)$ captures all other technological shocks. The presence of the first two components allows us to assume, without any loss of generality, that the average of $U_{i}(t)$ over time and across firms is always zero. However, because the econometric model will also include sectorial indicators, $I_{i s}$, we must assume that the average of $U_{i}(t)$ within each sector is also zero; that is, we assume that for every $s$,

$$
E\left[U_{i}(t) \mid I_{i s}=1\right]=0 .
$$

To identify the parameters of the model, additional assumptions are required. Probably the simplest route to obtain identification is to assume that $U_{i}(t)$ is an exogenous moving-average process. Accordingly, we assume that

$$
E\left[U_{i}(t) n_{i}(t-p)\right]=0
$$

for all $p>k^{1}$. We also assume that although these technological shocks may be correlated with the recent evolution wages, they are uncorrelated with the evolution of wages in the past; that is,

13. The complete derivation of the model is reported in appendix A. 


$$
E\left[U_{i}(t) w_{i}(t-p)\right]=0
$$

for all $p>k^{2}$. Notice that if $U$ were an exogenous moving-average process of order

$$
k=\max \left(k^{1}, k^{2}\right),
$$

then these two assumptions would be immediately satisfied.

Given this specification for the technological innovation, equation (2) may be rewritten as

(3) $n_{i}(t)=\alpha(t)+\beta_{i}^{*}+\sum_{s=1}^{m} \varphi_{s}^{*}(t) I_{i s}-\delta^{*}(t) w_{i}(t)+\lambda n_{i}(t-1)+U_{i}^{*}(t)$,

where

$$
\begin{aligned}
\alpha(t) & =\frac{1-\lambda}{\theta^{12}}\left[\theta^{11}(t)+\gamma(t)\right], \\
\beta_{i}^{*}(t) & =\frac{1-\lambda}{\theta^{12}} \beta_{i}, \\
\delta^{*}(t) & =\frac{1-\lambda}{\theta^{12}} \delta(t), \\
\varphi_{s}^{*}(t) & =\frac{1-\lambda}{\theta^{12}}(t), \\
U_{i}^{*}(t) & =\frac{1-\lambda}{\theta^{12}} U_{i}(t) .
\end{aligned}
$$

The presence of $\alpha(t)$ and $\beta_{i}^{*}$ in equation (3) poses some drawbacks for estimation. The presence of $\alpha(t)$ makes estimation of the other parameters unfeasible in a pure time series context, unless some function form for $\alpha(t)$ is imposed.

In a cross-section environment, the difficulty is imposed by the natural correlation between $\beta_{i}^{*}$ and $n_{i}(t-1)$. To solve this problem we must rely on longitudinal information. When this type of information is available, we can take first differences to obtain

(4) $\Delta n_{i}(t)=\Delta \alpha(t)+\sum_{s=1}^{m} \Delta \varphi_{s}^{*}(t) I_{i s}-\delta^{*}(t) \Delta w_{i}(t)+\lambda \Delta n_{i}(t-1)+\Delta U_{i}^{*}(t)$,

as long as the ratio between the overall variable cost of labor and the wage rate $\delta(t)$ is time invariant. This equation has the advantage of eliminating the idiosyncratic component $\beta_{i}^{*}$. Nevertheless, it still cannot be estimated as a multiple regression because

$$
E\left[\Delta n_{i}(t-1) \Delta U_{i}^{*}(t)\right] \neq 0 .
$$

However, it follows from the assumptions made previously about $U_{i}(t)$ that 


$$
E\left[n_{i}(t-p) \Delta U_{i}^{*}(t)\right]=0,
$$

and

$$
E\left[w_{i}(t-p) \Delta U_{i}^{*}(t)\right]=0
$$

for all $p>k+1$. Hence, the model can be estimated by instrumental variable using past values of employment and wages as instruments. Under the assumptions made on $U_{i}(t)$, all values of employment and wages lagged at least $k+2$ periods would be valid instruments. However, from a practical point of view it is necessary to limit the number of instruments. In this study we use as instruments 6 lags for employment and 6 lags for wages; that is, we use as instruments employment and wages lagged, $k+2, \ldots$, $k+7$ months. In the estimation we use two alternative values for $k$ (one month and ten months). Hence, to implement this econometric procedure it is necessary to count with panel information at least seventeen months long on firm-specific employment and wages.

Using this econometric model, based on equation (4), it is possible to estimate $\alpha(t), \lambda, \delta^{*}$, and $\varphi_{s}(t)$. Changes on the values of these parameters, especially $\lambda$ and $\delta^{*}$ after 1988 , indicate that the regulation might have impacted on labor market performance. ${ }^{14}$ One possibility for investigating these possible changes would be to estimate two sets of parameters, first using data from the years before 1988 and then data from recent years. The available data allows us to obtain monthly estimates of the parameters of the demand function.

This strategy has at least three advantages over the strategy of estimating just two models for a period before and after 1988. First, it is easier to implement because the econometric model is essentially estimated in a cross-section. This feature of the estimation procedure makes estimating the standard errors much easier because in this case it is not necessary to estimate the temporal correlation patterns of the technological shocks.

Second, the estimation of a model for every month has the great advantage of allowing a precise identification of the exact point in time where the parameters have changed. A precise identification of the moment when the parameters changed can provide important insights into the question of whether the constitutional change is the real force behind the changes in the demand for labor. For instance, if the parameters began to change long before or long after 1988, we would become suspicious about the causal

14. At this point it is worthwhile mentioning that, although the demand for labor is estimated for every month, in the estimation procedure the parameters $\theta^{12}$, $\eta$, and $\delta$ must be at least locally time invariant. The estimated parameters are consistent only if this assumption is valid. If the parameters $\theta^{12}$ and $\eta$ change over time, equation (2) would not be the solution of the Euler equation. Moreover, if $\delta$ varies from one month to the next, the first difference made to eliminate the firm-specific time invariant technological component, $\beta_{i}^{*}$, would still work but would generate a different function form to be estimated because in this case $\delta^{*}$ would not factor out. 
link between the 1988 constitutional change and those in the demand for labor.

Third, and more important, monthly estimations of the parameters allow us to identify in which sense their evolutions are determined-by the regulation (1988 constitutional change) or by the evolution of macroeconomic indicators. This is precisely what we do in the second step of this regression analysis.

In the next section we describe this second step in detail. It is worth mentioning that we can also obtain estimated values for coefficients of interest other than the ones mentioned previously. The first of these other coefficients is the long-run impact of changes in wages on employment, $\phi$, that can be obtained via

$$
\phi=\frac{\delta^{*}}{(1-\lambda)} .
$$

Other parameters of interest are the structural parameters of the production function, $\theta^{12}$, and of the cost function, $\eta$. Some additional information is required to obtain estimated values for these parameters. In this study, to recover these original parameters we assume that the discount rate, $\rho$, and the ratio between the unit cost of labor and the wage, $\delta$, are known and equal to 0.95 and 1.8 , respectively. Given the knowledge of these two parameters and estimates for $\lambda$ and $\delta^{*}$, estimates for the underlying parameters $\theta^{12}$ and $\eta$ can be obtained via

$$
\hat{\theta}^{12}=\frac{1-\hat{\lambda}}{\hat{\delta}^{*}}
$$

and

$$
\hat{\eta}=\frac{\hat{\lambda} \delta}{\hat{\delta}^{*}(1-\rho \hat{\lambda})} .
$$

\subsubsection{Identification Strategy: The Second Step}

The monthly estimate of demand functions was just the first step in our econometric strategy. Because the Brazilian economy underwent a process of trade liberalization and was subject to a series of stabilization plans at the same time as the change in the constitution, changes in the parameters of the labor demand function that may have occurred over this period cannot be immediately attributed to the constitutional change.

To isolate the effect of the constitutional change on the parameters of the demand function, we regress our monthly estimates of these parameters on a temporal indicator for the 1988 constitutional change, $D_{t}$, controlling for a variety of other macroeconomic indicators, $M_{t}$. Because the precision of estimates varies considerably over time, to control for this source of variation we use as our dependent variable the parameter estimate divided by its 
corresponding standard error. More specifically, we estimate the following regressions

$$
\frac{\hat{\lambda}(t)}{s_{\lambda}(t)}=a_{1}+b_{1} D(t)+c_{1} M(t)+e_{1}(t)
$$

and

$$
\frac{\hat{\delta}^{*}(t)}{s_{\delta}(t)}=a_{2}+b_{2} D(t)+c_{2} M(t)+e_{2}(t),
$$

where $s_{\lambda}(t)$ and $s_{\delta}(t)$ are the standard errors of $\hat{\lambda}(t)$ and $\hat{\delta}^{*}(t)$, and $D(t)=0$, if $t$ refers to a period prior to 1988 and $D(t)=1$ otherwise. We include the following as macroeconomic indicators: (1) the GDP real growth rate; (2) degree of openness measured by the ratio of total trade (exports plus imports) to the GDP; (3) inflation rate; and (4) inflation volatility measured by the inflation standard deviation. Monthly dummies and a linear trend were included in all regressions. These regressions are estimated by ordinary least square method using monthly data covering the period June 1986 to December 1997. Positive and statistically significant estimates for $b_{1}$ and $b_{2}$ would then be taken as evidence that the 1988 constitutional change had an important effect on the demand for labor and, consequently, on the level of employment and the speed of adjustment.

\subsubsection{The Database}

In the first step of the regression analysis we estimate the demand for labor using monthly longitudinal information from the Pesquisa Industrial Mensal (PIM). The PIM is a monthly industrial establishment survey conducted by the IBGE (Brazilian Census Bureau), covering the entire country. It is a longitudinal survey of a stratified sample of approximately 5,000 manufacturing establishments employing five workers or more. The panel covers the period from January 1985 to the present.

The survey collects information on labor inputs, labor costs, turnover, the value of production, and so on. The data on labor inputs includes both employment and the total number of hours paid. The survey has three major limitations in terms of measuring labor inputs. First, the information covers the total number of hours paid but not the actual number of hours worked. Second, all data refers only to the personnel directly involved in production. Finally, there is no information on the qualification of the labor force employed.

In relation to labor costs, two types of information are available: (1) total value of contractual wages (that is, value of wages and salaries as specified in labor contracts), and (2) total value of payroll. For the purposes of this study, the payroll data seems to be more informative because it includes, in addition to contractual wages, the payment for overtime, commissions, and other incentive schemes, such as a productivity premium. It also in- 
cludes all fringe benefits; paid vacations; and any additional payments for hazardous activities, night shifts, and other compensating schemes. ${ }^{15}$

Despite the fact that the payroll data covers a wide variety of labor costs, it does not include all of them. Major exceptions are the employer's contributions to social security, training programs, and other social programs. Fortunately, however, these contributions as fractions of contractual wages have been fairly constant over time, except for a significant change for the occasion of the 1988 constitution.

Hence, for each establishment in the survey we use essentially three pieces of information: (1) employment level, (2) total number of hours paid, and (3) total payroll. Basing our information on these three variables we construct two measures for variable labor cost. These two measures are obtained by dividing total payroll by the level of employment and the total number of hours paid, respectively. For labor input we use both available measures: employment and hours paid. As a result, each demand model is actually estimated twice, depending on whether labor inputs are measured by employment or hours paid. We will refer to the one based on employment level as model 1 and to the one based on hours paid as model 2 .

In the first step of the regression analysis we aggregate some macroeconomic indicators mentioned in the last section. The source of the gross domestic product (GDP) data is the IBGE. The data for exports and imports was calculated in joint work by the Fundação Centro de Estudos de Comércio Exterior (FUNCEX) and IPEA. Finally, we used the official inflation index to measure inflation.

Before we move to the labor demand estimates, we present some basic statistics from our sample of establishments. Panels A and B of figure 5.1 present the monthly evolution of the average level of the two measures of labor input used in the study. These figures reveal that firms in our sample employ 200 to 300 workers who are paid a total of 45,000 to 70,000 hours per month during the period analyzed. The average number of hours paid per month per worker in our sample is around 230 hours. Notice that a fraction of the hours paid is not actually worked. For instance, included in the hours paid is at least one day off per week (usually Sunday), which is paid but not worked.

All these figures reveal that, over the 1985-1997 period, employment and hours paid per manufacturing firm declined considerably, with the total decline concentrated in the first two years of the 1990s. The main goal of this study is to determine precisely to what extent this decline can be associated with the 1988 constitutional change or with other macroeconomic

15. In this study, all information on contractual wages and payroll has been deflated using the sector's specific wholesale price index, except for the pharmaceutical; plastic; textile; and perfume, soap, and candle sectors. All monetary values referred to constant reais at December 1997. 


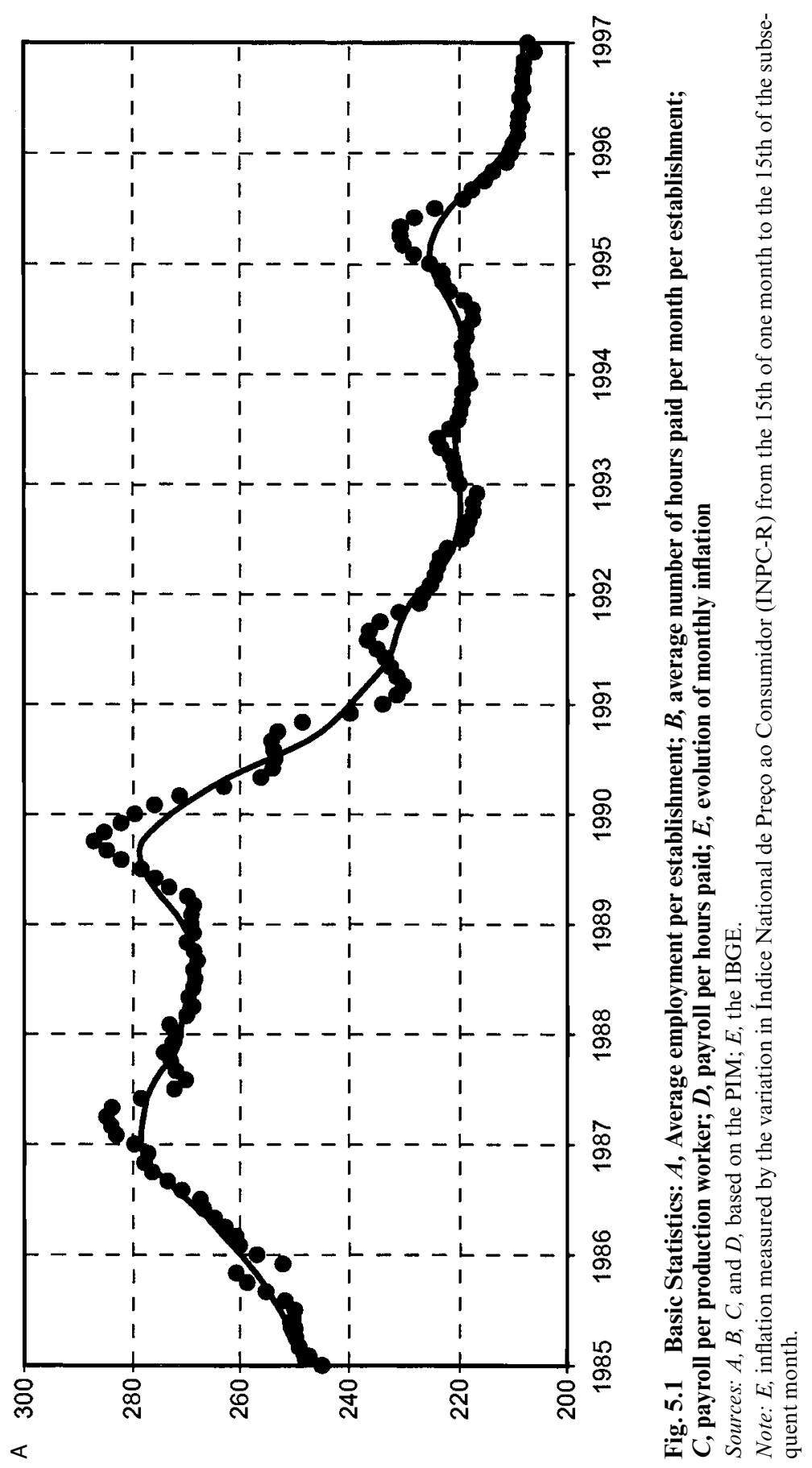




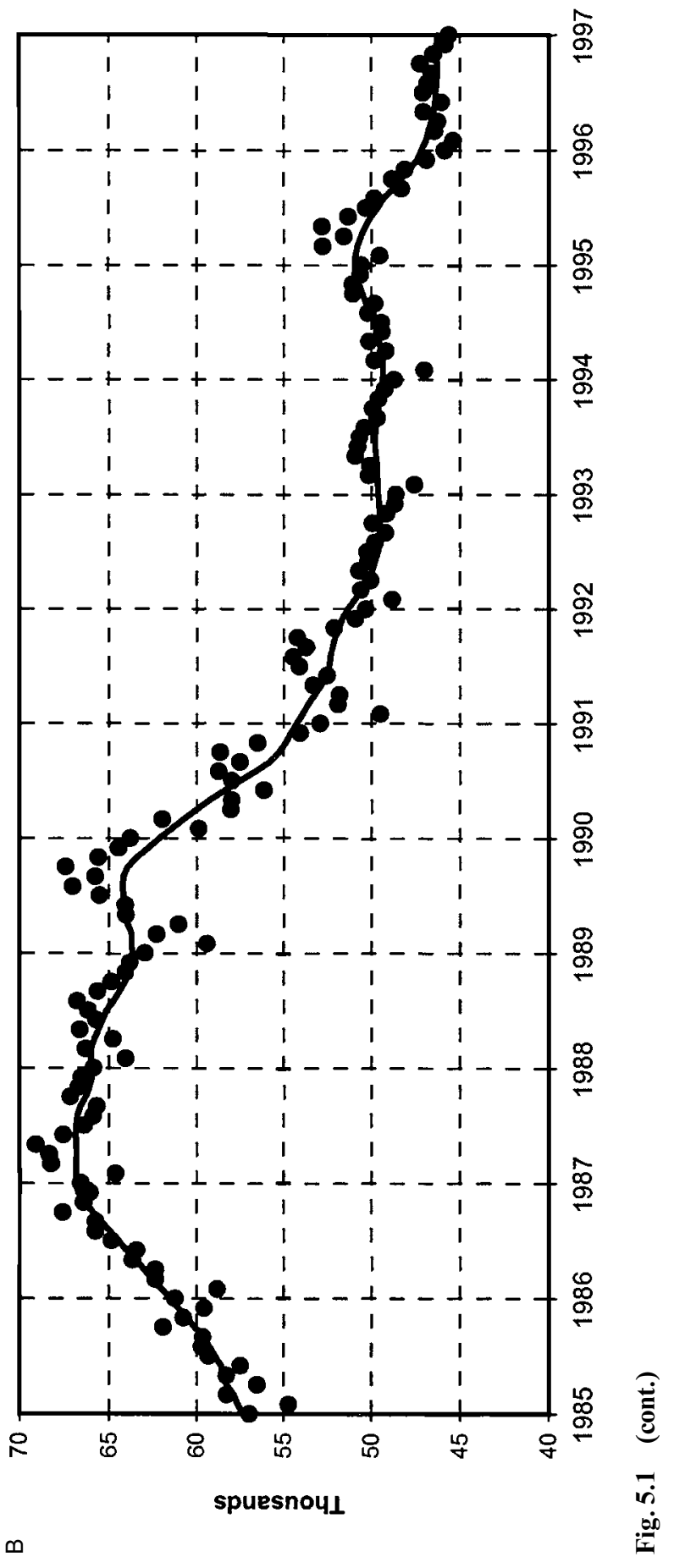




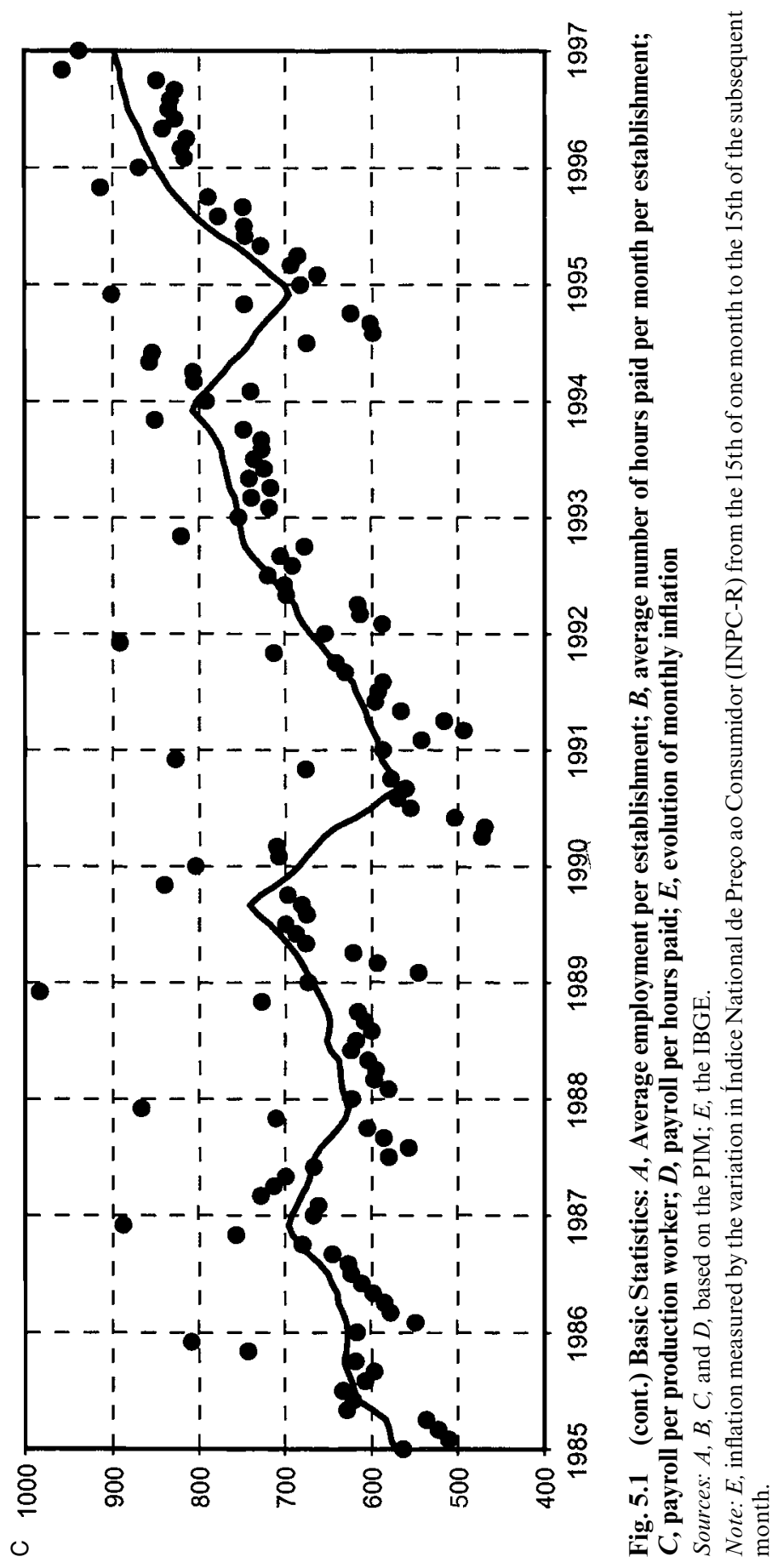




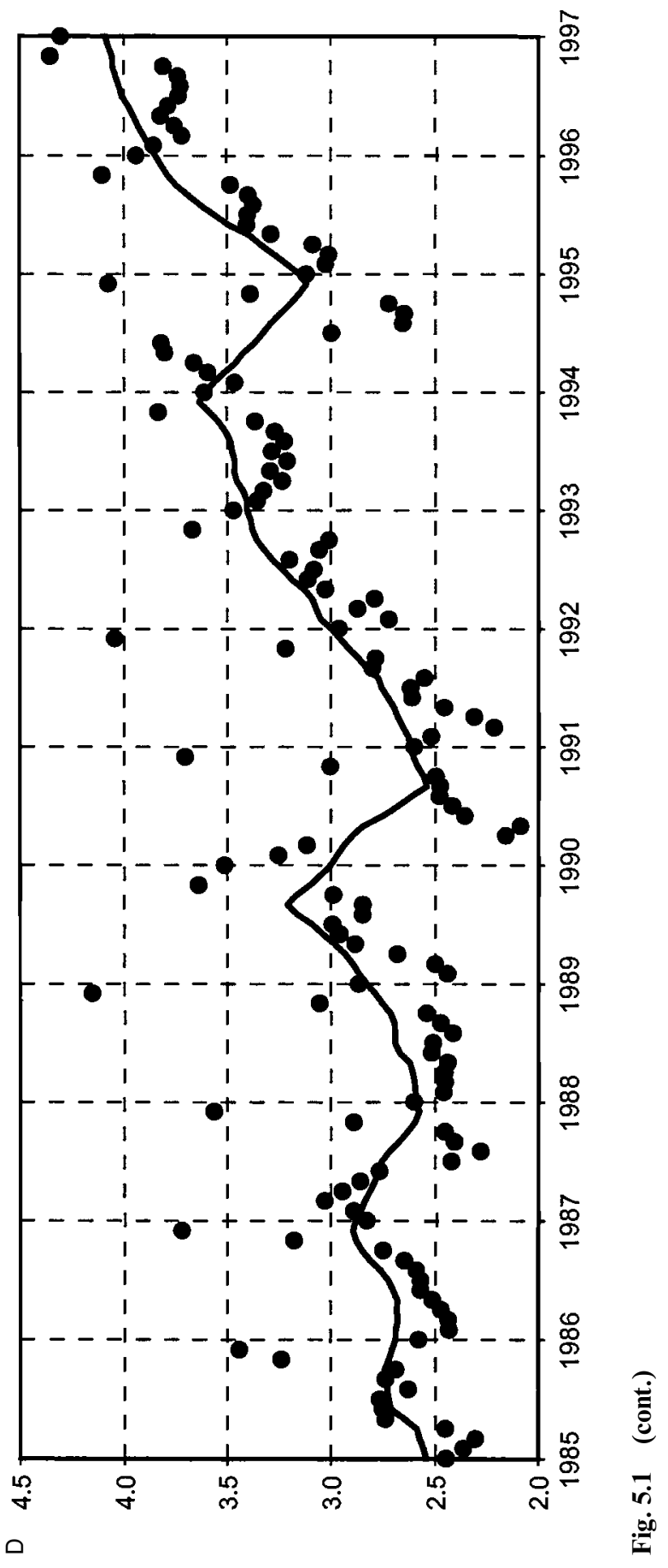




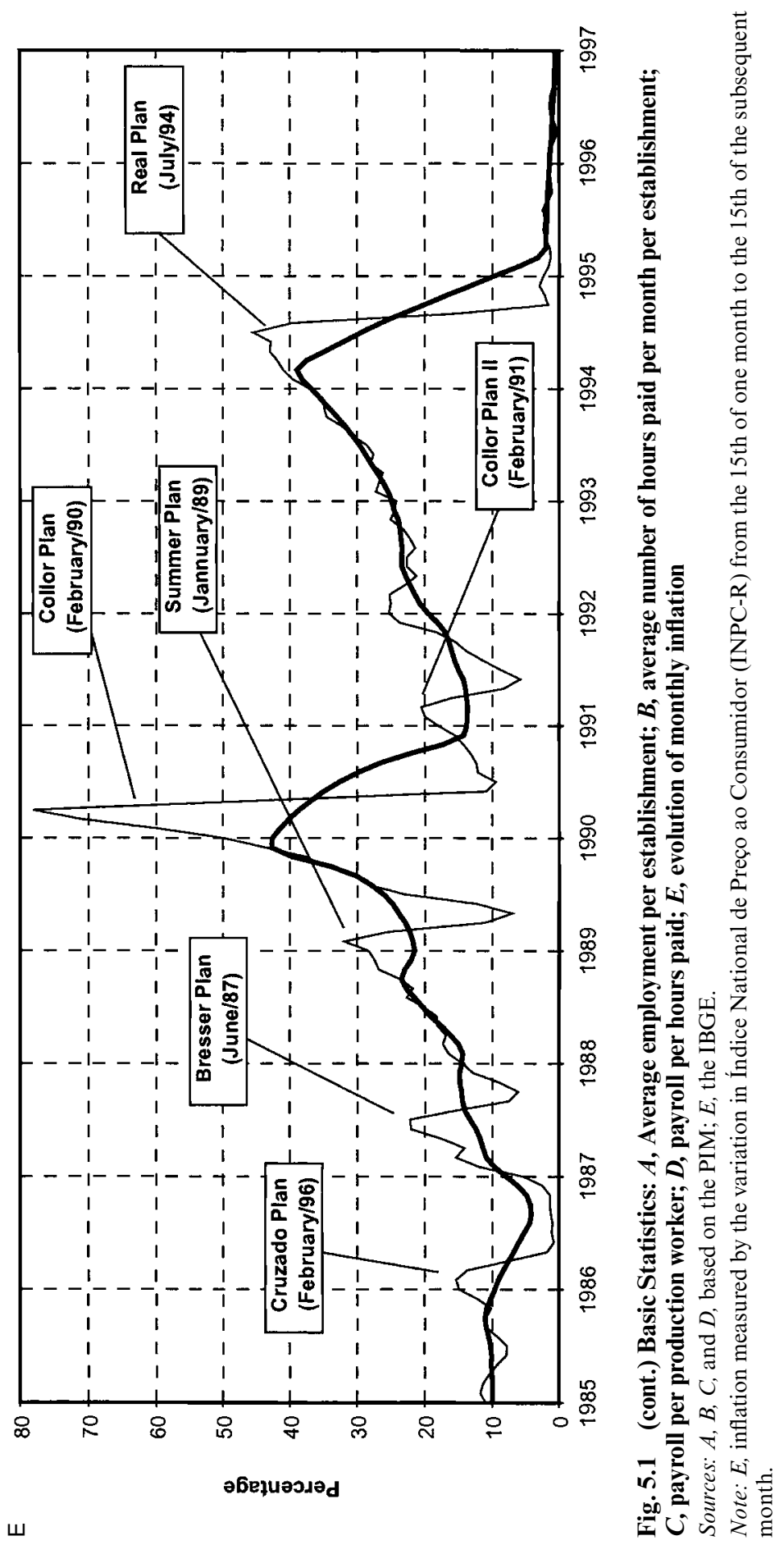


changes that marked the performance of the Brazilian economy over this period.

Panels C and D of figure 5.1 show the monthly evolution of our two measures for labor costs. These figures reveal that average wages (in Brazilian reais [R]) for production workers in Brazilian manufacturing were, most of the time, between $\mathrm{R} \$ 600$ and $\mathrm{R} \$ 800$ per month, leading to an hourly wage rate between $\mathrm{R} \$ 2.50$ and $\mathrm{R} \$ 3.50 .{ }^{16}$ These figures reveal an overall upward trend in wages over the period, coupled with at least four cyclical fluctuations. These cycles very closely match series of stabilization plans that marked the period 1985-1994; see panel E of figure 5.1.

\subsubsection{Empirical Results}

The 1988 constitutional change brought an increase in labor costs, firing costs in particular. To the extent that this change was of substantial importance, it would lead to a decline in the response of employment to wages, $\delta^{*}$ and $\phi$, and also in the speed of adjustment (i.e., an increase in the coefficient on lag employment, $\lambda$ ).

We estimate labor demand models for each month from June 1986 to December 1997. Although we have information since January 1985, the need for valid instruments determines that parameter estimates could only be obtained from mid-1986, that is, seventeen months after the actual sample information begins.

As already mentioned in the previous sections, two labor demand models were estimated, depending on the choices of measures for labor inputs. Moreover, two estimates are obtained for each model, depending on how far in the past we select the instruments. In total, four estimates for the labor demand function are obtained. In each case we directly estimate two basic parameters: (1) the coefficient on lag employment, $\lambda$; and (2) the coefficient on current wages, $\delta^{*}$. We also obtain estimates for the long-run impact of change in wages on employment $(\phi)$ and other structural parameters $\left(\theta^{12}\right.$ and $\left.\eta\right)$.

Figures 5.2 and 5.3 provide estimates of the monthly evolution of the short-run impact of changes in wages on employment, $\delta_{t}^{*}$. Figures 5.4 and 5.5 show corresponding estimates for the coefficient on lag employment, $\lambda_{t}$. Because the estimates vary considerably from month to month, we also compute a trimmed twelve-month moving average. We adopted a two-step procedure to calculate this moving average. First, we eliminate all values in the lowest and highest tenths of the distribution. ${ }^{17}$ Second, we calculate the twelve-month moving averages with the remaining estimates. The averages are weighted, using the inverse of the standard errors of each estimate as weights. Basing our information on these moving average estimates for the

16. The exchange rate was $1.11 \mathrm{R} \$ / \mathrm{US} \$$ in December of 1997.

17. In each figure, the lowest and highest tenths are indicated by two horizontal lines. 


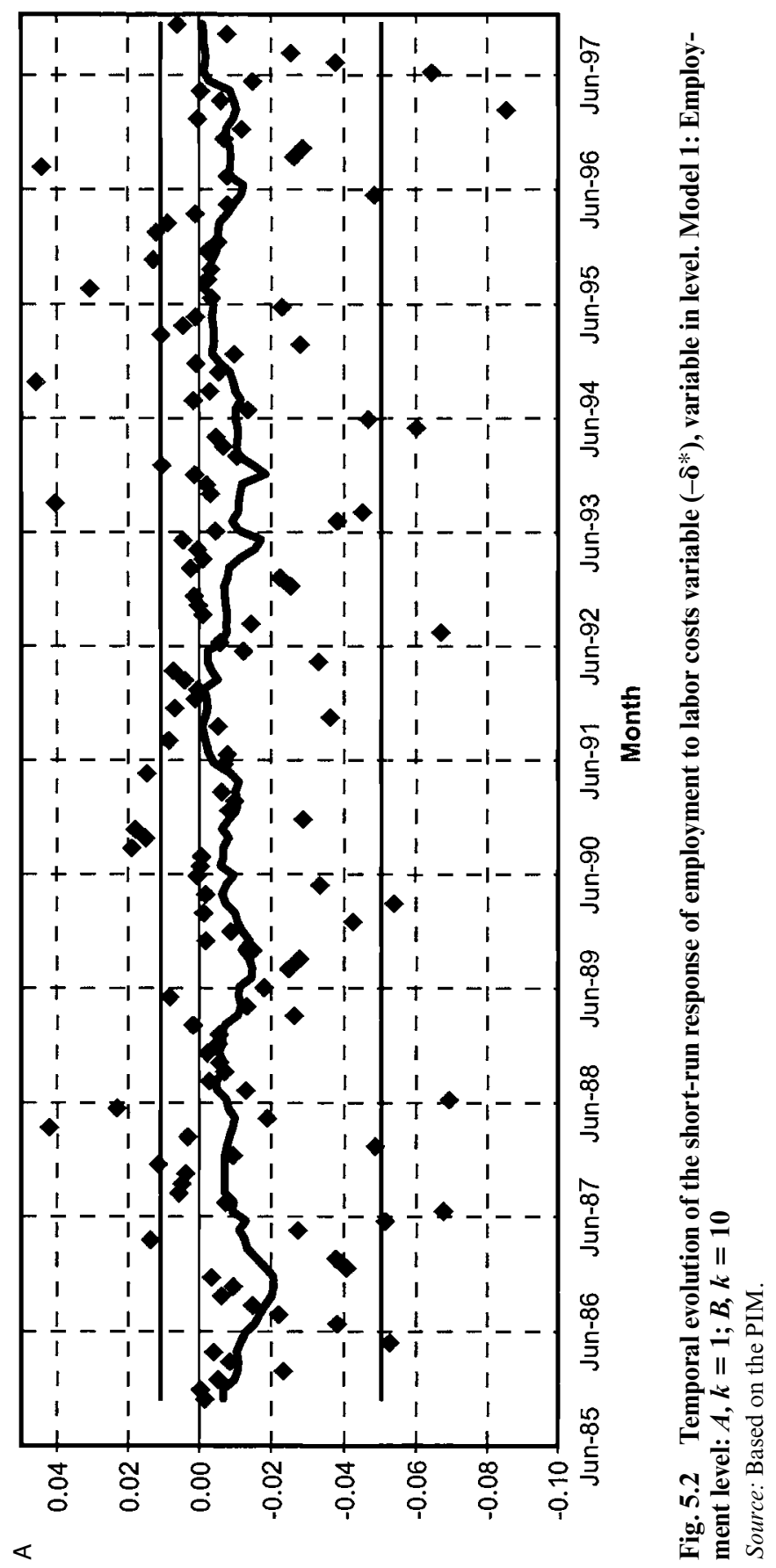




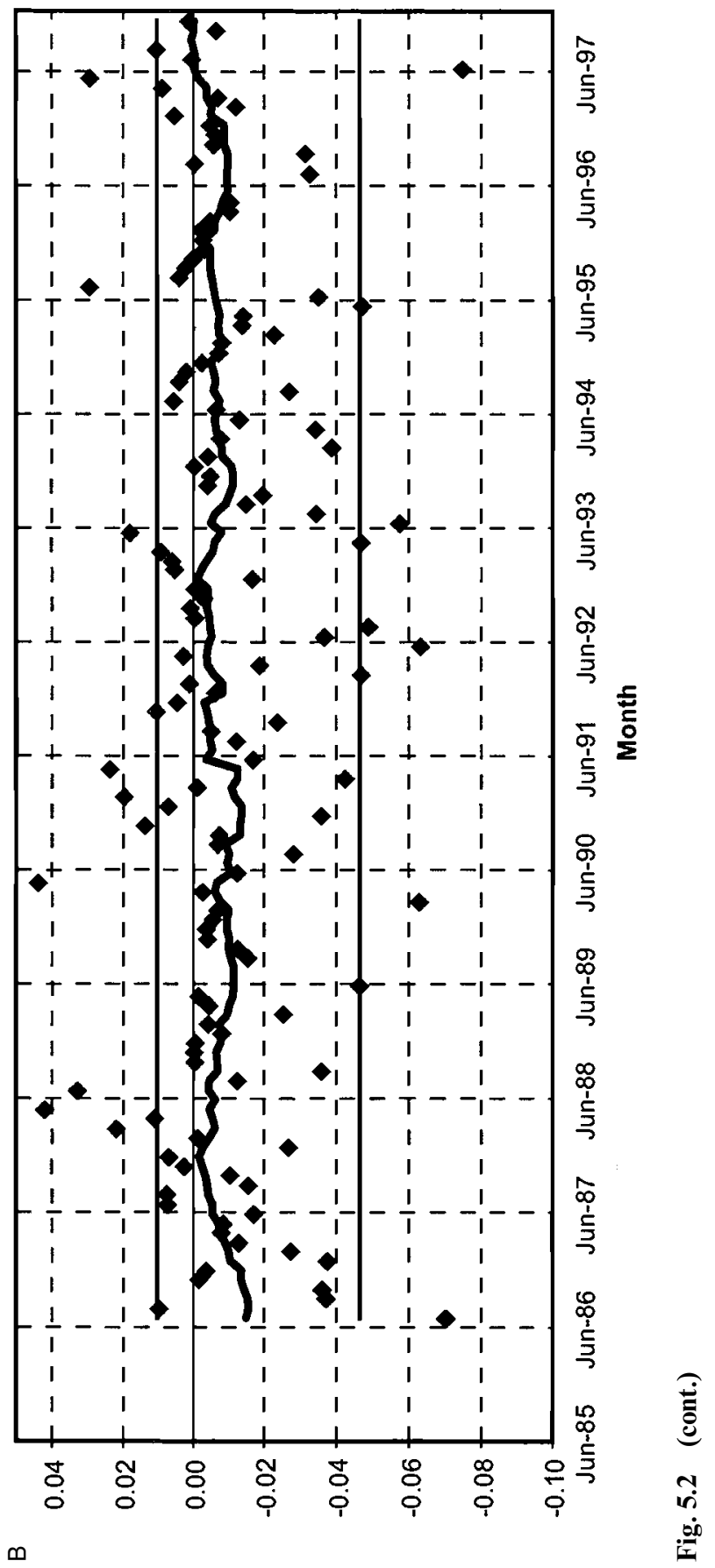




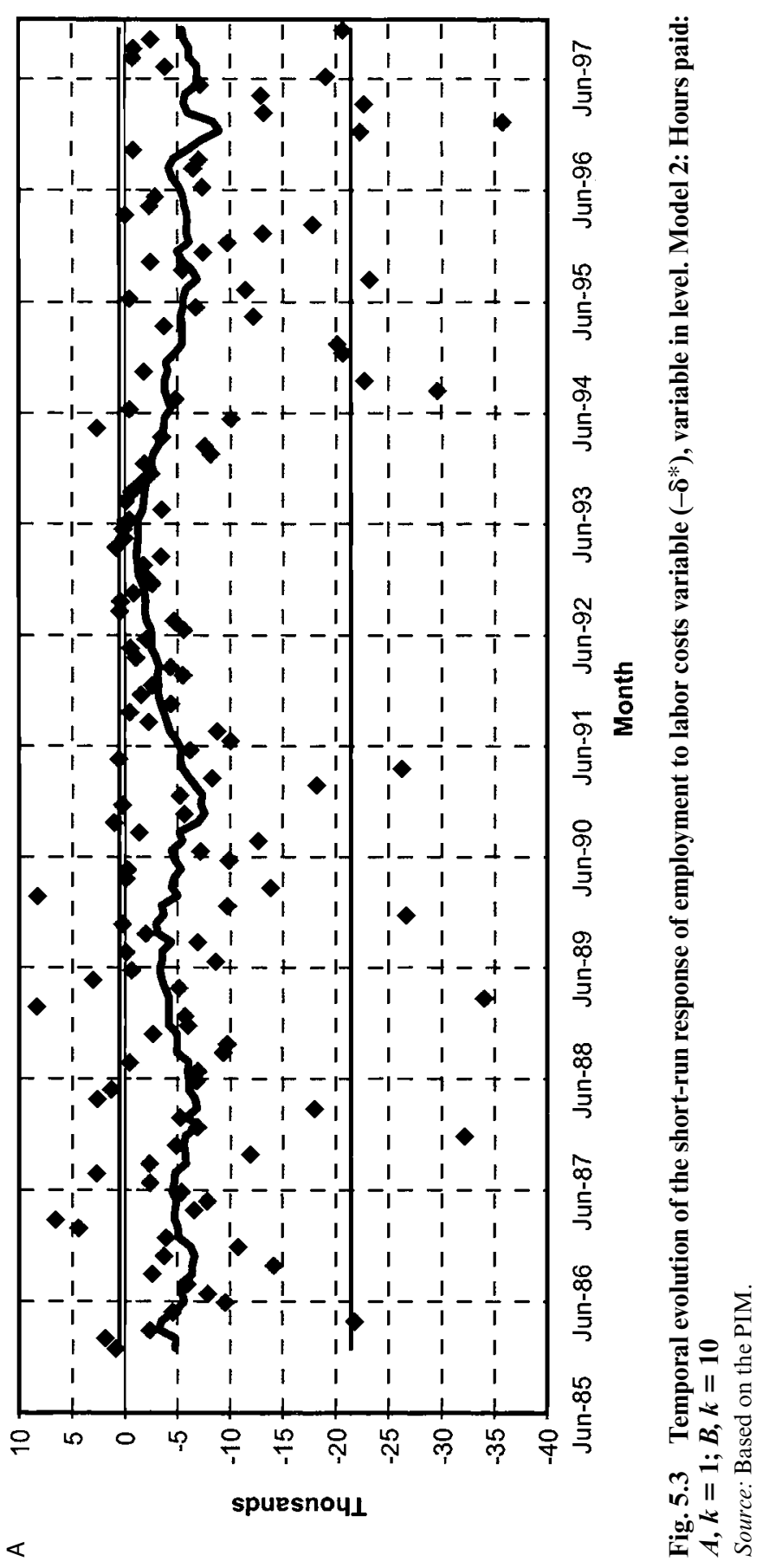




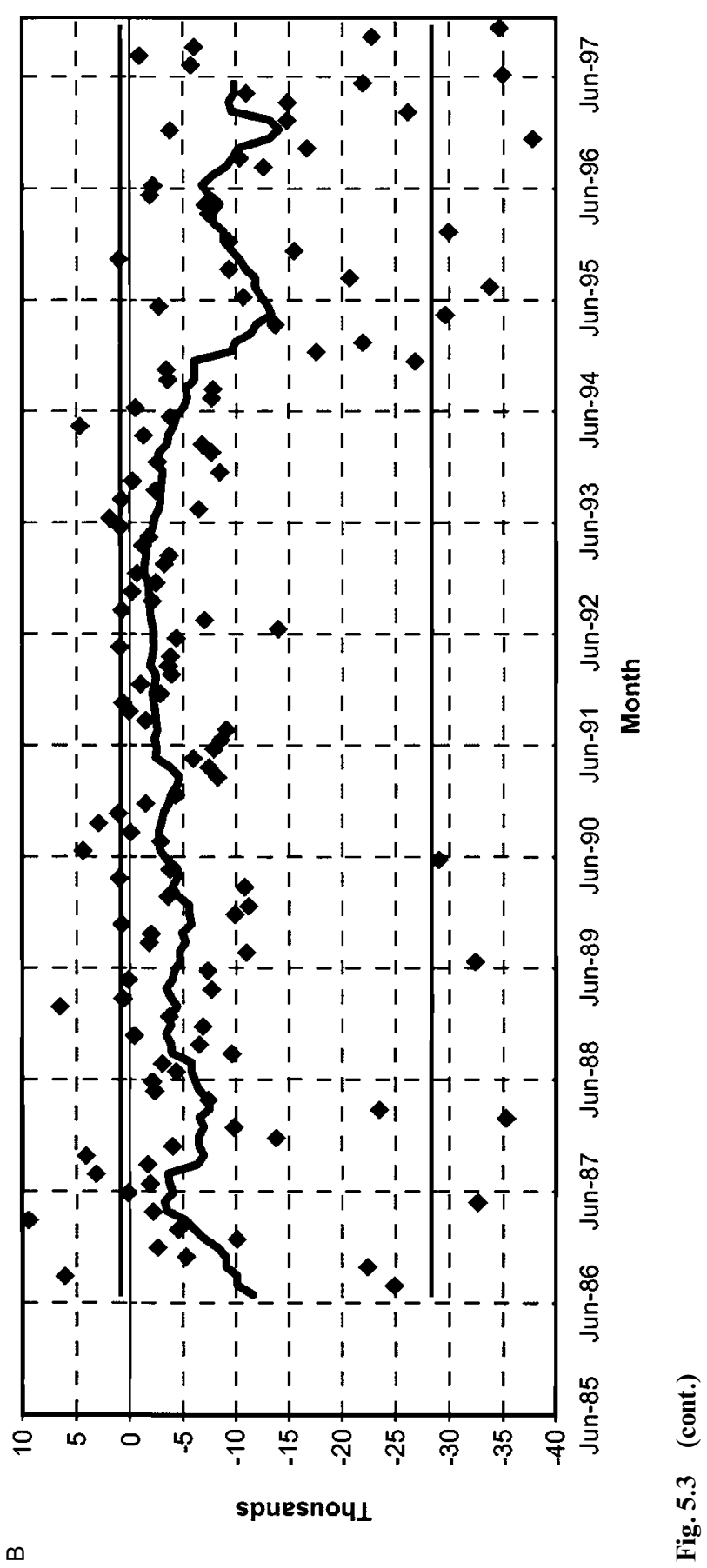




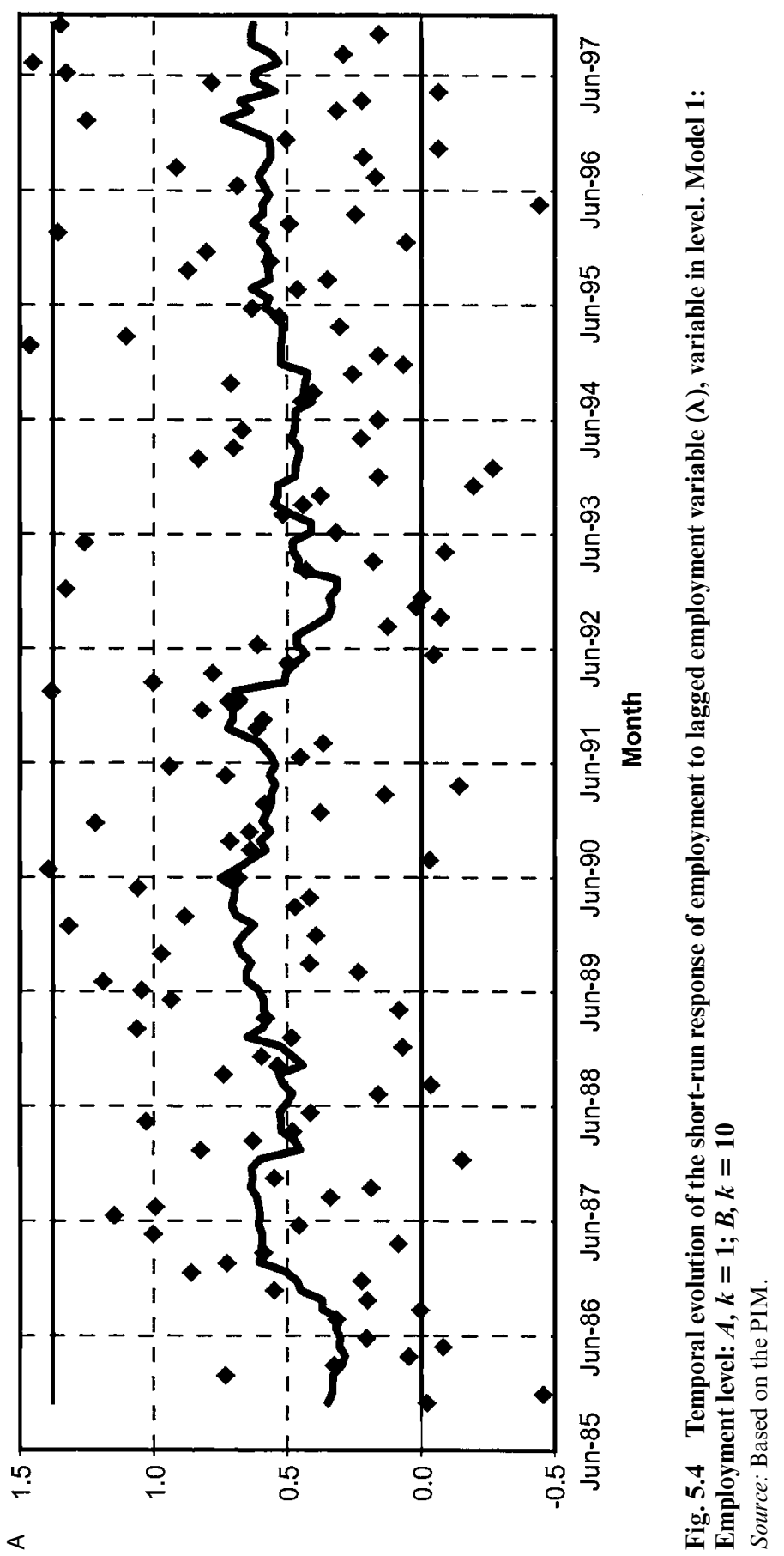




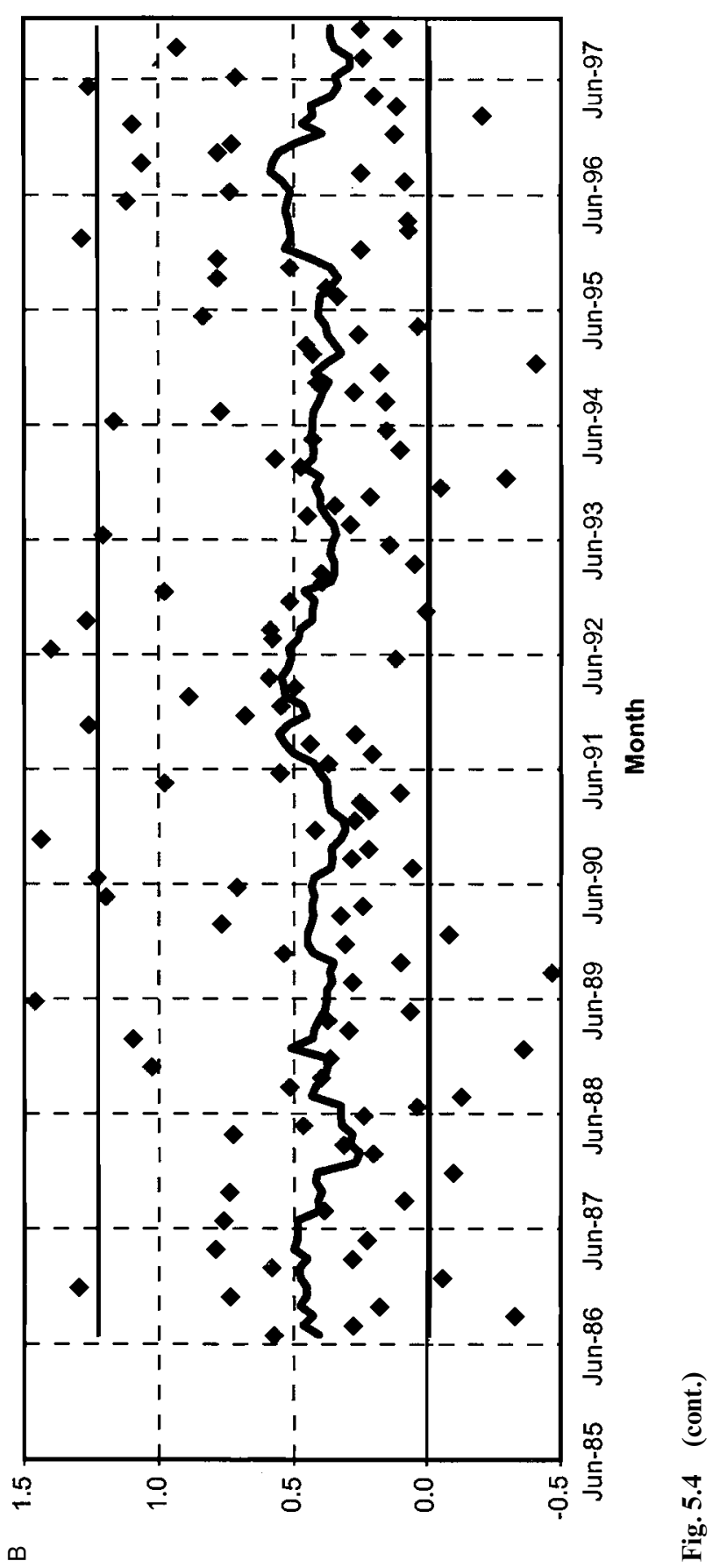




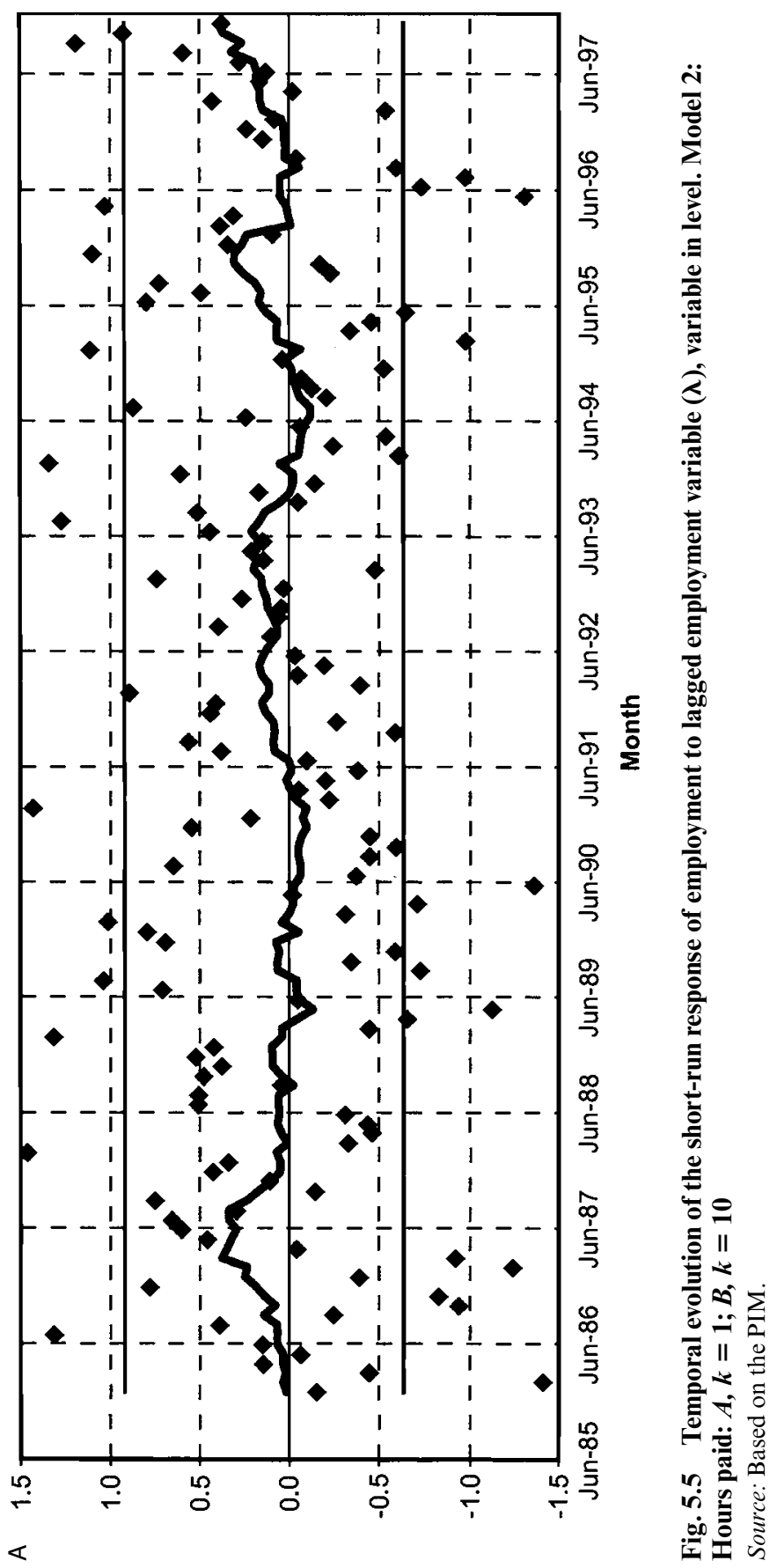




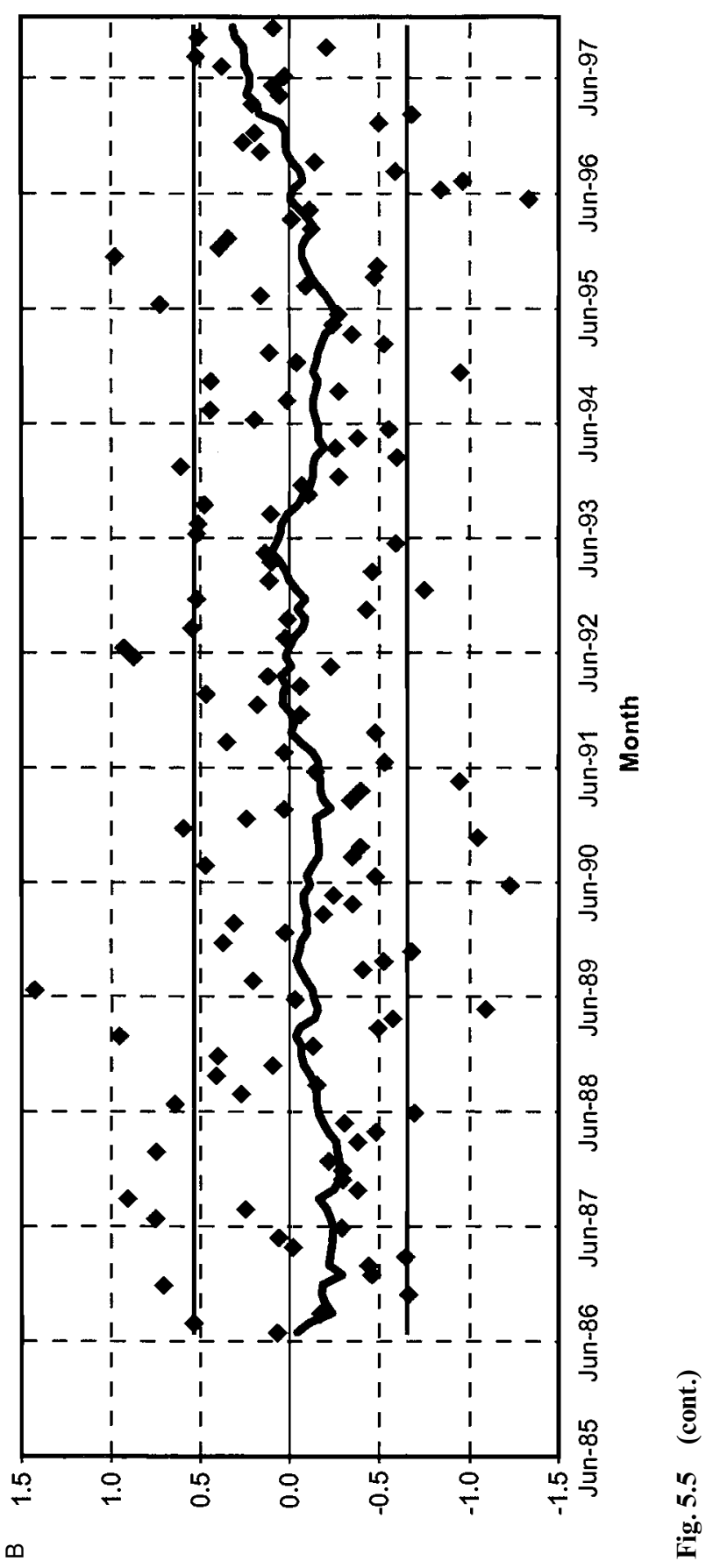


basic parameters of the model $\left(\lambda_{t}\right.$ and $\left.\delta_{t}^{*}\right)$, we obtain estimates for the longrun effect of wages on employment, $\phi_{t}$. These estimates are presented in figures 5.6 and 5.7.

Basing our information on two-year averages of the temporal evolution of these parameters and the values chosen for $\rho$ and $\delta$, we obtain estimates for some important remaining structural parameters of the model: $\boldsymbol{\theta}^{12}$ and $\eta$. These estimates are presented in figures 5.8, 5.9, 5.10, and 5.11.

Figures 5.2, 5.3, 5.6, and 5.7 provide clear evidence that both employment and hours paid decline as labor costs rise. These figures, however, provide no clear evidence that either the short- or long-run response of employment to labor costs increased as a consequence of the 1988 constitutional change.

Figures 5.4 and 5.5 give no evidence that the speed of adjustment was significantly affected by the 1988 constitutional change. In fact, figures 5.4 and 5.5 reveal a modest continuous increase in the speed of adjustment, contrary to what would be expected from a discrete increase in firing costs. It is worth mentioning, however, that the estimates for $\lambda$ have the correct signed and are statistically significant, at least when we use the number of employed workers as a measure of the labor input. These estimates, however, are considerably smaller (estimates for $\lambda$ are around 0.5 ) than what is commonly obtained from time series studies. Although the same pattern is observed when we use the number of hours paid, some point estimates became negative, and it becomes considerably less precise. Finally, figures 5.4 and 5.5 reveal that, as we choose instruments further into the past (i.e., as $k$ increases), the estimated values for $\lambda$ declines, indicating that serial correlation among technological shocks may seriously bias $\lambda$ upwards.

The interpretation of the basic parameters would be much easier if all variables were in logs. The specification with all variables in logs is also more similar, related to the tradition in labor demand models. For these reasons, we reestimate all previous models, changing all variables from levels to logs. Figures 5.12 to 5.17 show that the main results are robust to the $\log$ specification.

As in the basic model, these figures provide no clear evidence that the 1988 constitutional change had any significant impact on either the magnitude or the speed of the response of labor inputs to labor costs. These figures deserve a few additional comments. First, they show that the shortand long-term wage elasticities are around -0.2 and -0.4 , respectively. Second, it is worth mentioning that the estimates for the coefficient on lag of employment remain very close to 0.5 , as is the case in the basic model. Third, it should be noted that the further the instruments are in the past, the smaller the estimated coefficients on lag employment, another pattern common to the basic model.

To summarize the evidence about the effect of the 1988 constitutional 


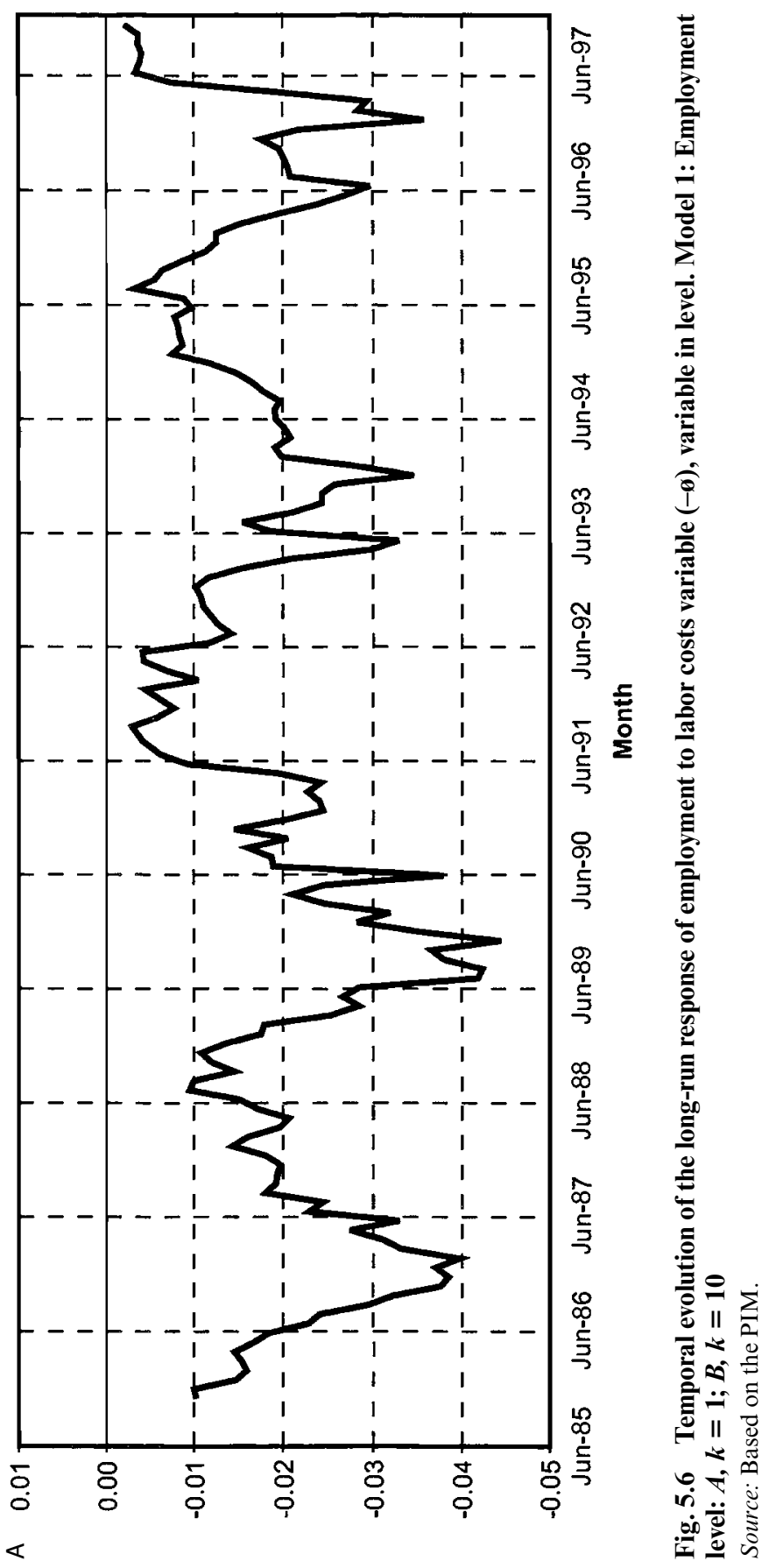




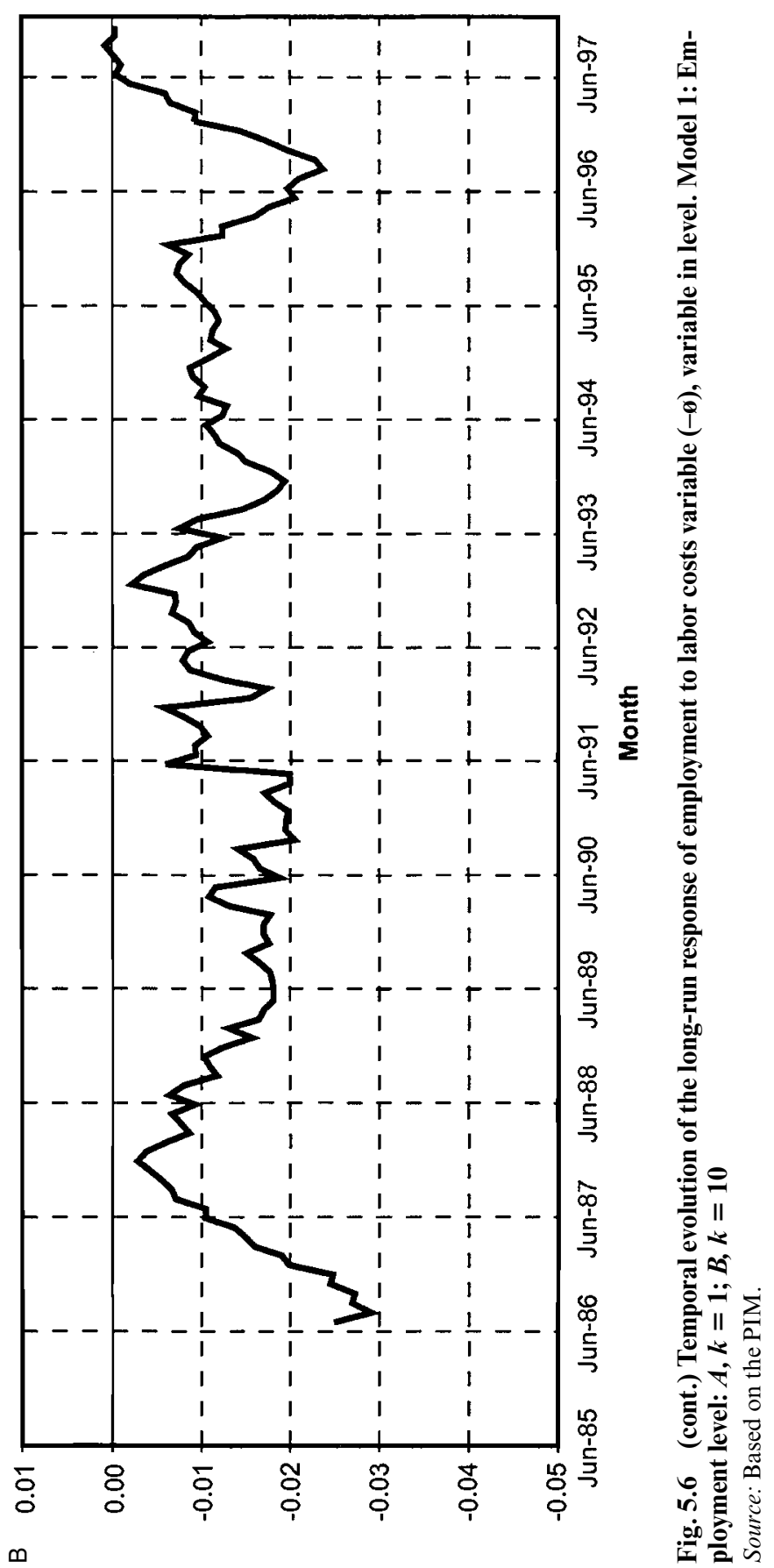




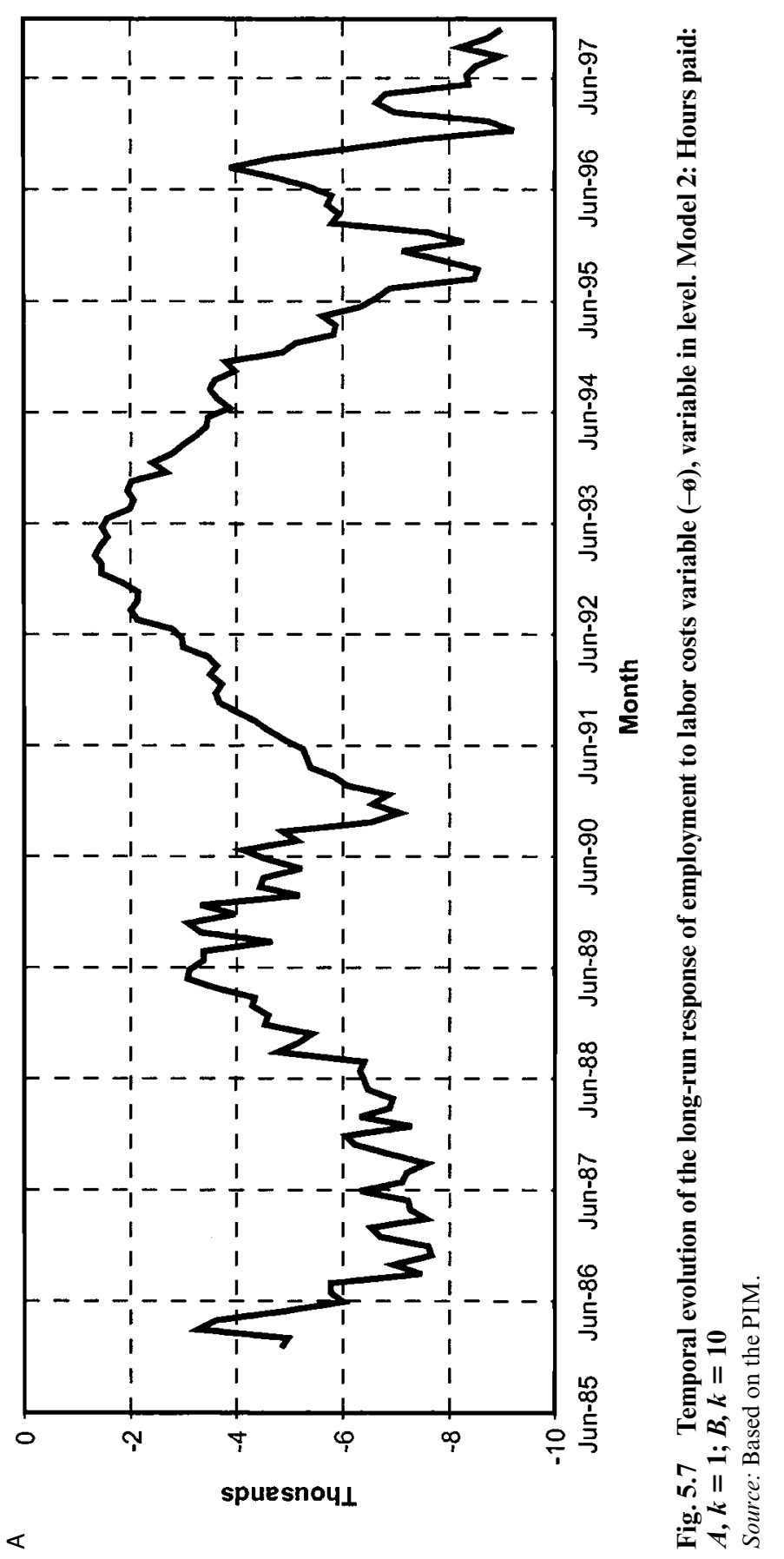




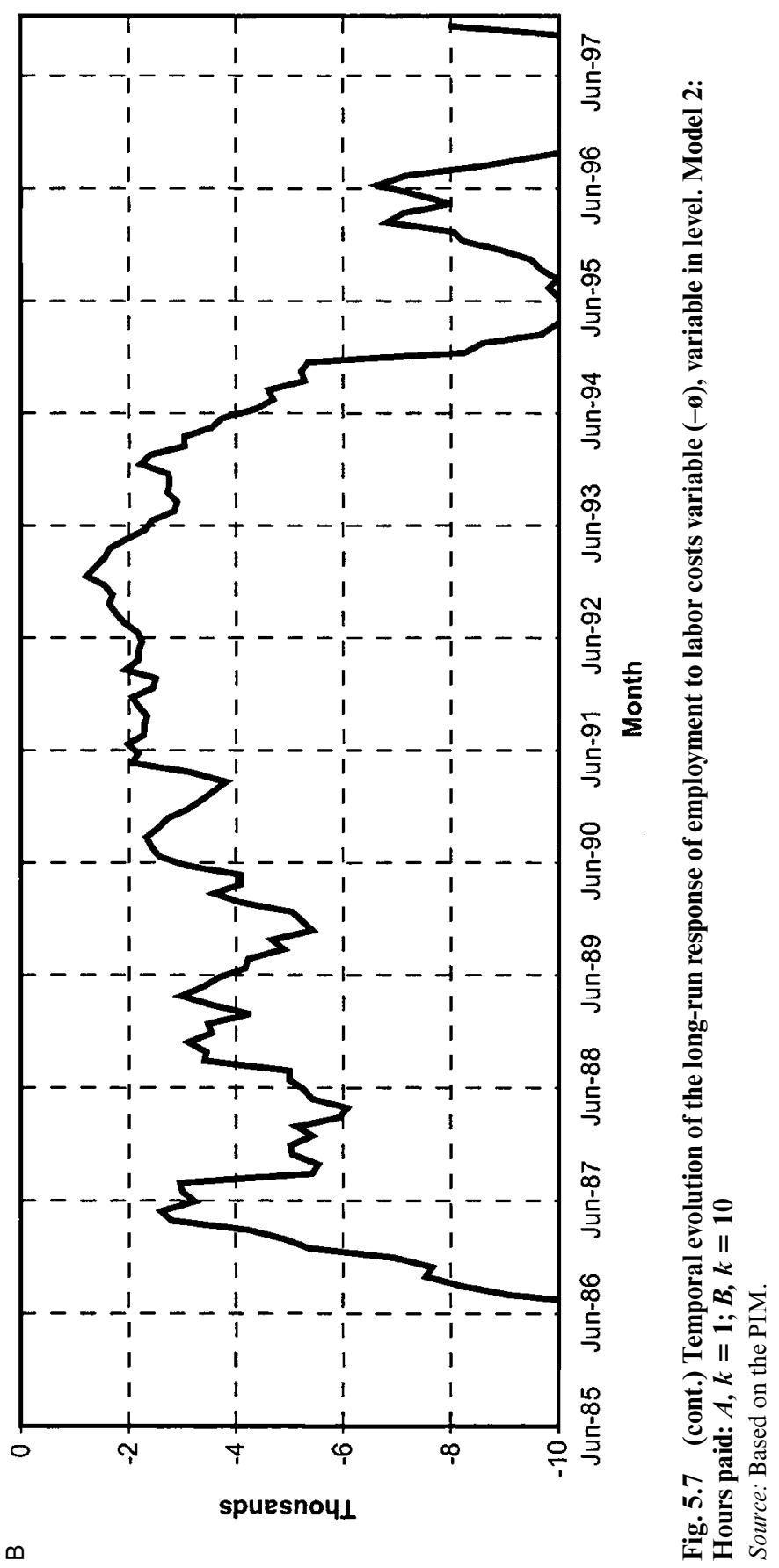




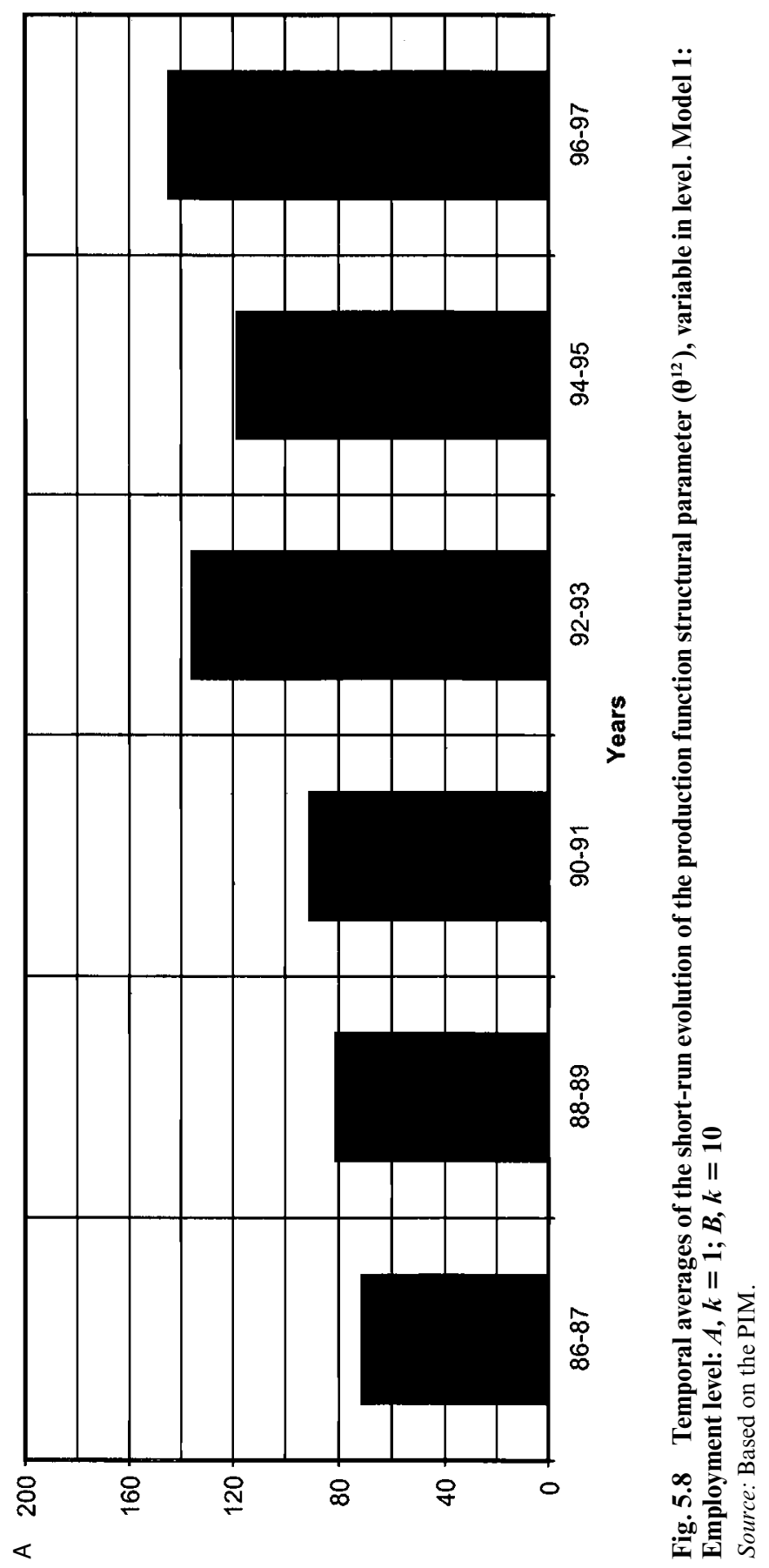




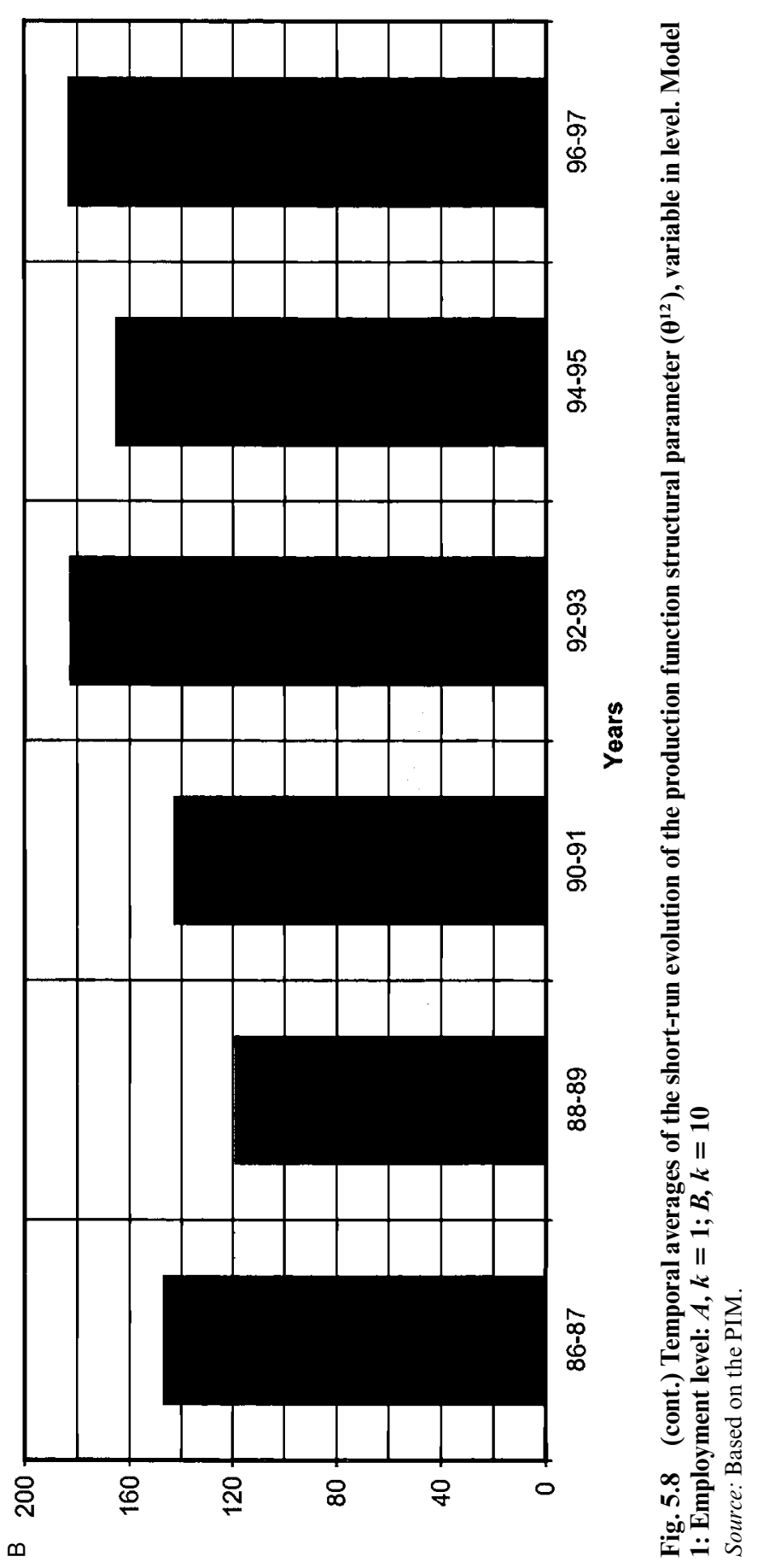




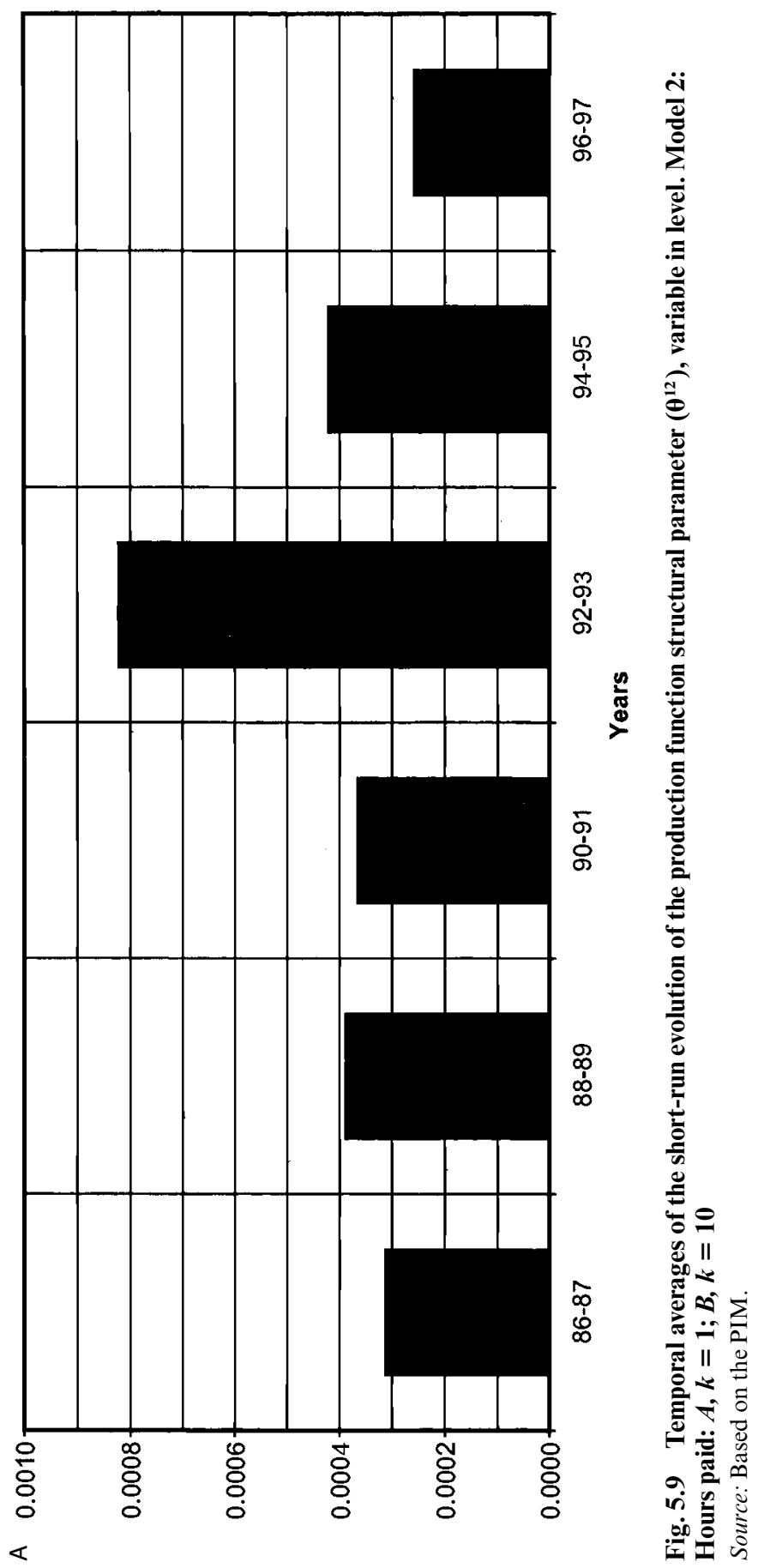




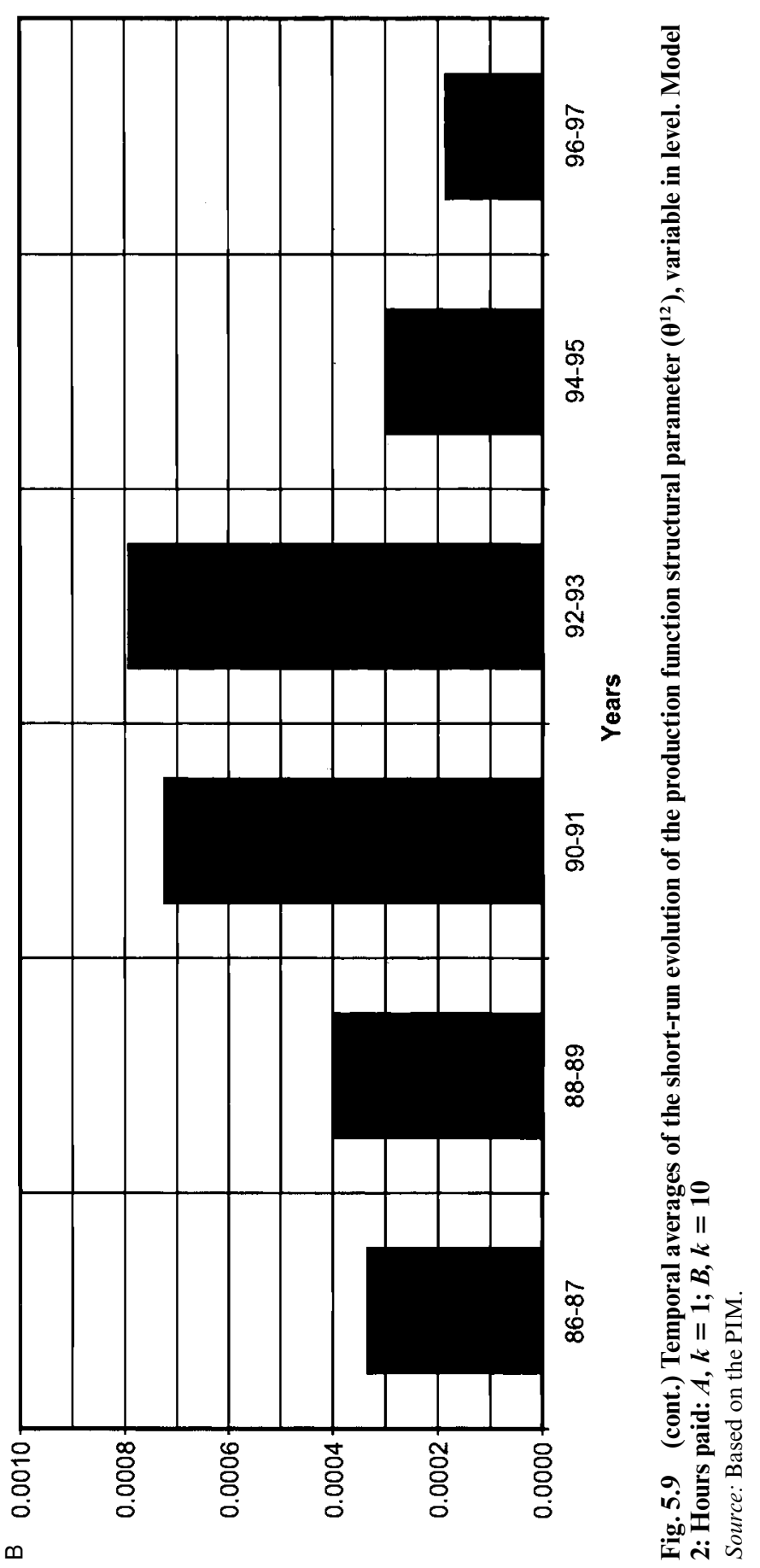




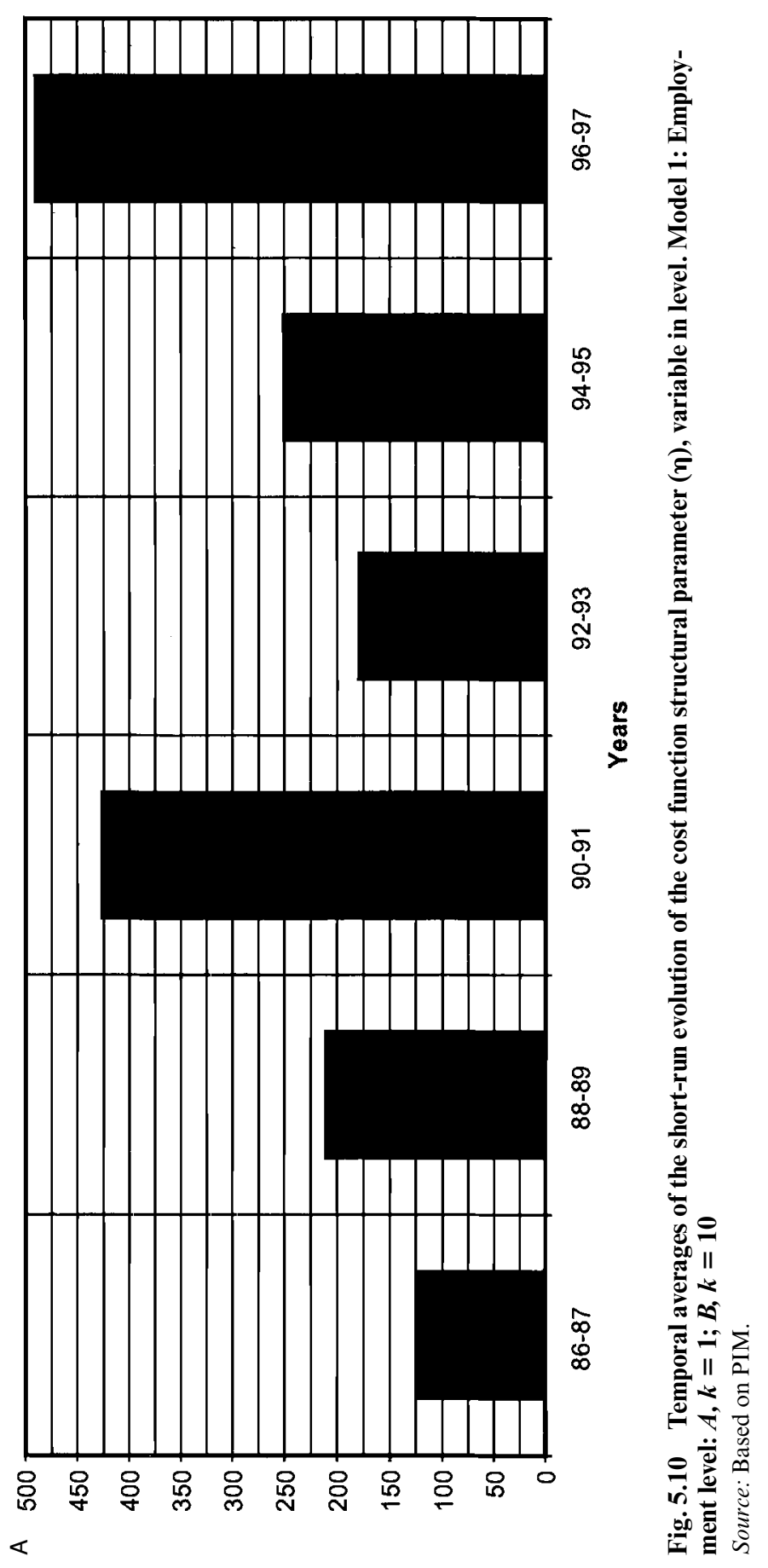




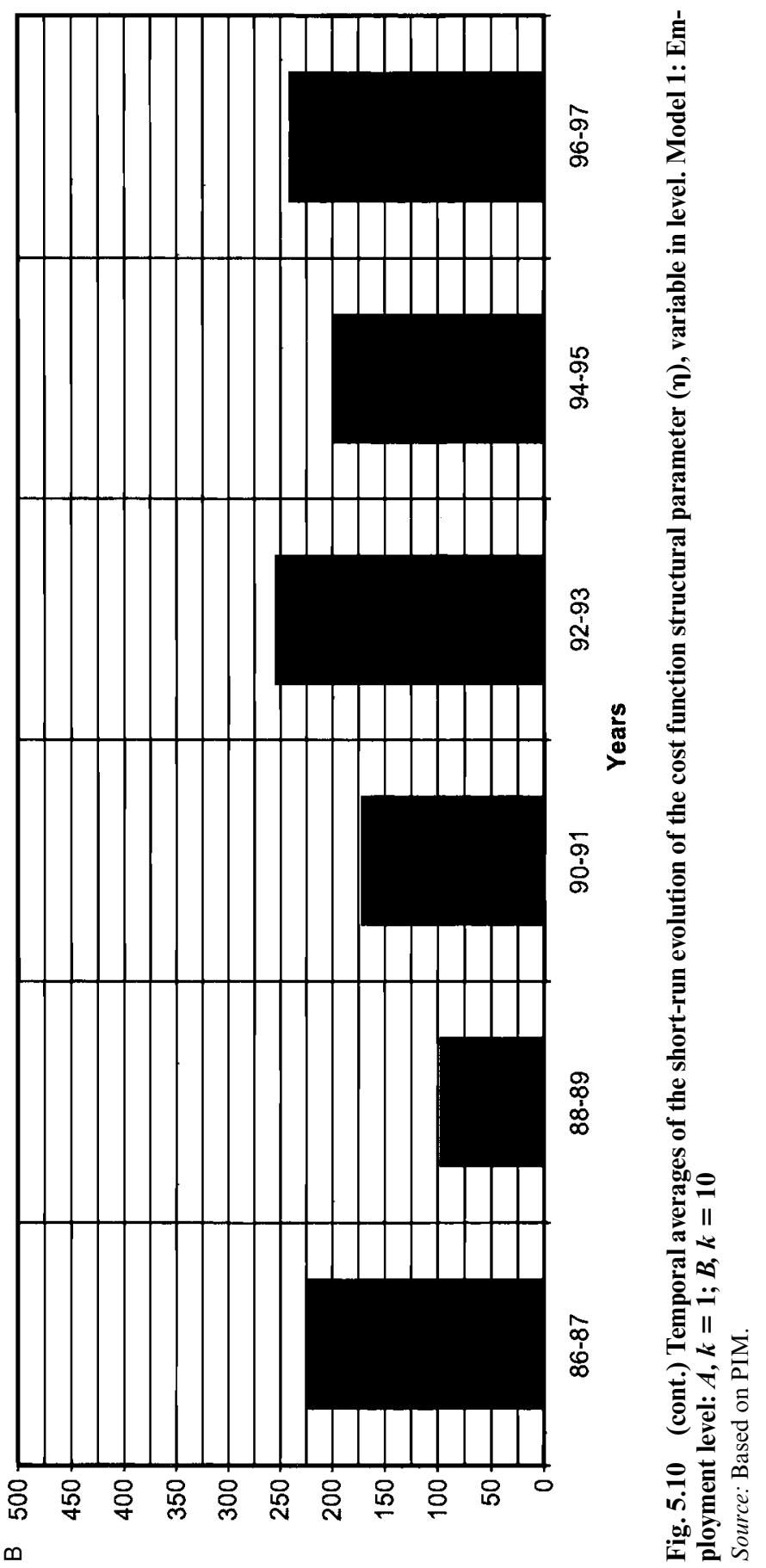




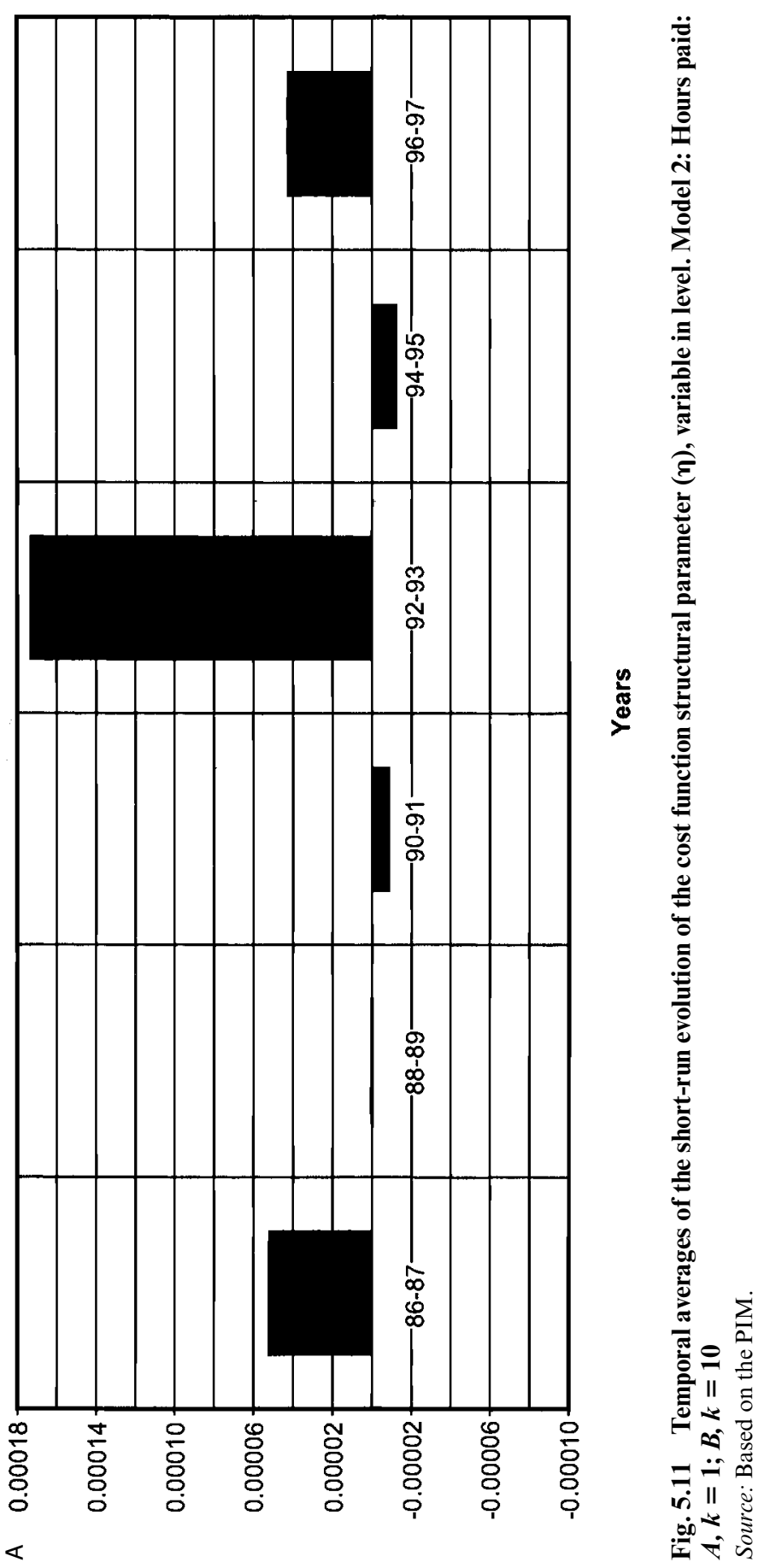




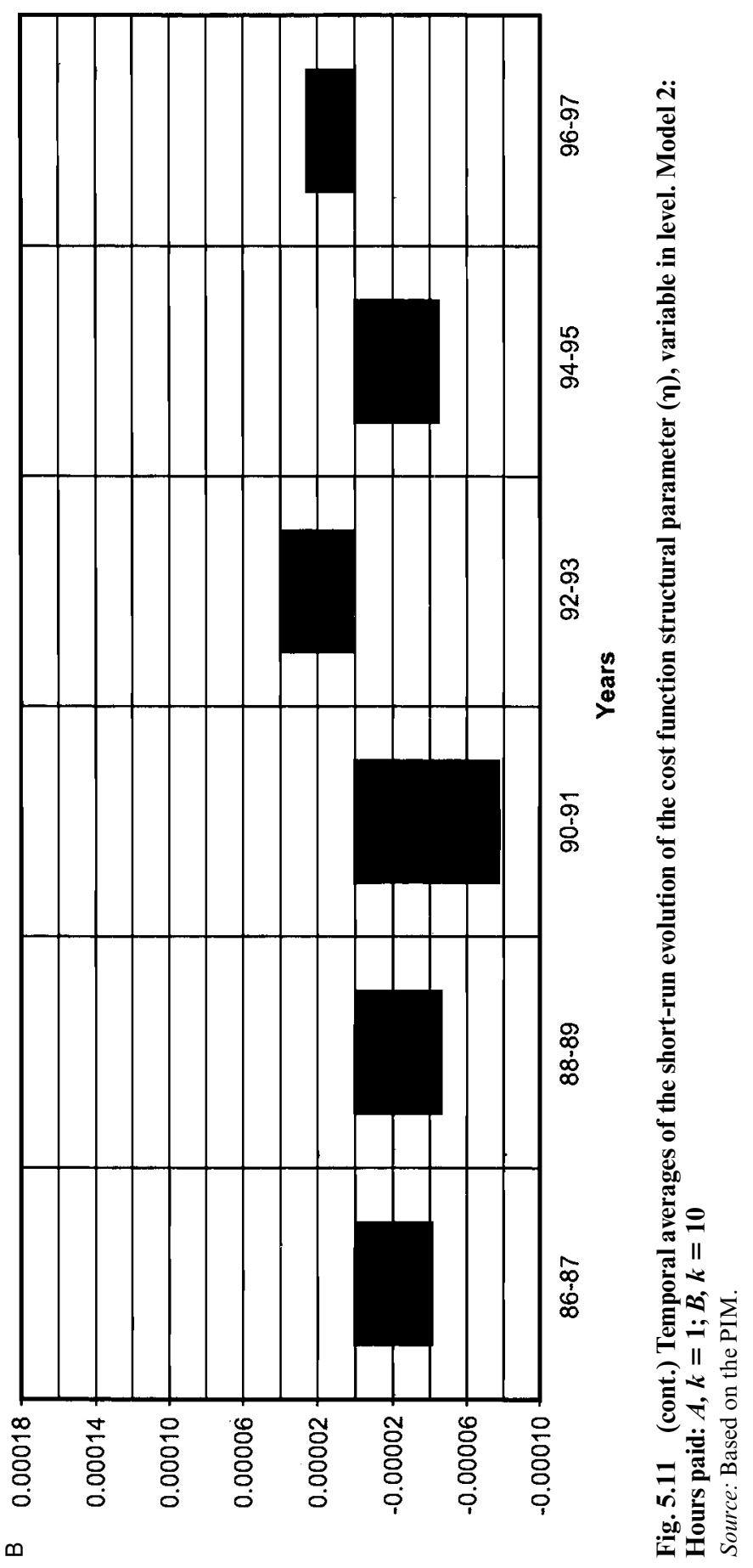




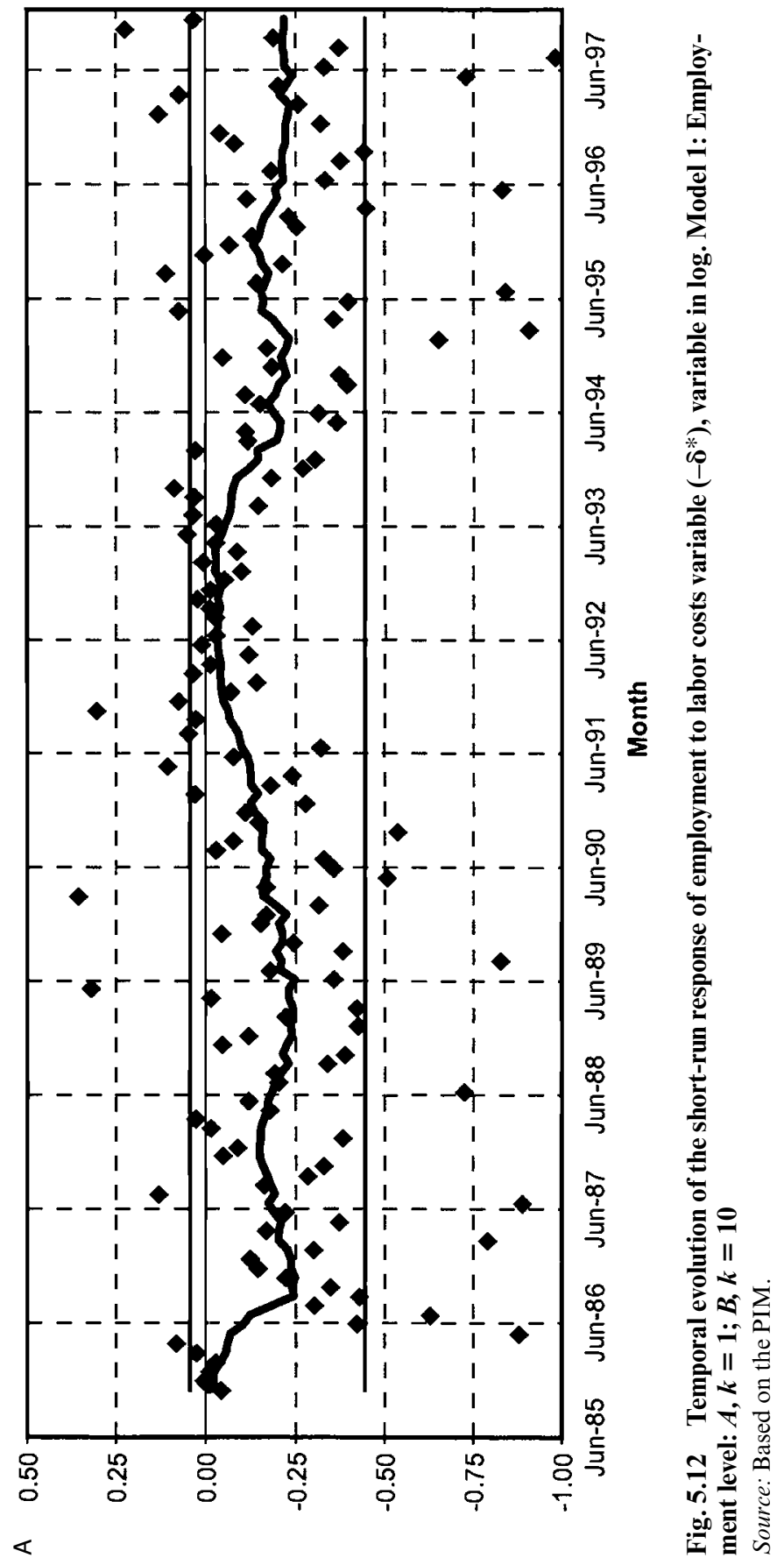




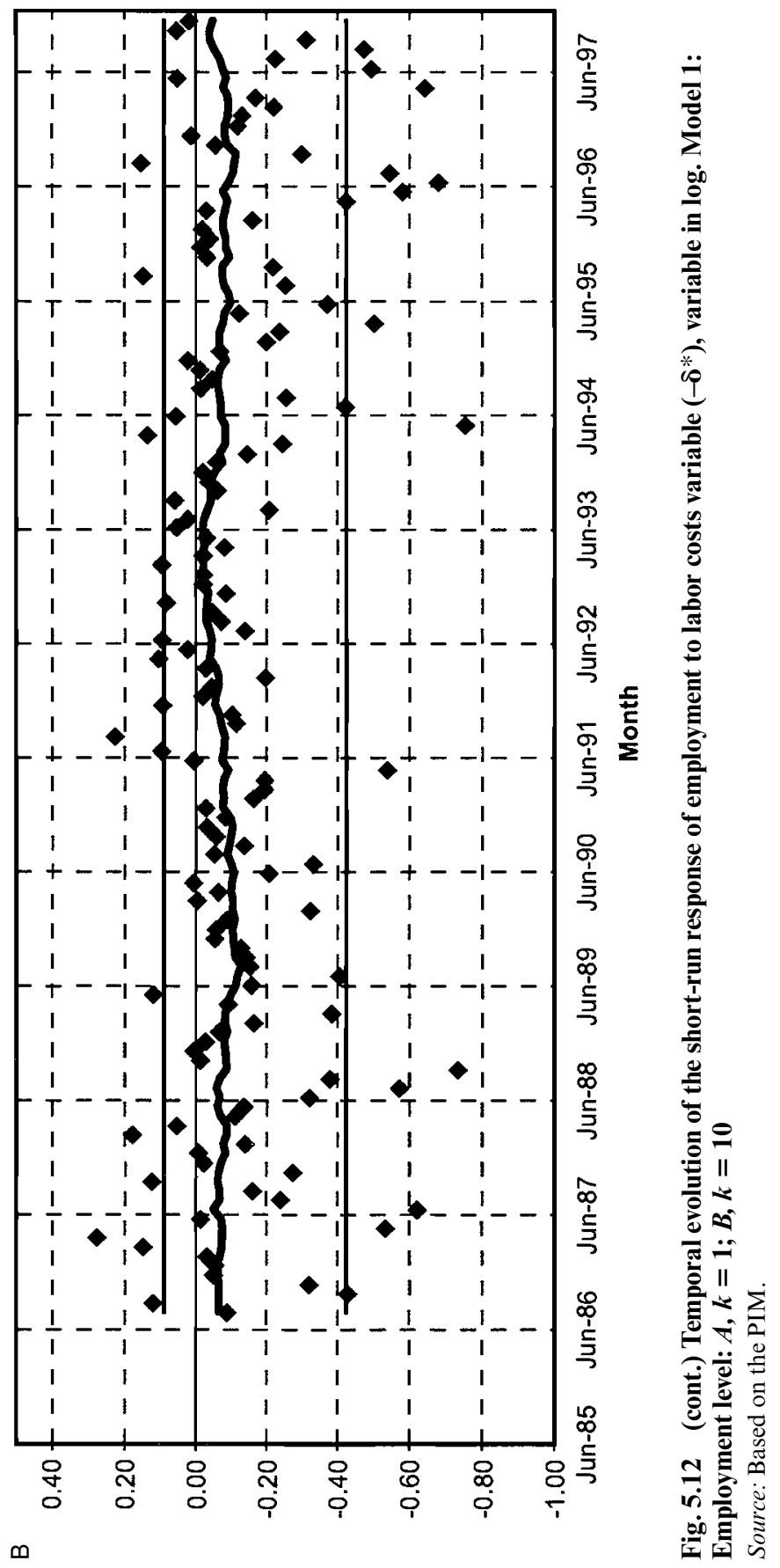




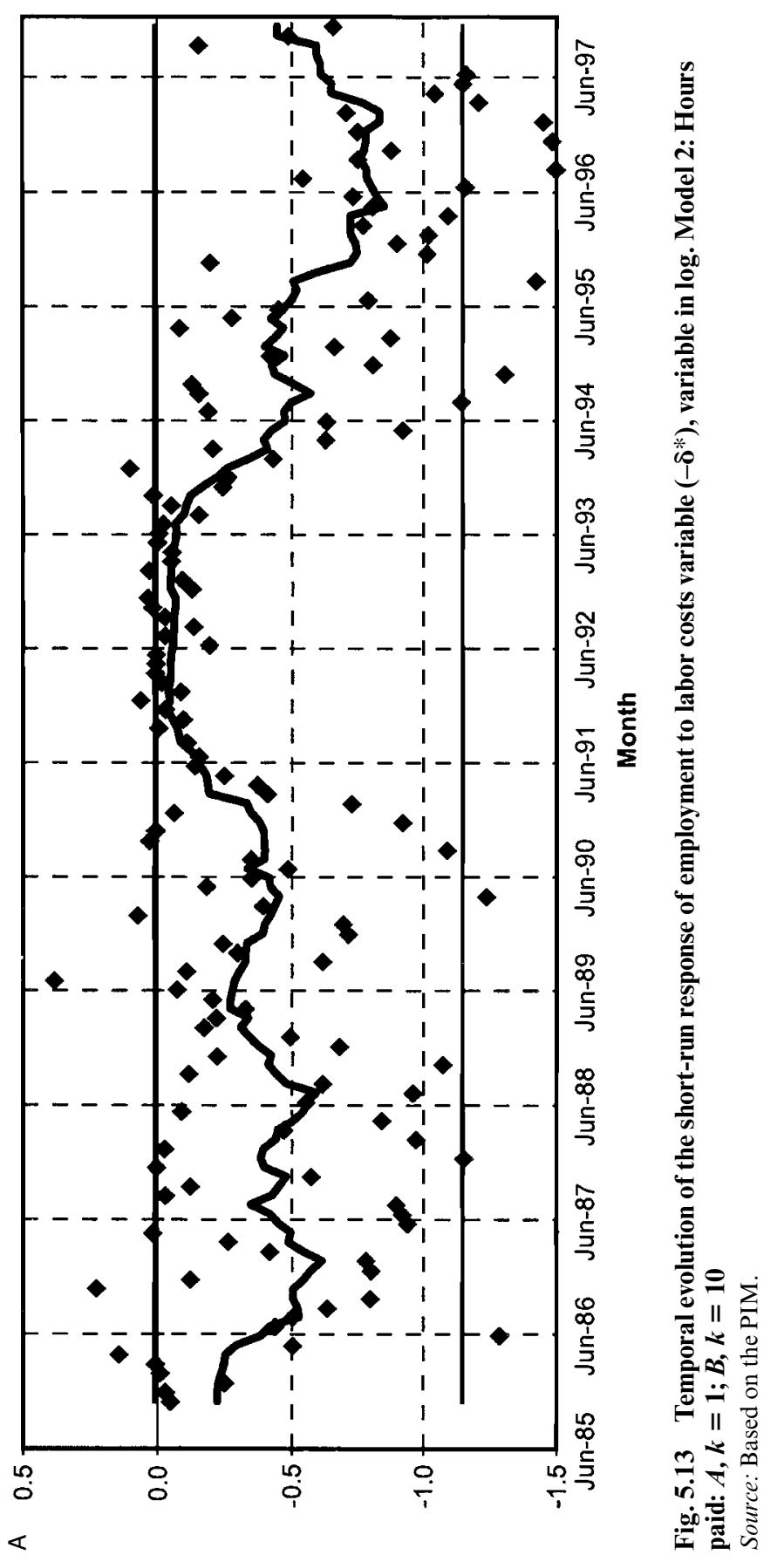




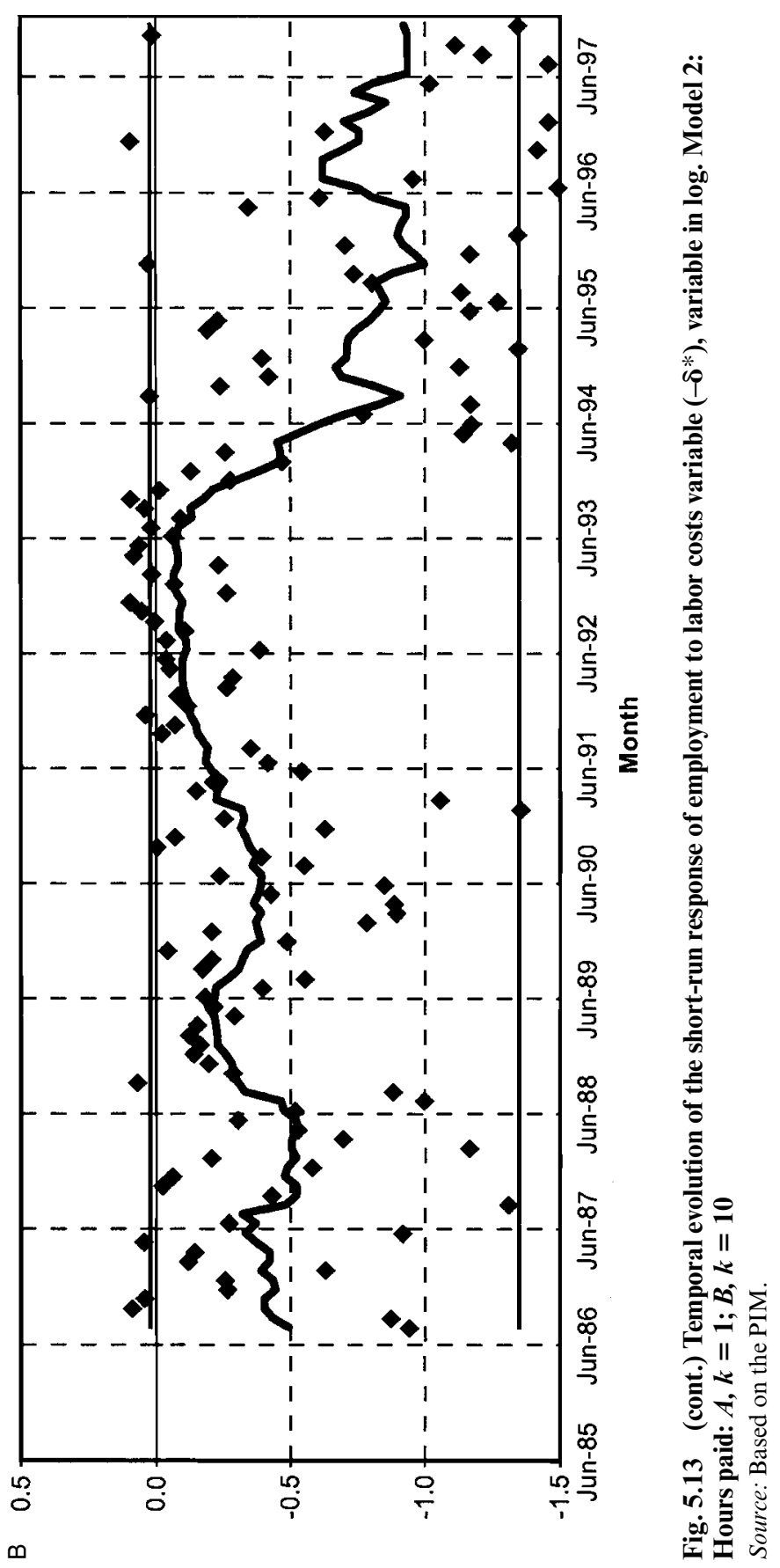




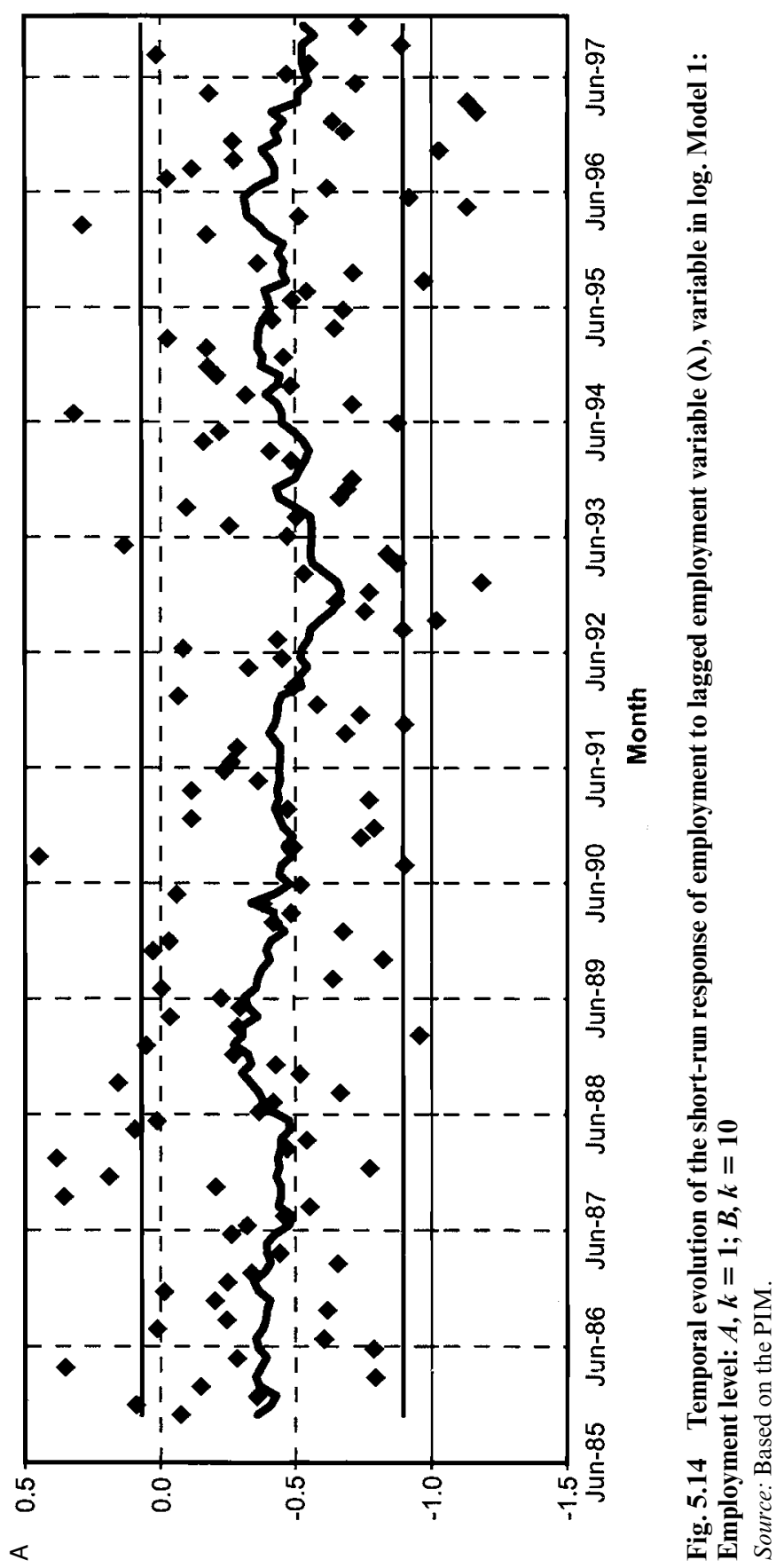




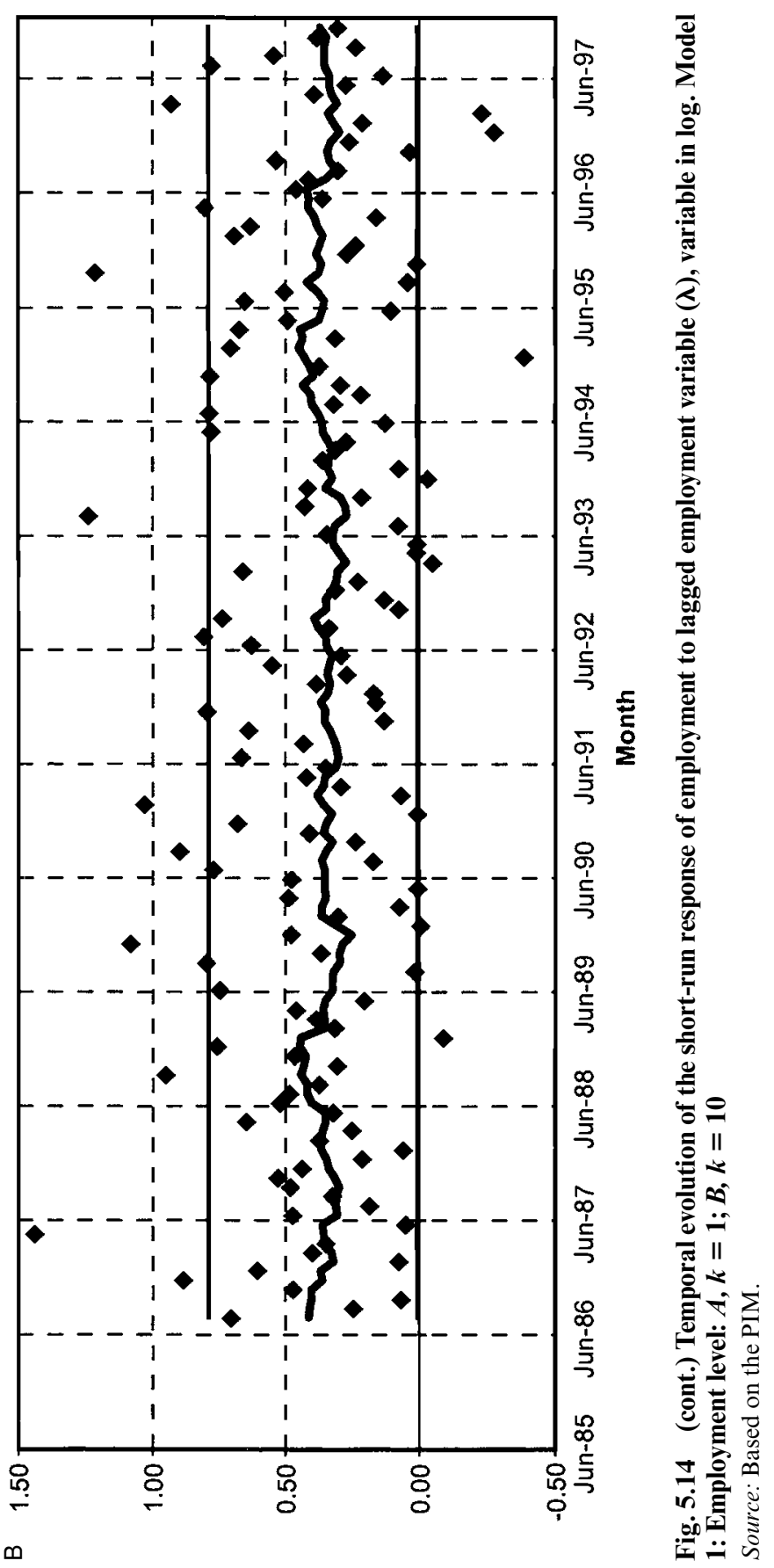




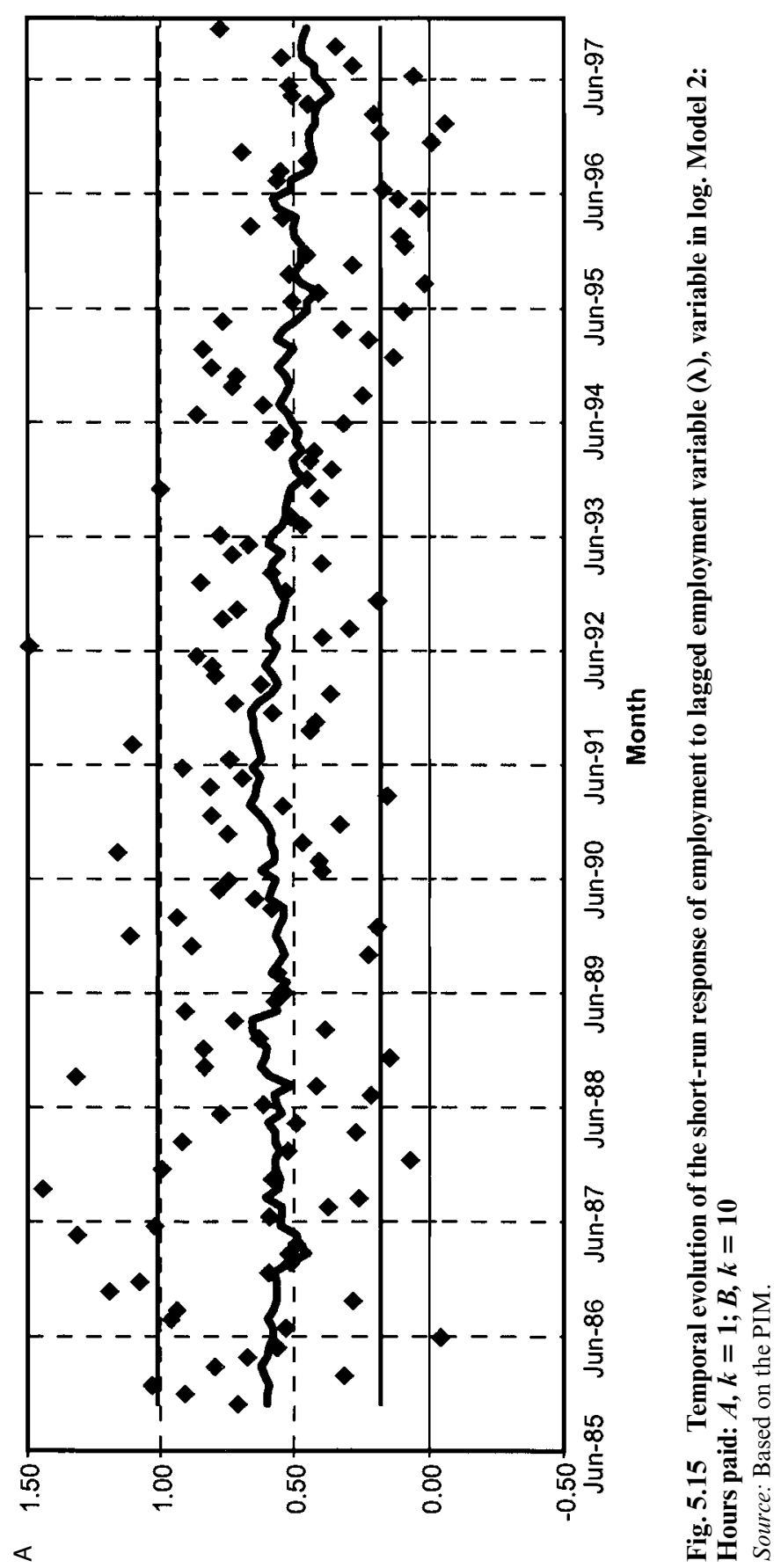




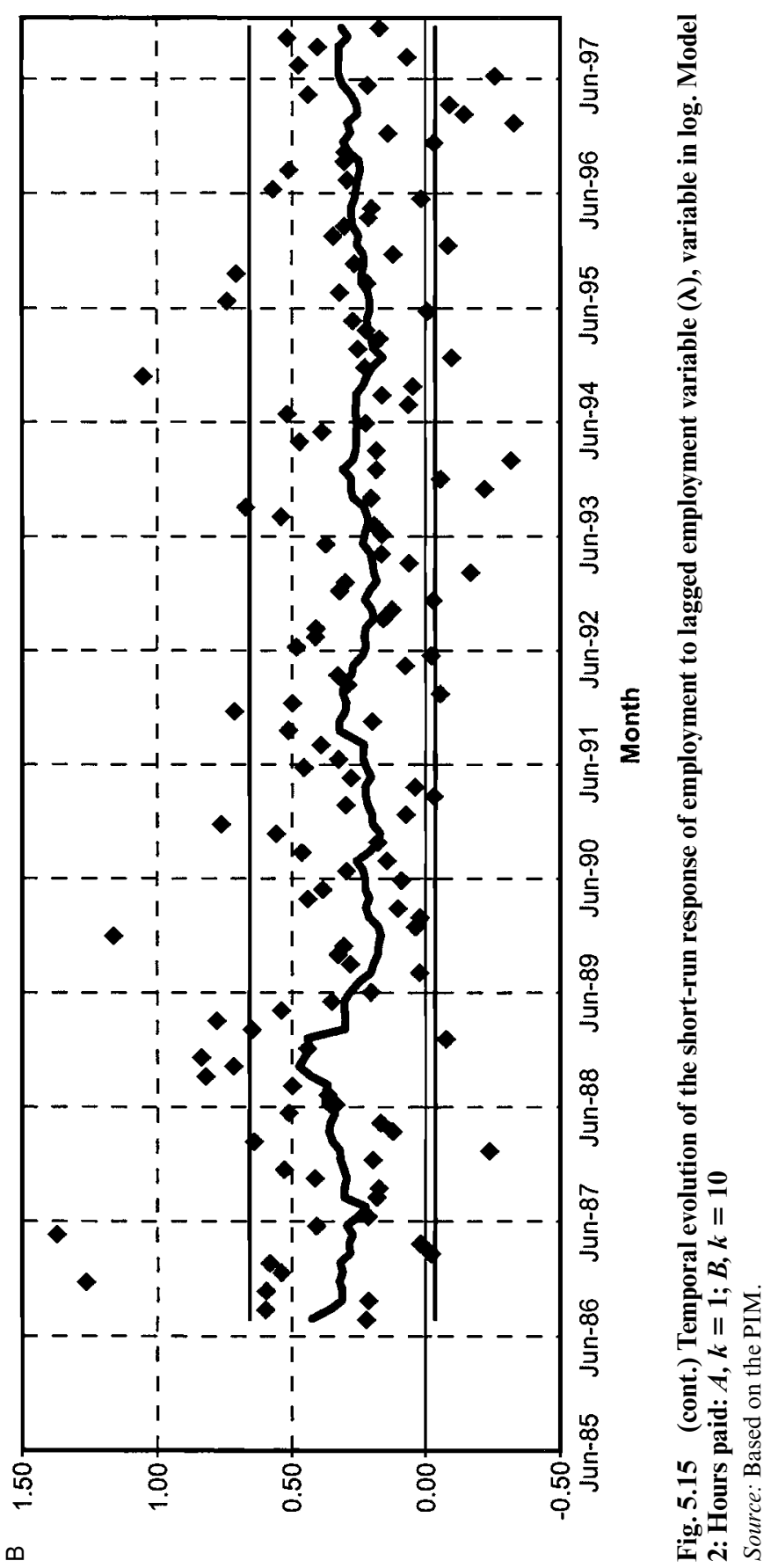




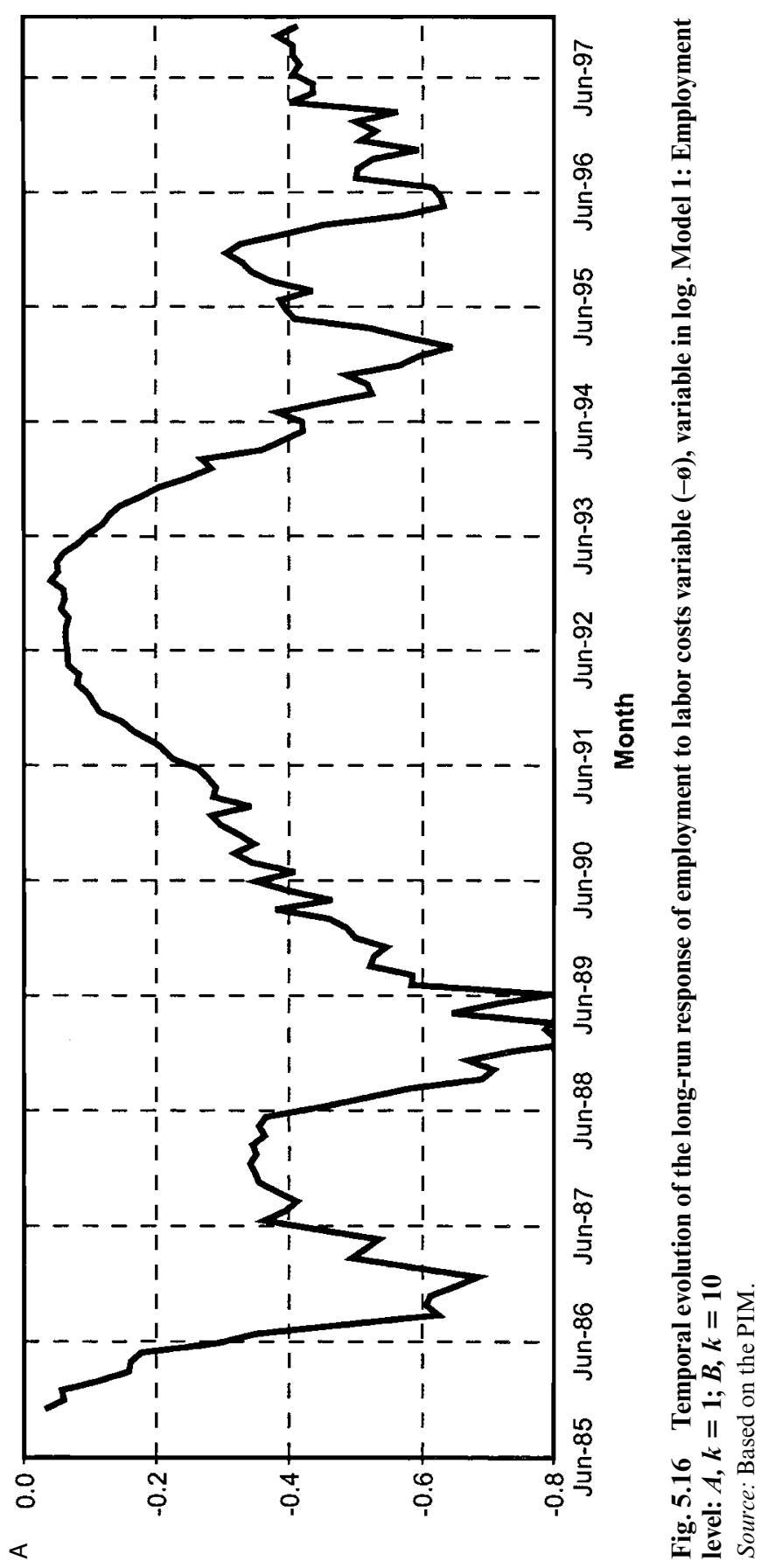




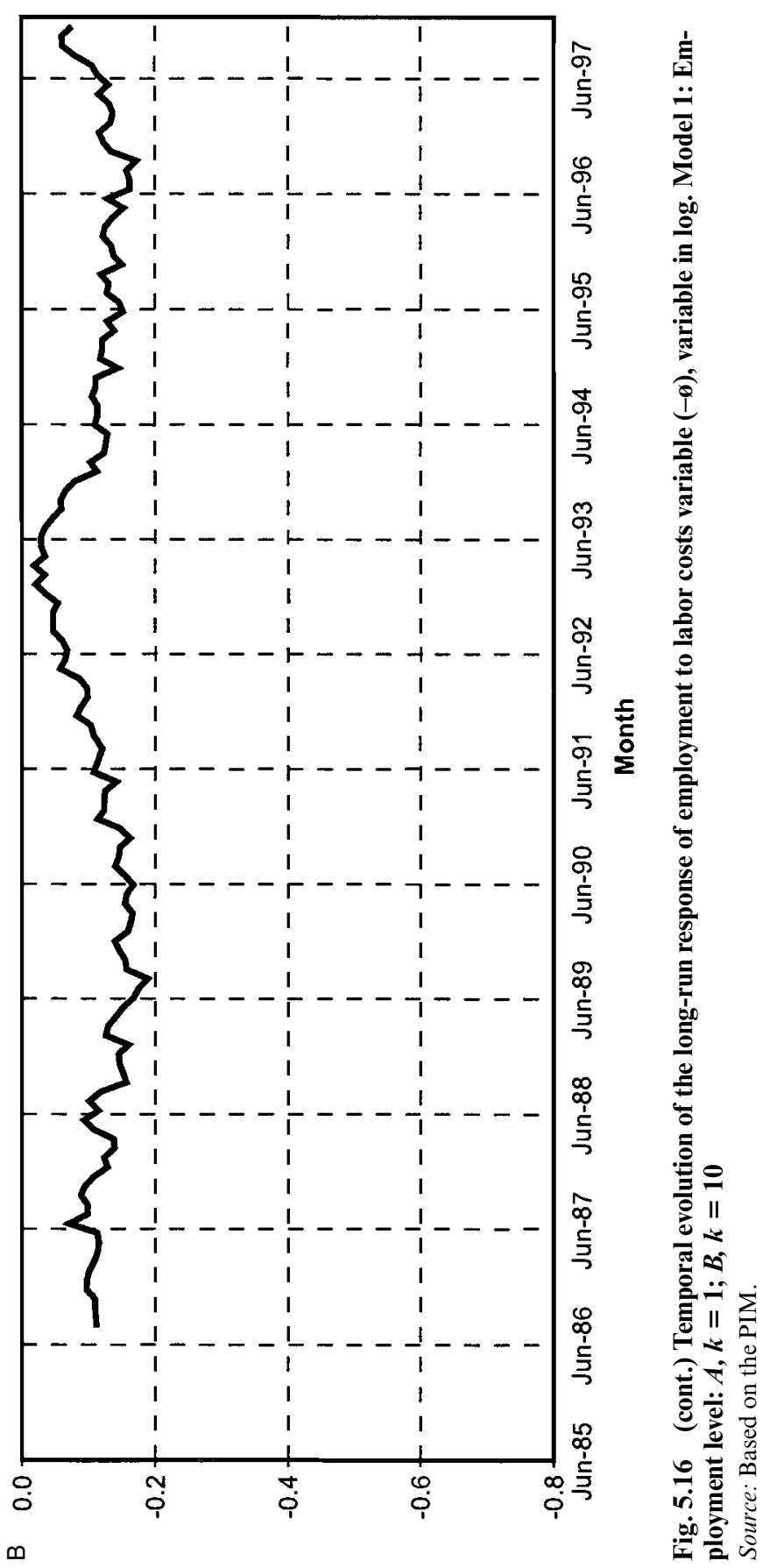




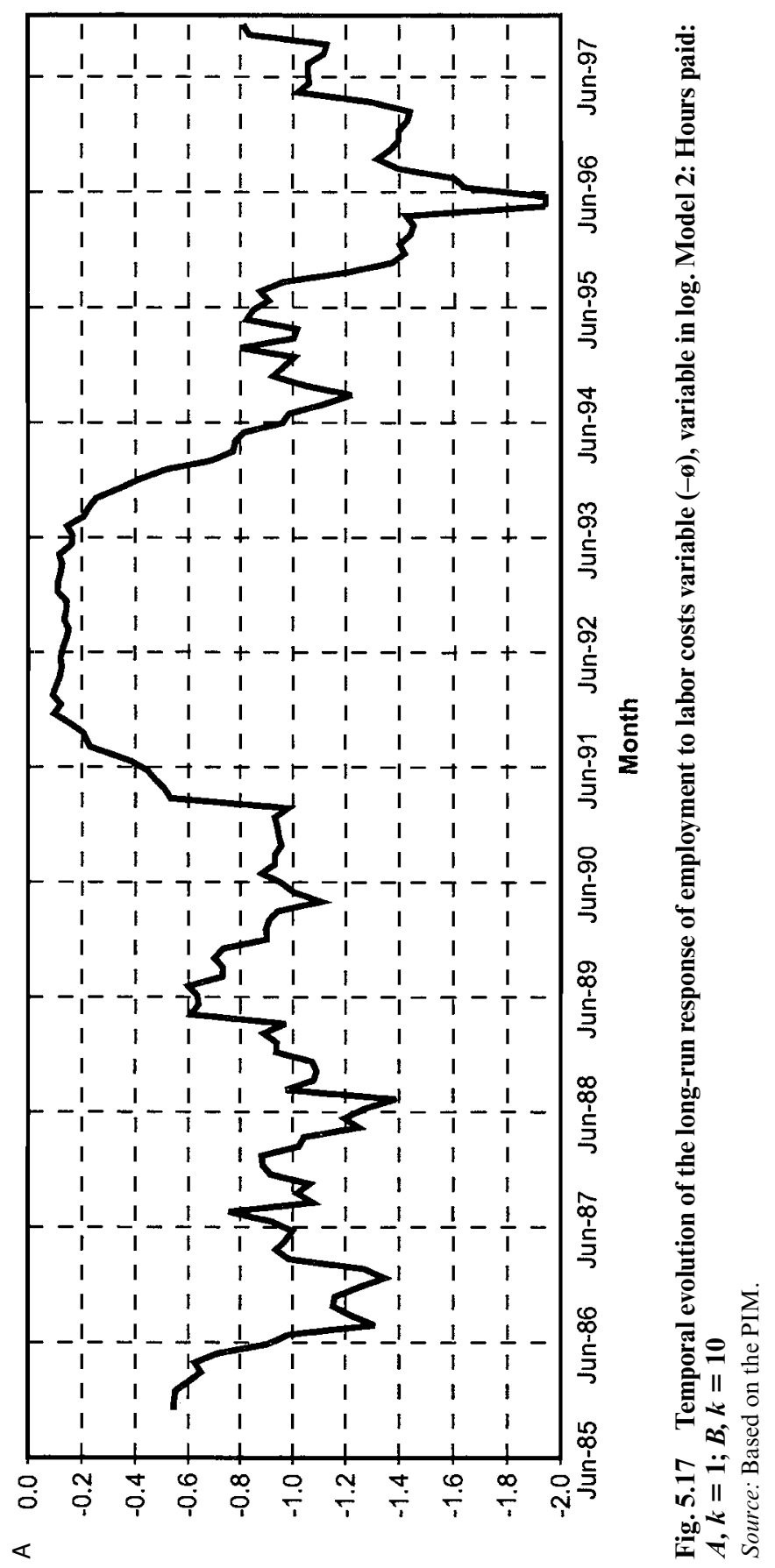




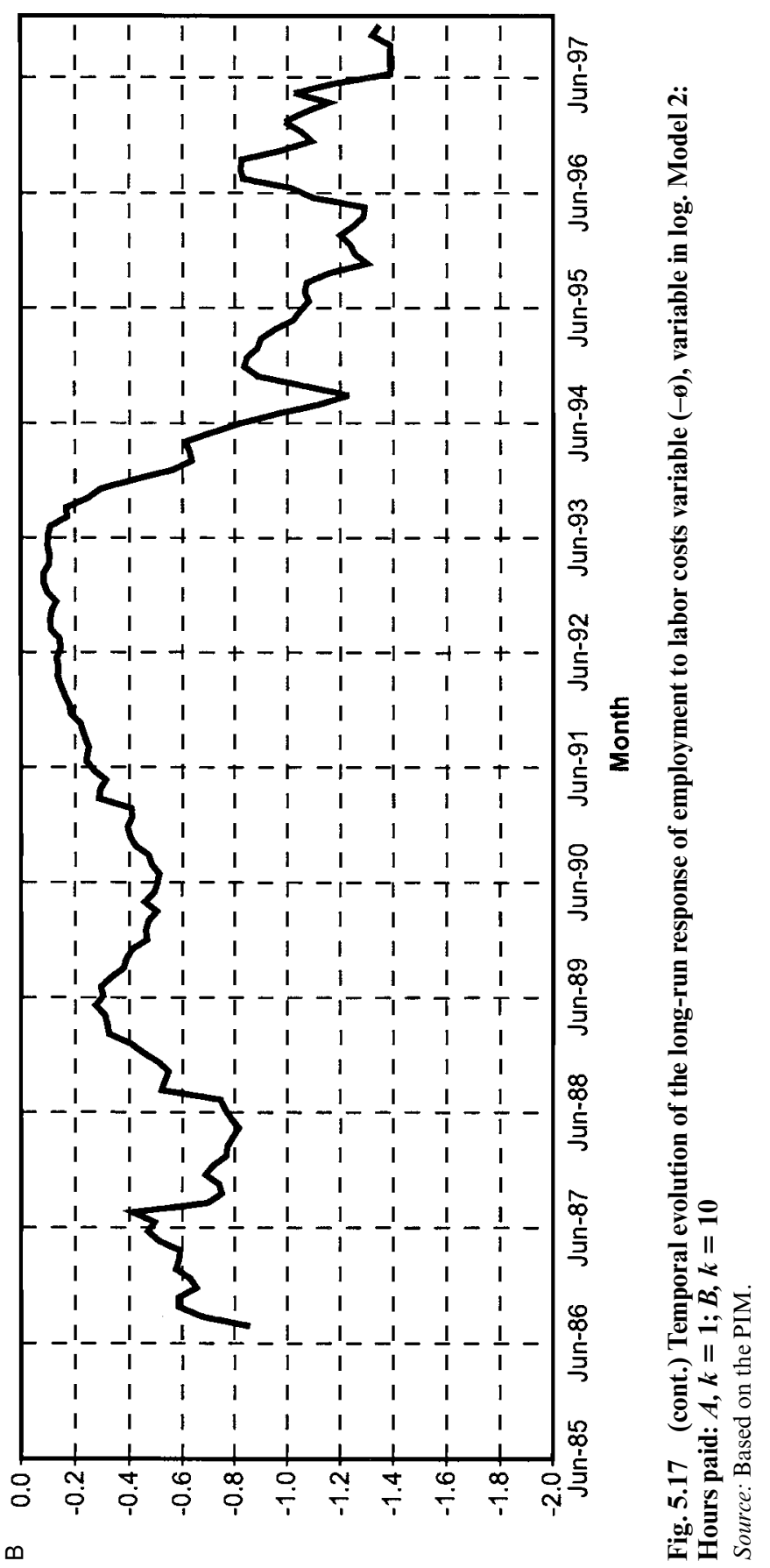


Regression Results $(k=1)$

\begin{tabular}{|c|c|c|c|c|}
\hline & \multicolumn{4}{|c|}{ Dependent Variable } \\
\hline & \multicolumn{2}{|c|}{ Lagged Employment $(\lambda)$} & \multicolumn{2}{|c|}{ Labor Cost $\left(\delta^{*}\right)$} \\
\hline & Coefficient & $P$-value $(\%)$ & Coefficient & $P$-value $(\%)$ \\
\hline \multicolumn{5}{|l|}{ Model 1} \\
\hline Indicator for the constitutional change & -1.542 & 77.1 & -1.861 & 58.3 \\
\hline GDP growth rate & -0.081 & 84.0 & -0.069 & 78.8 \\
\hline Degree of openness & 8.617 & 22.5 & -3.998 & 37.9 \\
\hline Inflation rate & 11.377 & 29.1 & -8.461 & 22.1 \\
\hline Inflation volatility & 2.491 & 15.6 & 1.460 & 19.4 \\
\hline Adjusted $R^{2}$ & \multicolumn{2}{|c|}{0.358} & \multicolumn{2}{|c|}{0.026} \\
\hline \multicolumn{5}{|l|}{ Model 2} \\
\hline Indicator for the constitutional change & -5.578 & 39.3 & 2.320 & 43.3 \\
\hline GDP growth rate & 0.743 & 13.6 & -0.177 & 43.2 \\
\hline Degree of openness & -1.499 & 86.4 & -2.111 & 59.4 \\
\hline Inflation rate & 20.985 & 11.5 & 9.474 & 11.7 \\
\hline Inflation volatility & -0.329 & 87.9 & -0.807 & 41.0 \\
\hline Adjusted $R^{2}$ & \multicolumn{2}{|c|}{0.135} & \multicolumn{2}{|c|}{0.065} \\
\hline
\end{tabular}

change on labor demand, we regress ${ }^{18}$ monthly estimates of the parameters $\lambda$ and $\delta^{*}$ on an indicator for the constitutional change and control for a set of basic macroeconomic variables. These regressions also include monthly dummies and a linear trend. The results are presented in tables 5.2 and 5.3.

If the constitutional change actually increases labor costs and, as a consequence, has an important effect on the demand for labor, then the estimated coefficients for the indicator of constitutional change would be positive and statistically significant in the regressions involving both parameters. This would be the case because an increase in variable labor costs would increase $\delta$ and hence $\delta^{*}$, whereas an increase in firing costs would increase the cost of adjustment and reduce the speed of adjustment leading to an increase in $\lambda$.

Contrary to these expected results, in the regressions presented in tables 5.2 and 5.3 we found no evidence indicating that the 1988 constitution change had any significant effect on the labor demand function. All estimates of the constitution indicator coefficient are not statistically significant, despite the regression $R^{2}$ reach values close to 0.4 .

18. As demonstrated in section 5.3.3, in these regressions we used as our dependent variable the parameter estimate divided by its corresponding standard error. Our purpose was to reduce the influence of outliers. If the standard error was influenced by the constitutional changes, this procedure would generate biased estimates. But, as this is not the case, estimates extracted from these same regressions, considering only the parameter as a dependent variable, leads us to the same conclusion about the lack of importance of constitutional changes for the level of the parameter. 
Regression Results $(k=10)$

\begin{tabular}{|c|c|c|c|c|}
\hline & \multicolumn{4}{|c|}{ Dependent Variable } \\
\hline & \multicolumn{2}{|c|}{ Lagged Employment $(\lambda)$} & \multicolumn{2}{|c|}{ Labor Cost $\left(\delta^{*}\right)$} \\
\hline & Coefficient & $P$-value (\%) & Coefficient & $P$-value $(\%)$ \\
\hline \multicolumn{5}{|l|}{ Model 1} \\
\hline Indicator for the constitutional change & 10.597 & 77.1 & -3.750 & 58.3 \\
\hline GDP growth rate & 0.049 & 84.0 & -0.248 & 78.8 \\
\hline Degree of openness & -5.272 & 22.5 & 1.961 & 37.9 \\
\hline Inflation rate & -8.950 & 29.1 & -5.417 & 22.1 \\
\hline Inflation volatility & -2.192 & 15.6 & 0.849 & 19.4 \\
\hline Adjusted $R^{2}$ & \multicolumn{2}{|c|}{0.213} & \multicolumn{2}{|c|}{0.057} \\
\hline \multicolumn{5}{|l|}{ Model 2} \\
\hline Indicator for the constitutional change & -3.242 & 39.3 & 1.526 & 43.3 \\
\hline GDP growth rate & 0.247 & 13.6 & -0.030 & 43.2 \\
\hline Degree of openness & 3.200 & 86.4 & -7.195 & 59.4 \\
\hline Inflation rate & 16.996 & 11.5 & 14.988 & 11.7 \\
\hline Inflation volatility & -0.701 & 87.9 & 1.363 & 41.0 \\
\hline Adjusted $R^{2}$ & \multicolumn{2}{|c|}{0.194} & \multicolumn{2}{|c|}{0.133} \\
\hline
\end{tabular}

\subsection{The Turnover Analysis}

This part of the chapter describes an attempt to estimate the impact of regulations on labor market performance based on turnover measures. We first investigate if these measures were affected by the constitution using a difference-in-differences methodology, described in section 5.4.1. The precise definition of the turnover measures that we make use of, as well as the description about how to implement these measures based on the available database, are presented in section 5.4.2. The results are commented on in section 5.4.3. Section 5.4.4 discusses some controversial issues in difference-in-differences methodology that motivates a regression analysis developed in section 5.4.5 with two objectives. These regressions test some hypotheses of the difference-in-differences methodology and access the robustness of the previous results.

\subsubsection{The Difference-in-Differences Methodology}

According to this methodology, we began by breaking down the overall population into two groups, the so-called treatment and control groups. If this partition attends some conditions, the evolution of the performance for the control group would indicate what would have happened to the treatment group if the 1988 constitutional change had not occurred. Hence, the contrast of the evolution of both performances (that is a difference of the previous differences) correspond to the estimation of the impact of the regulation on the performance of the treatment group. 
Ideally, the treatment group would be the group most affected by the change in legislation. The control group, on the other hand, ideally must have two properties. First, contrary to the treatment group, it should not be affected at all by the change in legislation. Second, the impact of the underlying macroeconomic changes on the treatment and control groups must be very similar.

To implement this methodology, we use three alternative ways to break down the population in treatment and control groups.

\section{Quits Versus Layoffs}

Data regarding the informal sector is not always available. This is particularly the case when administrative files are used. Hence, it is important to identify other sources of cross-section variation in the legislation. The dichotomy between quits and layoffs is one possibility.

In general, regulations involving quits are totally different from those regulating dismissals. In Brazil, quits remain essentially unregulated, while a considerable amount of legislation was designed to restrict dismissals without just cause. Moreover, the changes brought by the new constitution are entirely related to dismissals. They are silent with respect to quits. Hence, quits and layoffs correspond to our second alternative for the partition between treatment and control groups.

\section{Short Versus Long Employment Spells}

According to the new and previous constitutions, the entire regulation on dismissals without just cause only applies to employment spells that have lasted at least three months. Dismissals of workers that have not yet completed three months on the job have been and still are completely unregulated. Hence, an alternative partition in treatment and control groups can be achieved through the contrast between very short spells (control) and other employment spells (treatment), where we consider as very short spells all those that last less than three months.

\section{Formal-Informal Dichotomy}

According to the Brazilian labor laws all workers must have a document named carteira de trabalho. This document, which resembles a little notebook or passport, acts as a complete record of the main parameters of the worker's current, and all previous, formal labor contracts. In principle, whenever a worker's labor contract is modified, either by moving to a new job or by renegotiating his contract with his current employer, the main parameters of the new contract must be immediately transcribed to the worker's carteira de trabalho.

The existence of this document permits an easy empirical separation of workers with formal labor contracts that must comply with the labor laws from workers with informal labor contracts that are not under this legisla- 
tion. Workers with formal labor contracts are all employees who have the terms of their current labor contract transcribed to their carteira de trabalho. Those whose employers have not registered their labor contract in their carteira de trabalho should be considered informal.

This clear conceptual dichotomy would be of little practical relevance if the Brazilian employment surveys did not empirically investigate this question. Fortunately, however, essentially all household and employment surveys in Brazil do ask each employee in the sample whether their current labor contract is registered in their carteira de trabalho. As a result, it is possible and easy to separate empirically the pool of employees according to whether they have or do not have a formal (registered in their carteira de trabalho) labor contract. Moreover, this dichotomy is of the utmost importance, because around 25 percent of the urban occupied labor force is employed without a formal labor contract. So the formal and informal partition of the worker population corresponds to our first alternative of treatment (formal) and control (informal) groups.

\subsubsection{Measuring Turnover Rates}

\section{Conceptual Preliminaries}

As an indicator of turnover we use the probability that the employment spell will be terminated next month, conditional on its current duration. This probability as a function of the current duration of the spell is commonly referred as the hazard function. Evidently, in this case the indicator - the hazard function - is inversely related to the duration of employment.

The hazard function is usually preferred to its complement, the probability that it will not be terminated next month, conditional on its current duration. In part, this preference derives from the fact that it can be broken down according to the nature of the separation. In fact, if an employment spell can only be terminated by a quit or dismissal, then the hazard function is equal to the sum of the probability that the employment spell will be terminated by a quit and the corresponding probability that it will be terminated by a dismissal, where both probabilities are conditional on the current duration of the spell. The probability that an employment spell will be terminated by a quit (dismissal), conditional on its current duration, is commonly referred to as the transition intensity function. Hence, the property just stated can be summarized by saying that the hazard equals to the sum of the transition intensities.

To define these measures precisely, some symbols must be introduced first. Accordingly, let $\Omega_{t}$ be the universe of all active employment relationships at time $t$, and for each $\omega$ in $\Omega_{t}$, let $D_{t}(\omega)$ denote the incomplete duration of the relationship $\omega$ up to time $t$. Moreover, let $S_{t}(\omega)$ denote an indicator of whether $(S=1)$ or not $(S=0)$ the relationship $\omega$ will be terminated 
in the month beginning at time $t$. The hazard rate, $h_{t}(d)$, is then defined as the probability that an active employment relationship, which up to time $t$ has already lasted $d$ months, will be terminated next month, that is,

$$
h_{t}(d)=P\left(S_{t}=1 \mid D_{t}=d\right) .
$$

Moreover, let $Q_{t}(\omega)$ and $L_{t}(\omega)$ be indicators of whether the relationship $\omega$ will be terminated next month by a quit or a dismissal, respectively. The quit and dismissal transition intensities can be expressed, respectively, by

$$
h_{t}^{q}(d)=P\left(Q_{t}=1 \mid D_{t}=d\right)
$$

and

$$
h_{t}^{l}(d)=P\left(L_{t}=1 \mid D_{t}=d\right) .
$$

If a separation can only occur due to a quit or a dismissal, then

$$
h_{t}(d)=h_{t}^{q}(d)+h_{t}^{l}(d) .
$$

These equations refer to the probability of separation for employment spells of a given duration in months. In practice, however, it is more convenient to use the probability of separation for all employment spells with the duration in any given interval. ${ }^{19}$ For instance, it may be more convenient to analyze the probability of separations of employment spells that have already lasted six months but have not yet completed one year than the probability of separation of employment spells that have lasted up to now exactly seven months. Fortunately, the above equations can easily be adapted to define the probability of separations for all employment spells with the duration in any given interval. Resuming, we refer to these probabilities as the aggregated hazard and transition intensity rates.

To define them precisely, let $\left\{a_{i}: i=1, \ldots, z\right\}$ be a partition of $N=\{0$, $1, \ldots\}$, so that

$$
a_{i}=\left\{d_{i}, \ldots, d_{i+1}\right\}
$$

for all $i=1, \ldots, z, 0=d_{1}<d_{2}<\ldots<d_{z}$, and $a_{z}=\left\{d_{z}, d_{z+1}, \ldots\right\}$. Moreover, let $H_{t i}$ denote the probability that an active employment relationship that up to time $t$ has already lasted between $d_{i}$ and $d_{i+1}$ months will be terminated next month. Then $H_{t i}$ is given by

$$
H_{t i}=P\left(S_{t}=1 \mid d_{i} \leq D_{t}<d_{i+1}\right)=P\left(S_{t}=1 \mid D_{t} \in a_{i}\right) .
$$

By analogy we can define the corresponding transition intensities, respectively, by

$$
H_{t i}^{q}=P\left(Q_{t}=1 \mid d_{i} \leq D_{t}<d_{i+1}\right)=P\left(Q_{t}=1 \mid D_{t} \in a_{i}\right)
$$


and

$$
H_{t i}^{l}=P\left(L_{t}=1 \mid d_{i} \leq D_{t}<d_{i+1}\right)=P\left(L_{t}=1 \mid D_{t} \in a_{i}\right) .
$$

In this study we divide employment spells according to their duration in four intervals; that is, we consider the case $n=5$. These five intervals are determined by choosing $d_{1}=0, d_{2}=3, d_{3}=6, d_{4}=12, d_{5}=24$. Hence, spells in the first interval are those that have not yet lasted three months. To simplify the exposition, we refer to them as the very-short spells. The second interval consists of all spells that have already lasted at least three months but have not yet reached six months. Spells in this interval are referred to as the short spells. The third interval is made of all spells that have already lasted at least six months but have not yet reached one year. Spells in this interval are referred to as the not-so-short spells. The fourth interval is made of all spells that have already lasted at least one year but have not yet reached two years. We are going to refer to them as the long spells. Finally, the fifth interval is made of all spells that have already lasted at least two years. We are going to refer to them as the very-long spells.

To obtain estimates for hazard and transition intensities we combine three distinct data sets: the Relação Annual de Informações Sociais (RAIS), the Cadastro Geral de Empregados e Desempregados (CAGED), and the Pesquisa Mensal de Emprego (PME). The PME is a monthly employment survey, while RAIS and CAGED are administrative files. ${ }^{20}$ Three alternative empirical procedures are pursued to obtain consistent estimates of the temporal evolution of these probabilities from these data sets. First, two combine data from RAIS and CAGED, while the other relies exclusively on PME data. The data used as well as the nature of the hypothesis necessary to obtain consistent estimators vary considerably between these four procedures. We describe each one of the three empirical procedures in turn in the next subsection.

\section{Measures for Hazard and Transition Intensities}

Our first procedure to estimate the transition probabilities consists of using the information from RAIS on the stock of active employment relationships classified by their incomplete duration up to time $t$, December 31

20. The Relação Annual de Informações Sociais (RAIS) is an annual administrative file that provides, at December 31 every year, a complete list of all active employment relationships in the formal sector. The file also includes extensive characteristics of workers and firms. One of the characteristics available for every worker in the file is how long he has been in the current job, that is, the worker's tenure. Hence, based on this information, it is possible to estimate the distribution of active employment relationships according to their incomplete duration up to December 31 of each year. The RAIS is available for all years from 1985 to 1996. The Cadastro Geral de Empregados e Desempregados (CAGED) is a monthly administrative file that provides data on the formal sector of all separations that occurred in a given month. This file also includes information about the nature of the separation and basic information on workers and firms. In particular, it is possible to identify in each separation the reason for the separation (quits versus dismissals) and the complete duration of the employment spell. 
of a given year, and from CAGED on (1) how many of these active employment relationships are terminated in January of the following year; (2) how many are terminated by quits; and (3) how many are terminated by dismissals. The number of active employment relationships that at time $t$ has already lasted $d$ months is represented by $N_{t}(d)$, while the number correspondent to those terminated in January by $M_{t}(d)$. Those terminated by quits are represented by $M_{t}^{q}(d)$, and, finally, those terminated by dismissals by $M_{t}^{l}(d)$. More specifically, we have

$$
\begin{aligned}
& N_{t}(d)=\#\left(\omega \text { in } \Omega_{t} \mid D(\omega)=d\right) \\
& M_{t}(d)=\#\left(\omega \text { in } \Omega_{t} \mid D(\omega)=d \text { and } S(\omega)=1\right) \\
& M_{t}^{q}(d)=\#\left(\omega \text { in } \Omega_{t} \mid D(\omega)=d \text { and } Q(\omega)=1\right)
\end{aligned}
$$

and

$$
M_{t}^{l}(d)=\#\left(\omega \text { in } \Omega_{t} \mid D(\omega)=d \text { and } L(\omega)=1\right) .
$$

Basing our information on this, we obtain the hazard and the transition intensity functions for each year via

and

$$
\begin{aligned}
h_{t}(d) & =\frac{M_{t}(d)}{N_{t}(d)}, \\
h_{t}^{q}(d) & =\frac{M_{t}^{q}(d)}{N_{t}(d)}, \\
h_{t}^{l}(d) & =\frac{M_{t}^{l}(d)}{N_{t}(d)} .
\end{aligned}
$$

These expressions provide a useful method for estimating the probability of separations of employment spells during some months. Due to the nature of the available data, $t$ is always December 31 for any given year. Consequently, the month beginning at $t$ is always January of the following year. Hence, all estimates will refer to the probability that a separation will occur in January, conditional on the duration of employment spells up to December 31. Therefore, even though we label these estimates by the year associated with time $t$, they do not reflect the average for this year. Actually, the estimates refer to January of the following years. Estimates for the aggregated hazard and transition intensities can also be obtained by

$$
\begin{gathered}
H_{t i}=\frac{\sum_{\substack{d_{i+1} \\
s=d_{i}}} M_{t}(s)}{\sum_{\substack{d_{i+1} \\
s=d_{i}}} N_{t}(s)}, \\
H_{t i}^{q}=\frac{\sum_{\substack{d_{i+1} \\
s=d_{i}}}^{q} M_{t}^{q}(s)}{\sum_{\substack{d_{i+1} \\
s=d_{i}}} N_{t}(s)},
\end{gathered}
$$


and

$$
H_{t i}^{l}=\frac{\sum_{s=d_{i}}^{d_{i+1}} M_{t}^{l}(s)}{\sum_{s=d_{i}}^{d_{i+1}} N_{t}(s)} .
$$

Combining data from CAGED and RAIS it is possible to estimate all these transition probabilities for each year between 1986 and 1995.

As already mentioned, these estimates described previously refer only to transitions taking place in January. Because these probabilities may follow a seasonal pattern during the year, it is important to verify to what extent our conclusions are sensitive to the choice of a reference month. Unfortunately, we cannot precisely compute these transition probabilities for each month because we only have data for the stock at December 31. Nevertheless, an approximation of the average over the year can be obtained. In fact, because flows are observed for all months, we can combine the average monthly flow for the year with the stock at December 31 in order to obtain an approximation for average monthly transition probabilities for the year. Estimates of the aggregated hazard rate can be obtained by

$$
\bar{H}_{t i}=\frac{\frac{1}{12} \sum_{i=0}^{11} \sum_{s=d_{i}}^{d_{i+1}} M_{t+i}(s)}{\sum_{s=d_{i}}^{d_{i+1}} N_{t}(s)} .
$$

Once more combining data from CAGED and RAIS, it is possible to estimate all these transition probabilities for each year between 1986 and 1995.

We can also use data from PME to estimate transition probabilities for the formal and informal sectors. PME is a typical employment survey covering the six major Brazilian metropolitan areas. For this study we use monthly data from this survey covering the period 1982-1997. The important feature of this survey is the fact that it has information on the complete duration of previous employment spells for those currently unemployed. The survey also has information on whether these employment spells ended as quits or layoffs.

To obtain estimates for the hazard and transition intensities out of employment from this data source, we have to assume, in addition to the steady state hypothesis, that the duration of employment and unemployment spells are stochastically independent. In this case, we can show (see appendix B) that the aggregated hazard rate can be approximated by the following equation:

$$
H_{t i} \approx \frac{\frac{1}{\left(d_{i+1}-d_{i}\right)} \sum_{s=d_{i}}^{d_{i+1}} U_{t}^{l}(s)}{\sum_{s=d_{i}}^{\infty} U_{t}(s)+\frac{1}{2} \sum_{s=d_{i}}^{d_{i+1}} U_{t}(s)},
$$


where $U_{t}(s)$ defines the number of unemployed workers at time $t$ whose previous job lasted a period contained in the interval denoted by $s$. Similar equations help estimate the aggregated transition intensities.

\subsubsection{Empirical Results}

To implement the difference-in-differences methodology we must specify a period before and after 1988. For a pre-1988 period we use the years $1986-$ 1987. The choice of a post-1988 period is more difficult. We would like to pick a period as close to 1988 as possible. On one hand, this choice would be useful to isolate the effect of the drastic change in the constitution from the impact of other concomitant macroeconomic changes that occurred spread out over time. In other words, the closer the pre- and post-1988 periods, the better for separating the impact of the constitutional change from the impact of changes in the macroeconomic environment. On the other hand, because the effects of the 1988 constitutional change may also be spread out over time, capturing a significant portion of them would be necessary to use them for a post-1988 period, a time not very close to 1988. In the latter case, however, there would be no guarantee that the effect of changes in the macroeconomic environment was properly separated. By virtue of this trade-off, we choose the years 1991-1992 to represent the post1988 period.

Estimates of the contrast between the aggregate hazard rates related to these two periods are given in table 5.4. The estimates in this table indicate that the hazard rate, mainly for short spells, dropped considerably just after the constitutional change. The values stay around 2 percentage points for this group.

Because the underlying macroeconomic environment did not remain constant over this period, this finding should be taken with caution. In order to achieve a more precise result, we have to contrast the temporal difference of the hazard rates associated with the treatment and control groups.

To describe the methodology more explicitly, let $Y_{0}^{r}$ and $Y_{1}^{r}$ be an indicator of the duration of employment for the treatment group before and after the constitutional change, respectively. Moreover, let $Y_{0}^{c}$ and $Y_{1}^{c}$ be the

Table 5.4

First Differences of Hazard Rates: (1991/92)-(1986/87)

\begin{tabular}{lccc}
\hline & $1 / 4-1 / 2$ year & $1 / 2-1$ year & $1-2$ years \\
\hline Administrative files & & & \\
$\quad$ Rais and caged (January flows) & -2.7 & -0.3 & -0.3 \\
$\quad$ Rais and caged (average flows) & -2.0 & -0.5 & -0.2 \\
Employment survey & & & \\
$\quad$ Formal & -1.7 & -0.7 & -0.1 \\
$\quad$ Informal & -0.8 & -0.3 & 0.0 \\
\hline
\end{tabular}

Sources: Based on the RAIS, CAGED, and PME. 
corresponding indicator of the duration of employment for the control group before and after the constitutional change, respectively. In the latter case, the impact of the constitutional change on the treatment group will be estimated by the difference-in-differences estimator, $\Delta$, given by

$$
\Delta=\left(Y_{1}^{r}-Y_{0}^{r}\right)-\left(Y_{1}^{c}-Y_{0}^{c}\right) .
$$

To implement this methodology, we use three alternative ways to breakdown the population in treatment and control groups. First, we use informal workers as the control group and formal workers as the treatment group. Second, we divide job separations into quits and dismissals. In this case, quits form the control group and dismissals the treatment group. Finally, we use the very-short spells as a control group.

The decision about when to use each of these alternative control and treatment groups was finally totally guided by data availability. In fact, we use every alternative that the available data permitted us to use.

When quits are used as controls, the equation for this estimator is simpler. To arrive at this result, we should first notice that the response of quits to macroeconomic changes behaves contrary to dismissals. In fact, as the economy moves into a recession, layoffs will increase while quits fall. Hence, when taking difference-in-differences we should change the sign of the first difference in quits before taking the second difference. More specifically, in this case the difference-in-differences estimator, $\Delta$, is given by

$$
\Delta=\left(Y_{1}^{l}-Y_{0}^{l}\right)+\left(Y_{1}^{q}-Y_{0}^{q}\right)
$$

or the equivalent

$$
\Delta=\left(Y_{1}^{l}+Y_{1}^{q}\right)-\left(Y_{0}^{l}+Y_{0}^{q}\right)
$$

because, in general, $Y_{1}^{l}+Y_{1}^{q}=Y_{1}$ and $Y_{0}^{l}+Y_{0}^{q}=Y_{0}$, where $Y_{0}$ and $Y_{1}$ are the corresponding indicator for all separations before and after the constitutional change, respectively. It follows that in this case $\Delta=Y_{1}-Y_{0}$, which is the simple difference estimator investigated in the previous section. In other words, all results presented in table 5.4 could be interpreted as being obtained from the difference-in-differences estimator that use quits as a control group.

Table 5.5 presents difference-in-differences estimates for the impact of the constitutional change on employment duration, using the informal sector and very-short spells as control groups.

When the informal sector is used as a control, at least for short spells, the estimated impact of the constitutional change on the duration of employment is still negative and appreciable. The hazard rate for short spells declined in both the formal and informal sector from before to after the constitutional change, but the decline was 1 percentage point larger in the formal sector.

Table 5.5 also presents estimates using very-short spells as a control 
Differences-in-Differences of Hazard Rates: Treatment-Control

\begin{tabular}{|c|c|c|c|}
\hline Database & Dismissal-Quit & Other Spells-Very Short Spell & Formal-Informal \\
\hline \multicolumn{4}{|c|}{$\begin{array}{l}\text { Rais and caged } \\
\text { (January flows) }\end{array}$} \\
\hline $0-1 / 4$ year & -1.8 & - & - \\
\hline $1 / 4-1 / 2$ year & -2.7 & -0.9 & - \\
\hline $1 / 2-1$ year & -0.3 & 1.5 & - \\
\hline $1-2$ years & -0.3 & 1.5 & - \\
\hline \multicolumn{4}{|c|}{$\begin{array}{l}\text { Rais and caged } \\
\quad \text { (average flows) }\end{array}$} \\
\hline $0-1 / 4$ year & -0.8 & - & - \\
\hline $1 / 4-1 / 2$ year & -2.0 & -1.2 & - \\
\hline $1 / 2-1$ year & -0.5 & 0.3 & - \\
\hline $1-2$ years & -0.2 & 0.6 & - \\
\hline \multicolumn{4}{|l|}{ PME } \\
\hline $0-1 / 4$ year & -1.3 & - & 0.2 \\
\hline $1 / 4-1 / 2$ year & -1.7 & -0.5 & -0.9 \\
\hline $1 / 2-1$ year & -0.7 & 0.6 & -0.4 \\
\hline $1-2$ years & -0.1 & 1.2 & 0.0 \\
\hline
\end{tabular}

Sources: Based on the RAIS, CAGED, and PME.

Note: Dashes indicate that no calculations were implemented.

group. The decline in the hazard rate for very-short spells was 0.5 to 1.5 percentage point smaller than for short spells. However, when we compare the evolution of the hazard rates for very-short spells with groups other than the short spells, we have opposite results with similar magnitude; that is, the hazard rates for other spells were .5 to 1.5 percentage point smaller than for very-short spells.

So the results seem to be easier to analyze by employment spell. We have evidence that the hazard rates declined for short spell according to any of the three definitions implemented for the control group. No other employment spells reported such a consistent pattern for hazard rates.

\subsubsection{Some Limitations of the Methodology}

Although changes in the legislation would not have a direct effect on these control groups (one of the necessary conditions that the partition between treatment and control has to attend), it is very likely that they would be indirectly affected by the constitutional change. In section 5.2.2 we mention two mechanisms through which the constitution may affect quitting behavior and the turnover among very-short duration spells. First, it is argued that increases in dismissal penalties are likely to reduce quits as some workers prefer to wait or even to force their dismissal in order to collect the compensation, whereas according to the second argument, firms may increase the dismissal of employees before they complete three months on the job in order to avoid the payment of dismissal penalties later. 
In addition to those arguments, there are also arguments that suggest the informal sector may be indirectly affected by the constitution through at least two channels. First, changes in the formal sector tend to affect the informal sector through its effects on overall labor market conditions, for instance, as a result of its effect on the unemployment rate. Second, changes in the legislation may play a role in the bargaining process even in the informal sector through their effect on the notion of fair labor relation.

There also exists another reason why the informal sector quits, and veryshort spells may not be an ideal control group. Ideally, it is also necessary that changes in the macroeconomic environment have identical impact on the control and treatment groups. However, there is no theoretical or empirical reason why the response of quits and layoffs, short and long spells, and the formal and informal sectors to macroeconomic shocks should be of the same magnitude. Due to these limitations we decided to analyze results from an alternative methodology.

\subsubsection{Regression Analysis}

The preceding empirical strategy requires data for only two periods in time: a pre- and a post-1988 period. However, if data is available for a large number of points in time and the macroeconomic changes can be characterized by measurable indicators, then it is possible to obtain estimates of the impact of the constitutional change and macroeconomic factors on hazard rates through a regression analysis.

The procedure would essentially consist of regressing monthly estimates (based on the PME) for the aggregated hazard rate on an indicator for the constitutional change (i.e., an indicator that will have 0 as the value before and 1 as the value after the constitutional change), on another indicator for the group (the treatment group is associated with the 0 value whether the control group is associated with 1), on a set of macroeconomic indicators and interactions between the group indicator and each of the macroeconomic indicators, and also on the constitution indicator.

$$
\begin{aligned}
h_{t, i}\left(x_{1}, x_{2}, c, r\right)= & \boldsymbol{\beta}_{0}+\mathbf{x}_{1 t}^{\prime} \cdot \boldsymbol{\beta}_{1}+\mathbf{x}_{2 t}^{\prime} \cdot \boldsymbol{\beta}_{2}+\beta_{3} \cdot c_{t}+\beta_{4} \cdot g_{i} \\
& +\mathbf{x}_{1 t}^{\prime} \cdot \boldsymbol{\beta}_{5} \cdot g_{i}+\beta_{6} \cdot g_{i} \cdot c_{t}+\mathbf{r}_{i}^{\prime} \cdot \boldsymbol{\beta}_{7}+\varepsilon_{t i}
\end{aligned}
$$

$\mathbf{x}_{1 t}^{\prime}$ is the transpose vector of values obtained for the four macroeconomic indicators in period $t: a$ ) the GDP real growth rate; $b$ ) the degree of openness as measured by the ratio between total trade (import plus exports) and the GDP; $c$ ) the inflation rate; and $d$ ) the volatility of the inflation rate as measured by its temporal standard deviation. $\mathbf{x}_{2 t}$ is a transpose vector of time invariant explanatory variables other than the constitutional indicator $\left(c_{t}\right)$. These variables are a linear time trend and monthly seasonal dummies. Regional indicator $\left(\mathbf{r}_{i}\right)$ and group indicator $\left(g_{i}\right)$ complement our specification. Finally, bold characters represent vector notation. 
According to this framework the effect of constitution on the treatment group can be written as $\beta_{3}$. The estimation of this effect through regression $\left(b_{3}\right)$ will be a valid procedure even if the control group is affected by the constitution or there are unbalanced macroeffects. On the other hand, the procedure relies on the assumption that no other factor is related to hazard rates besides those considered in the regression framework. ${ }^{21}$

This procedure was done considering each one of the alternatives for the control group and for each interval in turn, except for the very-short spell (this interval is never supposed to be affected by the constitution, even when it is part of the treatment group). The estimated coefficients are reported on the upper part of tables 5.6, 5.7, and 5.8. The values associated with the constitutional indicator $b_{3}$ are an alternative estimation for the impact of the change in legislation on treatment groups' turnover rates. The regression, however, adds an important information namely the confidence of the estimates.

We can see that from the nine alternative estimates of $b_{3}$ (three employment spells multiplied by three controls), four are significantly different from zero. These significant coefficients are those associated with short and long employment spells when either very-short spell or quit are used as control. Among these four results we have two negative and two positive estimates. The positive results correspond to those estimated for workers whose employment spell is long, while negative results correspond to those estimated for workers whose employment spell is short. This last result is consistent with findings in the last section.

The next step is the analysis of which control satisfies the necessary conditions stipulated for difference-in-differences estimators. Despite the fact that the test is based on a regression framework, the conditions are not necessary for the regression estimators of the constitutional effects.

As already mentioned, for a control group to be considered valid, it must satisfy two properties. First, it must not be affected by the constitutional change. Second, macroeconomic changes must have the same impact on the treatment and the control groups. As we described in section 5.4.4, those properties may not be valid for the control groups considered in this study. However, both properties are testable under the assumption that we can have explicit control for macroeconomic changes.

If the first property is valid (i.e., the constitutional change had no effect on the control group), then the expected value for the hazard rates associated with the control group should be equal for periods before and after the constitutional change. It can be precisely written as

$$
Z=E\left(h_{t, i} \backslash g_{i}=1, c_{t}=1\right)-E\left(h_{t, i} \mid g_{i}=1, c_{t}=0\right),
$$

21. In fact, the regression would still produce valid results if those omitted factors affect in the same way in both groups and the control is not affected by the constitution. In this case our estimator of the effect of the constitution on the treatment group would be $-\beta_{6}$. 


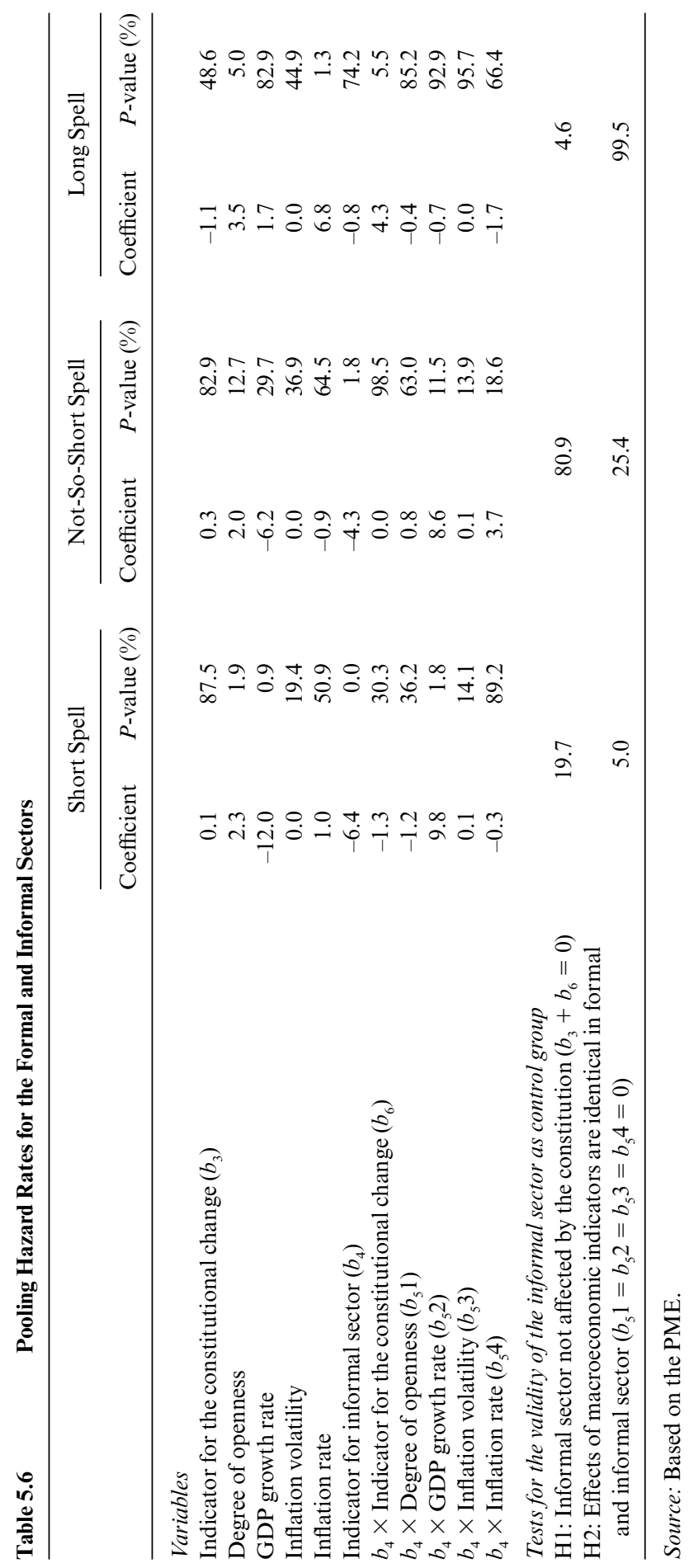




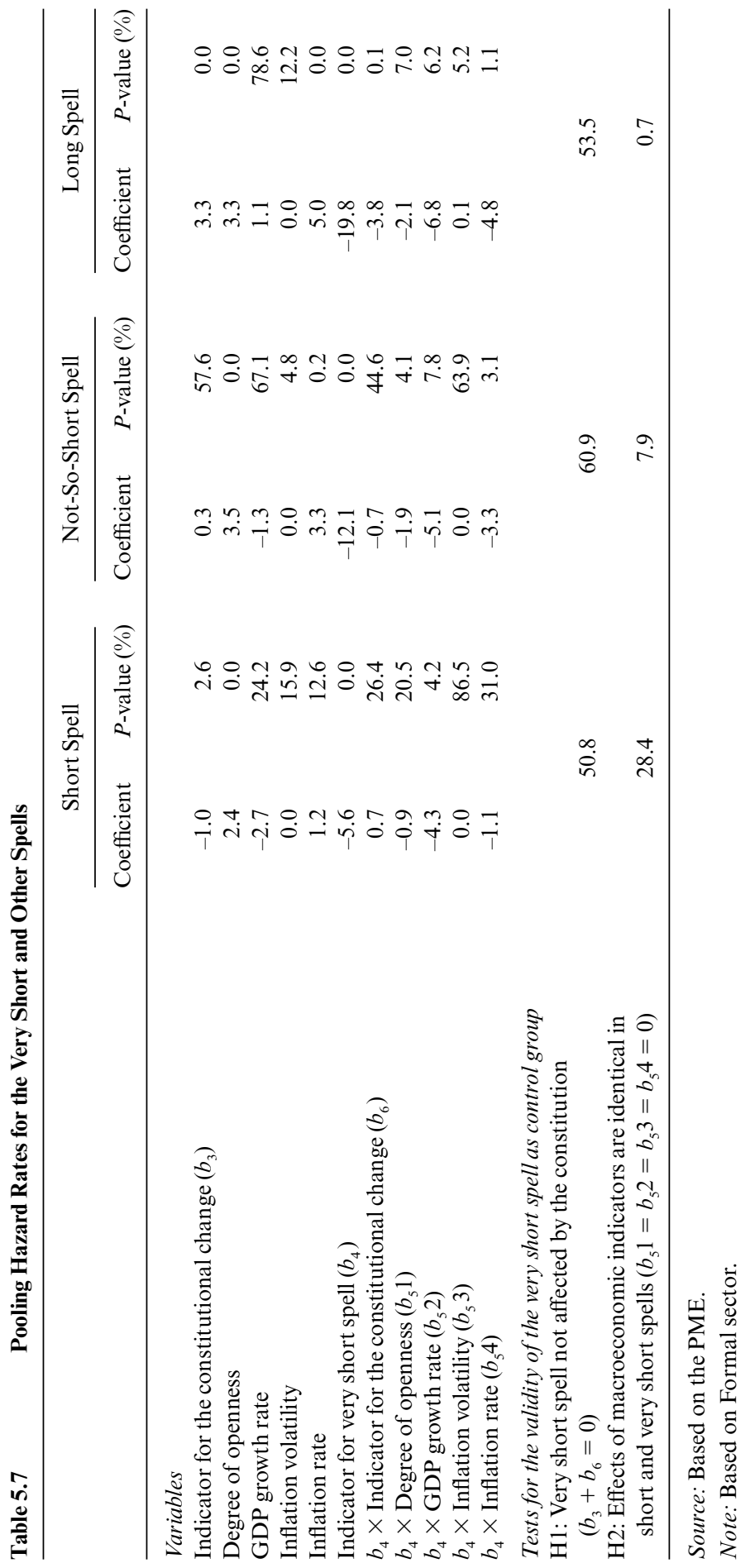




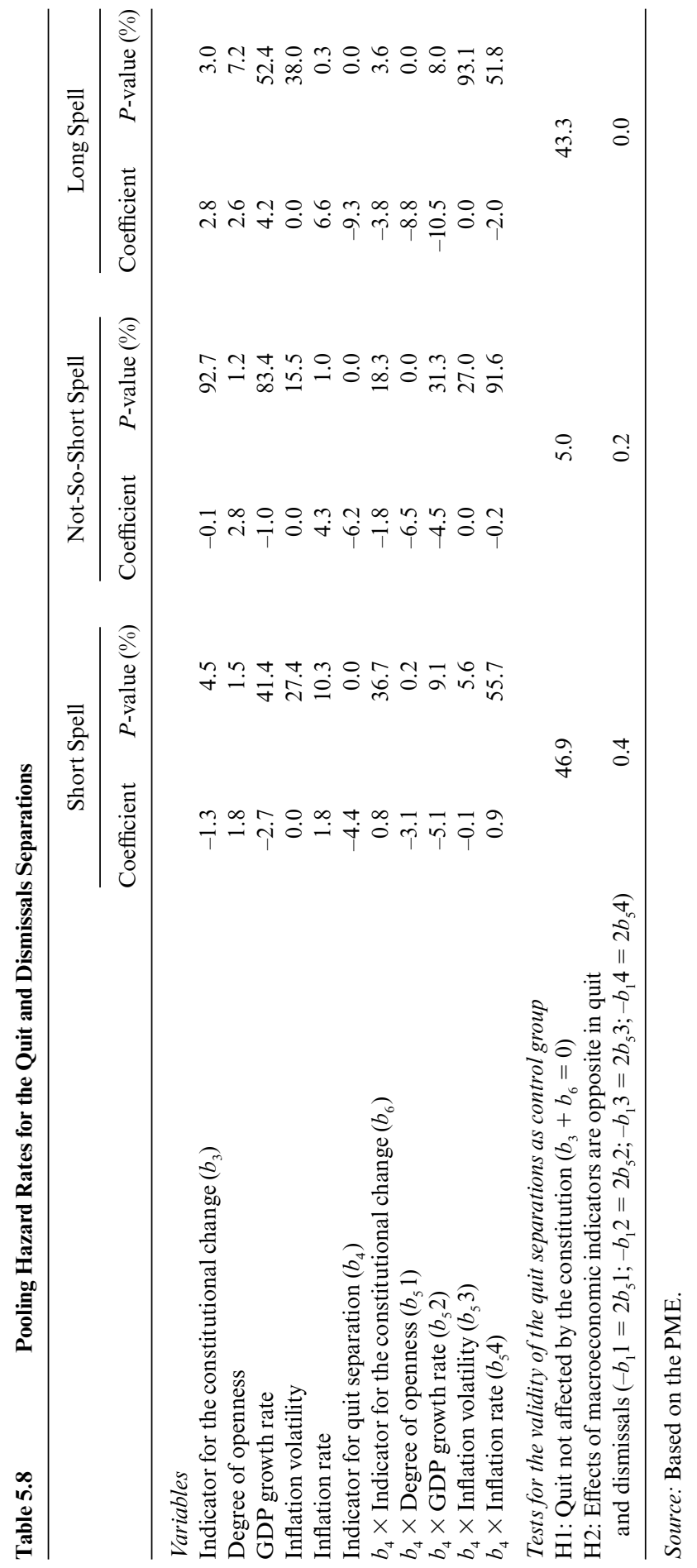


where according to (9) we can see that ${ }^{22}$

$$
Z=\beta_{3}+\beta_{6} \text {. }
$$

Our statistic test will be based on the analogous estimated coefficients,

$$
b_{3}+b_{6}
$$

where we denoted as $b$ the estimations of the true $\beta$ coefficients. So we have that if the constitutional change did not affect the control group, the sum of the coefficient on the indicator for the constitutional change and the coefficient on the interaction between the constitution and group indicators must be zero.

If the second property is valid (i.e., macroeconomic changes have the same effect on the control and treatment groups), then the expected value for the effect of the macroeconomic indicators on the hazard rates associated with the treatment and control groups must be equal. It can be precisely written as

$$
E\left(\frac{\partial h_{t, i}}{\partial \mathbf{x}_{1 t}^{\prime}} \backslash g_{i}=1\right)=E\left(\frac{\partial h_{t, i}}{\partial \mathbf{x}_{1 t}^{\prime}} \backslash g_{i}=0\right),
$$

which is equivalent to see if $\boldsymbol{\beta}_{5}=0 .{ }^{23}$

Once more we will base our statistic tests on the analogous vector of estimated coefficients $\left(b_{5}\right)$ to see if each of the elements of this vector is null $\left(b_{5}^{1}=b_{5}^{2}=b_{5}^{3}=b_{5}^{4}=0\right)$. This test is different when we consider quit as the control. In this case we test if the effect of macroeconomic changes for both groups (quit and dismissals) had the same magnitude but opposite signs, that is,

$$
E\left(\frac{\partial h_{t, i}}{\partial \mathbf{x}_{1 t}^{\prime}} \backslash g_{i}=1\right)=-E\left(\frac{\partial h_{t, i}}{\partial \mathbf{x}_{1 t}^{\prime}} \backslash g_{i}=0\right),
$$

which is equivalent to see if $-\boldsymbol{\beta}_{5}=2 \boldsymbol{\beta}_{1}$.

The $p$-value related to both statistics tests mentioned previously, for each of the nine regressions, is shown on the bottom part of tables 5.6, 5.7, and 5.8. The results related to whether the control was affected by the constitution are mostly in accordance with the null hypothesis of a null effect. Only one of the nine alternative combinations of control groups and employment spells considered presents any evidence that it was affected by the constitution - the informal workers whose duration spells are long. So

22. $E\left(h_{t, i} \backslash g_{i}=1, c_{t}=1\right)=\beta_{0}+E\left(\mathbf{x}_{1 i}^{\prime} \cdot \boldsymbol{\beta}_{1} \backslash g_{i}=1, c_{t}=1\right)+E\left(\mathbf{x}_{2 t}^{\prime} \cdot \boldsymbol{\beta}_{2} \backslash g_{i}=1, c_{t}=1\right)+\beta_{3}+$ $\beta_{4}+E\left(\mathbf{x}_{1 t}^{\prime, t} \cdot \boldsymbol{\beta}_{5} \backslash g_{i}=1, c_{t}=1\right)+\beta_{6}$ and $E\left(h_{t, i} \backslash g_{i}=1, c_{t}=0\right)=\beta_{0}+E\left(\mathbf{x}_{2 t} \cdot \boldsymbol{\beta}_{1} \backslash g_{i}=1, c_{t}=1\right)+$ $E\left(\mathbf{x}_{2 t} \cdot \boldsymbol{\beta}_{2} \backslash g_{i}=1, c_{t}=1\right)+\beta_{4}+E\left(\mathbf{x}_{1 t}^{\prime} \cdot \boldsymbol{\beta}_{5} \backslash g_{i}=1, c_{t}=1\right)$.

23. According to equation (9) we have

$$
E\left(\frac{\partial h_{t, i}}{\boldsymbol{x}_{1 t}^{\prime}} \backslash g_{i}=1\right)=\boldsymbol{\beta}_{1}+\boldsymbol{\beta}_{5} \text { and } E\left(\frac{\partial h_{t, i}}{\boldsymbol{x}_{1 t}^{\prime}} \backslash g_{i}=0\right)=\boldsymbol{\beta}_{1} .
$$


there is almost no evidence of any effect of the constitution change on the informal sector, the very-short employment spell, or quitting behavior.

However, when we consider whether the groups were equally affected by factors other than the constitution, the results are not so favorable. This hypothesis (considering the sign correction) was rejected among quit and dismissal separations. It was not rejected for the formal and informal partition, and for the very-short and other spells it was rejected only for those workers whose employment spell was long.

So the best alternative to implementing the difference-in-differences methodology requires the use of the very-short spell or the informal sector as control groups restricted to short and not-so-short employment spells.

\subsection{Final Considerations}

This study is an attempt to estimate the impact on the Brazilian labor market performance due to the 1988 constitutional change. As a result of this change, the compensation for dismissals without just cause increased fourfold. We investigate the impact of these changes on the parameters of the demand for labor and on hazard rates. If the constitutional change had a major impact, we should observe an important change in labor demand parameters and hazard rates around 1988.

Figures 5.2 and 5.3, however, provide no evidence at all that the constitutional change had any effect on labor demand parameters. Nevertheless, these figures reveal considerable temporal fluctuations in the coefficients that could be explained by macroeconomic events. To verify this possibility, we regress our monthly estimates for the parameters of the demand function on an indicator for the constitution change and a series of macroeconomic indicators. The results presented in tables 5.2 and 5.3 reveal that even when taking into account macroeconomic variables, we still found no evidence that the 1988 constitution had any effect on the demand for labor.

Naturally, the fact that we were unable to find significant effects does not necessarily imply that they do not exist. Our results are limited by the richness and quality of our data and economic models. Much further research is still necessary to reach a definite conclusion that labor demand dynamics were not very responsive to this constitutional change.

The estimations using hazard rates show ambiguous results. According to difference-in-differences methodology (applied to appropriated controls), this turnover measure has declined for short employment spells (three to six months) but seems to have increased for not-so-short employment spells (six to twelve months). Regression analysis also provides ambiguous results because it points to a decline for hazard rates associated with short spells and an increase for long spells (twelve to twenty-four months).

Resuming, separation rates have decreased after the constitutional changes for the short employment spell and increased for longer spells, while parameters related to speed of adjustment and wage elasticity of em- 
ployment have not changed. These facts may be consistent if the movements registered to separations in opposite directions cancel each other, keeping aggregate turnover and, consequently, the parameter mentioned unchanged.

There is a possible explanation for the movements on separation driven by a combination of dismissals and quits movements. On one hand, firms might become more reluctant to fire a worker that did not fit the job offered. They may then give more chances to see the worker perform according to what is expected. On the other hand, the accumulated amount of money on FGTS became more attractive to workers, and this attractiveness increases with the employment spell. Hence, workers may have become more active in proposing a collusion with firms that he quits, pretending a firing and then having access to the fund. So if there is a correspondence between the three- to six-month employment spell and the time at which the firm became reluctant, and between longer employment spells and the time at which worker tries the collusion, the results should be those presented.

\section{Appendix A}

\section{The Complete Derivation of the Structural Model for Labor Demand Shown in Section 5.2.1}

In order to obtain an explicit solution to this problem of maximization, we mentioned the introduction of a series of simplifying assumptions. These assumptions are described below.

First, we assume that the revenue function is separable in the following sense:

$$
R\left(n_{i}(t), \mathbf{p}_{i}(t), \boldsymbol{\theta}(t), \mu_{i}(t)\right)=F\left(n_{i}(t), \boldsymbol{\theta}^{1}(t)\right)+\left[G\left(\mathbf{p}_{i}(t), \boldsymbol{\theta}^{2}(t)\right)+\mu_{i}(t)\right] n_{i}(t)
$$

Under this assumption, the Euler equation associated with maximizing equation (1) is given by ${ }^{24}$

$$
\begin{aligned}
F_{n}\left(n_{i}(t), \boldsymbol{\theta}^{1}(t)\right)+G\left(\mathbf{p}_{i}(t), \boldsymbol{\theta}^{2}(t)\right)+ & \mu_{i}(t)-\delta(t) w_{i}(t)-C_{\Delta}\left(\Delta n_{i}(t), \eta(t)\right) \\
& +\rho E_{t}\left\{C_{\Delta}\left(\Delta n_{i}(t+1), \eta(t+1)\right)\right\}=0 .
\end{aligned}
$$

We further simplify this model by assuming that the revenue function is linear-quadratic and the adjustment cost is quadratic; that is, we assume that

$$
F\left(n_{i}(t), \boldsymbol{\theta}^{1}(t)\right)=\theta^{11}(t) n_{i}(t) \frac{\theta^{12}(t)}{2} n_{i}(t)^{2}
$$

24. We use $F_{n}$ and $C_{\Delta}$ to denote the derivatives of the $F$ and $c_{t}$ functions in relation to their first arguments. 
and

$$
C\left(\Delta n_{i}(t), \eta(t)\right)=\frac{\eta(t)}{2}\left(\Delta n_{i}(t)\right)^{2},
$$

where

$$
\boldsymbol{\theta}^{1}(t)=\left(\theta^{11}(t), \theta^{12}(t)\right) .
$$

Furthermore, we assume that all firms in the same sector undergo the same price of inputs. As a result,

$$
G\left(\mathbf{p}_{i}(t), \boldsymbol{\theta}^{2}(t)\right)=\sum_{s=1}^{m} \varphi_{s}(t) I_{i s},
$$

where $I_{i s}$ indicates whether firm $i$ belongs to sector $s$, that is, $I_{i s}=1$ if firm $i$ belongs to sector $s$ and $I_{i s}=0$ otherwise. Under these additional assumptions the Euler equation becomes

$$
\begin{aligned}
& {\left[\theta^{11}(t)+\mu_{i}(t)+\sum_{s=1}^{m} \varphi_{s}(t) I_{i s}-\delta(t) w_{i}(t)\right]-} \theta^{12}(t) n_{i}(t)-\eta(t) \Delta n_{i}(t) \\
&+\rho \eta(t)\left\{E_{t}\left[n_{i}(t+1)\right]-n_{i}(t)\right\}=0 .
\end{aligned}
$$

Under the assumption that parameters $\theta^{12}(t)$ and $\eta(t)$ are time invariant and that

$$
\begin{aligned}
E_{t}\left[\theta^{11}(t+1)+\mu_{i}(t+1)+\right. & \left.\sum_{s=1}^{m} \varphi_{s}(t+1) I_{i s}-\delta(t+1) w_{i}(t+1)\right] \\
& =\left[\theta^{11}(t)+\mu_{i}(t)+\sum_{s=1}^{m} \varphi_{s}(t) I_{i s}-\delta(t) w_{i}(t)\right],
\end{aligned}
$$

the solution of this equation is given by

$$
n_{i}(t)=\lambda n_{i}(t-1)+\frac{(1-\lambda)}{\theta^{12}}\left[\theta^{11}(t)+\mu_{i}(t)+\sum_{s=1}^{m} \varphi_{s}(t) I_{i s}-\delta(t) w_{i}(t)\right]
$$

as mentioned in section 5.2.1, where $\lambda$ is implicitly defined by

$$
\theta^{12} \lambda=(1-\lambda)(1-\rho \lambda) \eta .
$$




\section{Appendix B}

\section{Aggregate Hazard Rates and Transition Intensities Based on Employment Surveys, Steady-State Assumption, and Stochastic Independence of Employment and Unemployment Spells}

Let $p_{t}(d, u)$ represent the probability that a worker, whose previous job lasted $d$ months and who is unemployed at time $t$ for $u$ months, will not leave the unemployment pool next month. Then, at each moment in time $t$, the number of unemployed workers whose previous jobs last $d$ months, $U_{t}(d)$, is given by

$$
U_{t}(d)=\sum_{s=-\infty}^{t}\left\{M_{s}(d)\left(\prod_{r=\mathrm{s}}^{t-1} p_{r}(d, r-s)\right)\right\} .
$$

The steady state assumption implies that the time subscripts are not relevant. Thus, in particular, this equation can be rewritten as

$$
U(d)=M(d) \sum_{s=-\infty}^{\infty}\left\{\left(\prod_{r=s}^{\infty} p(d, r-s)\right)\right\} .
$$

Moreover, the stochastic independence of the duration of the employment and unemployment spells implies that

$$
p(d, r-s)=\lambda(r-s) .
$$

Therefore,

$$
U(d)=M(d) \sum_{s=-\infty}^{\infty}\left\{\left(\prod_{r=s}^{\infty} \lambda(r-s)\right\}=\Lambda M(d)\right.
$$

where

$$
\Lambda=\sum_{s=-\infty}^{\infty}\left\{\left(\prod_{r=s}^{\infty} \lambda(r-s)\right\} .\right.
$$

Hence, we have established the useful result that at each moment in time the number of unemployed workers whose previous jobs lasted $d$ months, $U_{t}(d)$, is proportional to the number of employment spells of duration $d$ ending at time $t, M_{t}(d)$.

From steady-state assumption it is possible to write the hazard rate as a function of the separations as shown in the following expression:

$$
h_{t}(d)=\frac{M_{t}(d)}{N_{t}(d)}=\frac{M_{t}(d)}{\left\{N_{t}(0)-\sum_{s=0}^{d-1} M_{t}(s)\right\}}=\frac{M_{t}(d)}{\sum_{s=d}^{\infty} M_{t}(s)},
$$

where we used the assumption that all employment spells have finite duration to obtain that $\lim _{d \rightarrow \infty} N_{t}(d)=0$, which implies in 


$$
N_{t}(0)=\sum_{s=0}^{\infty} M_{t}(s) .
$$

Therefore, the hazard rate can be obtained from the data on unemployed workers by

$$
h_{t}(d)=\frac{M_{t}(d)}{\sum_{s=d}^{\infty} M_{t}(s)}=\frac{U_{t}(d)}{\sum_{s=d}^{\infty} U_{t}(s)} .
$$

If it is also assumed that the duration of the unemployment spell is independent of whether the previous employment spell ended by a quit or dismissal, then the transition intensities could also be obtained from data on unemployment workers by

$$
q_{t}(d)=\frac{U_{t}^{q}(d)}{\sum_{s=d}^{\infty} U_{t}^{q}(s)}
$$

and

$$
l_{t}(d)=\frac{U_{t}^{1}(d)}{\sum_{s=d}^{\infty} U_{t}^{1}(s)},
$$

where $U_{t}^{q}(d)$ is the number of unemployed workers at time $t$ whose previous job lasted $d$ months and ended in a quit, and $U_{t}^{l}(d)$ is the number of unemployed workers at time $t$ whose previous jobs lasted $d$ months and ended in a dismissal.

We take similar steps to write the aggregate hazard rates that can be written as

$$
H_{t i}=\frac{\sum_{i=d_{i}}^{d_{i+1}} M_{t}(s)}{\sum_{\substack{d_{i+1} \\ s=d_{i}}}^{\infty} \sum_{r=s}^{\infty} M_{t}(r)}
$$

to the extent that

$$
\frac{\sum_{\substack{d_{i+1} \\ s=d_{i}}} M_{t}(s)}{\sum_{\substack{\infty \\ s=d_{i}}} M_{t}(s)}
$$

is very small.

$$
\sum_{s=d_{i}}^{d_{i+1}} \sum_{r=1}^{\infty} M_{t}(r) \approx\left(d_{i+1}-d_{i}\right)\left[\sum_{s=d_{i+1}}^{\infty} M_{t}(s)+\frac{1}{2} \sum_{s=d_{i}}^{d_{i+1}} M_{t}(s)\right]
$$

That allows us to simplify the expression for the aggregates hazard rate to

$$
H_{t i} \approx \frac{\frac{1}{\left(d_{i+1}-d_{i}\right)} \sum_{\substack{d_{i} \\ s=d_{i}}} M_{t}(s)}{\sum_{s=d_{i+1}}^{\infty} M_{t}(s)+\frac{1}{2} \sum_{\substack{d_{i+1} \\ s=d_{i}}} M_{t}(s)} .
$$


Considering that

$$
U_{t}(d)=\Lambda M(d),
$$

the aggregated hazard rate can be approximated by the following equation:

$$
H_{t i} \approx \frac{\frac{1}{\left(d_{i+1}-d_{i}\right)} \sum_{\substack{d_{i+1} \\ s=d_{i}}} U_{t}^{l}(s)}{\sum_{s=d_{i}}^{\infty} U_{t}(s)+\frac{1}{2} \sum_{\substack{d_{i+1} \\ s=d_{i}}} U_{t}(s)}
$$

\section{References}

Almeida, Sandra Cristina. 1992. As contribuições sociais de empregadores e trabalhadores: Repercussões sobre o mercado de trabalho e grau de evasão. IPEA Policy Document no. 8. Rio de Janeiro, Brazil: Institute for Applied Economic Research.

Almeida, Wanderly J. M. de, and José Luiz Chautard. 1976. FGTS: Uma política de bemestar social. IPEA/INPES Research Report no. 30. Rio de Janeiro, Brazil: Institute for Applied Economic Research.

Amadeo, Edward, Ricardo Paes de Barros, José Márcio Camargo, and Rosane Mendonça. 1995. Brazil. In Reforming the labor market in a liberalized economy, ed. Gustavo Márquez, 35-78. Washington, D.C.: Inter-American Development Bank.

Amadeo, Edward, and José Márcio Camargo. 1993. Labour legislation and institutional aspects of the Brazilian labour market. Labour 7 (1): 321-54.

- 1996. Instituições e o mercado de trabalho brasileiro. In Flexibilidade do mercado de trabalho no Brasil, ed. José Márcio Camargo, 47-94. Rio de Janeiro, Brazil: FGV.

Bacha, Edmar Lisboa, Milton da Mata, and Ruy Lyrio Modenesi. 1972. Encargos trabalhistas e absorção de mão-de-obra: Uma interpretação do problema e seu debate. IPEA Research Report no. 12. Rio de Janeiro, Brazil: Institute for Applied Economic Research.

Barros, Ricardo Paes de, Carlos H. Corseuil, and Mônica Bahia. 1999. Labor market regulation and the duration of employment in Brazil. Rio de Janeiro, Brazil: IPEA Discussion Paper no. 676. Rio de Janeiro, Brazil: Institute for Applied Economic Research.

Barros, Ricardo Paes de, Carlos H. Corseuil, and Miguel Foguel. 2001. Os incentivos adversos e a focalização dos programas de proteção ao trabalhador no Brasil. IPEA Discussion Paper no. 784. Rio de Janeiro, Brazil: Institute for Applied Economic Research.

Barros, Ricardo Paes de, Carlos H. Corseuil, and Gustavo Gonzaga. 1999. Labor market regulation and the demand for labor in Brazil. Rio de Janeiro, Brazil: IPEA Discussion Paper no. 656. Rio de Janeiro, Brazil: Institute for Applied Economic Research.

Camargo, José Márcio, and Edward Amadeo. 1990. Labour legislation and institutional aspects of the Brazilian labour market. Discussion Paper no. 252. Rio de Janeiro, Brazil: Pontificia Universidade Catolica. 
Carvalho, Carlos Eduardo, and Maurício Mota Saboya Pinheiro. 1999. FGTS: Avaliação das propostas de reforma e extinção. Rio de Janeiro: IPEA Discussion Paper no. 671. Rio de Janeiro, Brazil: Institute for Applied Economic Research.

Chadad, José Paulo Zeetano. 1993. Encargos sociais e emprego no Brasil. Discussion Paper. São Paulo, Brazil: FIPE, USP.

Hamermesh, Daniel. 1993. Labor demand. Princeton, N.J.: Princeton University Press.

Hamermesh, Daniel, and Gerard A. Pfann. 1996. Adjustment costs in factor demand. Journal of Economic Literature 34:1264-92.

Jatobá, Jorge. 1994. Encargos sociais, custos da mão de obra e flexibilidade do mercado de trabalho no Brasil. In Conferência sobre regulamentação do mercado de trabalho no Brasil, ed. IPEA, 1-36. Rio de Janeiro, Brazil: Institute for Applied Economic Research.

Macedo, Roberto Bras Matos. 1985. Diferenciais de salários entre empresas privadas e estatais no Brasil. Revista Brasileira de Economia 39 (4): 448-73.

- 1993. Reforma da previdência social: Resenha e consolidação. In A previdência social e a reforma constitucional, ed. Brasil, Ministério da Previdência Social, 4-47. Brasília, Brazil: CEPAL.

Malaga, Guillermo Tomás. 1992. Dynamic labor demands: Cases of interest for Brazil. In Anais XV. Encontro Brasileiro de Econometria, 1992, Campos do Jordão (SP). São Paulo: SBE.

Nascimento, Amauri Mascaro. 1993. Iniciação ao direito do trabalho, ed. SBE, 40930. São Paulo, Brazil: Sociedade Brasileira de Econometria.

Nickell, S. J. 1986. Dynamic models of labour demand. In Handbook of labor economics, vol. 1, ed. Orley Ashenfelter and Richard Layard, 437-522. Amsterdam: Elsevier.

Pastore, José. 1994. Encargos sociais no Brasil e no exterior: uma avaliacao critica. São Paulo, Brazil: SEBRAE.

World Bank. 1991. Brazil: The Brazilian labor market in the 1980s. World Bank Report no. 9693-BR. Washington, D.C.: World Bank. 